\title{
Infection control of Staphylococcus aureus - spa typing to elucidate transmission
}

\author{
Sara Mernelius
}

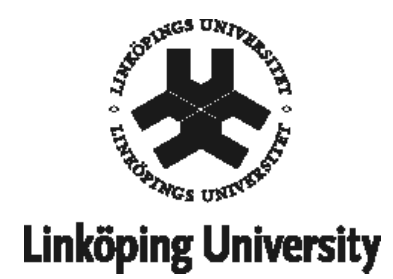

Laboratory Medicine,

Ryhov County Hospital, Jönköping

Division of Medical Microbiology,

Department of Clinical and Experimental Medicine,

Faculty of Health Sciences,

Linköping University, Sweden

Linköping 2015 
(C) Sara Mernelius, 2015

Printed by LiU-Tryck, Linköping 2015

ISBN 978-91-7519-096-9

ISSN 0345-0082 
Till Pål, Astor och Silve - för att ni förgyller varje dag av mitt liv 



\section{En stor glasburk och två koppar kaffe}

En professor stod inför sina filosofistudenter med några föremål på bordet framför sig. När lektionen började lyfte han under tystnad upp en mycket stor och tom glasburk och fyllde upp den till kanten med golfbollar.

Han frågade sedan sina studenter om burken var full. Studenterna samtyckte till att den var det.

Då lyfte professorn upp en ask med småsten och hällde dem i burken. Han skakade burken lätt. Småstenarna rullade ner i tomrummen mellan golfbollarna.

Återigen frågade han studenterna om burken var full. De höll med om att den var det. Därefter lyfte professorn upp en ask med sand och hällde sanden i burken. Naturligtvis fyllde sanden upp resten av tomrummen.

Han frågade ännu en gång om burken var full. Studenterna svarade med ett enhälligt "ja".

Då lyfte professorn upp två koppar kaffe som stått under bordet och hällde hela deras innehåll i burken, vilket effektivt fyllde upp det återstående tomrum som kunde finnas kvar mellan sandkornen. Studenterna skrattade.

"Nu", sa professorn medan skratten klingade ut, "vill jag att ni påminns om att den här burken representerar ert liv. Golfbollarna representerar de viktiga sakerna. Familj, barn, hälsa och annat som ligger er varmt om hjärtat. Sådant som, om allt annat gick förlorat och bara dessa återstod, ändå skulle uppfylla och berika ert liv.”

"Småstenarna representerar de andra sakerna som betyder något, som ett hem, jobb och bil. Sanden representerar allt annat, småsakerna."

"Om ni lägger sanden i burken först", fortsatte professorn, "går det inte att fä plats med golfbollarna eller småstenarna. Samma sak är det med livet. Om du lägger all tid och energi på småsakerna finns det inte plats för det som är viktigt för dig." 
"Så, var uppmärksam på det som är oumbärligt för din lycka. Umgås med dina barn. Ta med din partner ut på middag. Ägna lite mer tid åt det som gör dig lycklig. Tids nog kan du städa huset och vika tvätten. Ta hand om golfbollarna först, sakerna som verkligen betyder något. Återställ det som är viktigast i ditt liv. Resten är bara sand."

En av studenterna räckte upp handen och frågade vad kaffet representerar.

Professorn log. "Jag är glad att du frågar. Kaffet finns med för att visa er att hur fullt och pressat ert liv än känns, så finns det alltid plats för en fika."

Okänd 


\section{Abstract}

Staphylococcus aureus is a commensal of the human flora, primarily colonizing the anterior nares and throat, but it may also cause infections ranging from mild skin and soft tissue infections to severe diseases such as endocarditis and septicemia. S. aureus is also a major nosocomial problem increasing with the worldwide dissemination of methicillin-resistant $S$. aureus (MRSA). The main vector for bacterial cross-transmission in healthcare settings is the hands of healthcare workers (HCWs). No S. aureus was detected in the air in this thesis demonstrating that transmission through air is not important. Despite the fact that good compliance with hand hygiene is essential to prevent cross-transmission the compliance is generally less than $50 \%$. Gold standard to track bacterial transmission in healthcare settings has for long been pulsedfield gel electrophoresis (PFGE), a method that is labor-intensive, lacks consensus protocol and relies on semi-subjective analysis. Molecular typing by sequencing of the hypervariable part of the S. aureus protein A gene (spa typing) has overcome these problems and has shown promising results in epidemiological investigations.

The aims of this thesis were to study bacterial transmission with $S$. aureus colonization of newborn infants as a model and to evaluate spa typing as a molecular tool. Additionally, the influence of compliance with hygiene guidelines on S. aureus transmission was assessed.

Analysis of 280 MRSA isolates by spa typing revealed excellent typeability and epidemiological concordance and satisfactory discriminatory power. Additionally, spa typing was considered superior to PFGE thanks to its accessibility, ease of use and rapidity. Also, spa typing results are registered in a global database, facilitating inter-laboratory comparison.

The prevalence of S. aureus ranged from $41 \%$ to $66 \%$ in the populations studied and males had the highest colonization rate. Throat was the premier colonization site for adults and transmission from individuals colonized in the throat only was documented, suggesting that throat cultures should be included in $S$. aureus screening programs. The umbilicus was the premier colonization site for newborn infants. Incubating the swabs in enrichment broth prior to plating increased the prevalence of $S$. aureus positive samples by $46 \%$, resulting in prevalence 
ranging from $51 \%$ to $70 \%$ in the populations studied. Thus enrichment prior to plating is necessary to determine more truthful $S$. aureus colonization rates. There were no indications of an institutional flora, as the colonization rates, spa type distribution and antibiotic resistance prevalence were similar among parents and HCWs.

Direct observations and self-reporting by HCWs were both validated as tools for monitoring compliance with hygiene guidelines. The compliance with hygiene guidelines was significantly higher following a 10-point hygiene intervention as compared to baseline. The compliance was also higher three years after the intervention in three of four participating departments. These data show that it is possible to markedly improve the compliance with hygiene guidelines, but to achieve a long-term effect, continuous and varied reminders seems necessary.

Both at baseline and following the intervention almost $60 \%$ of the colonized infants were colonized with an S. aureus of the same spa type as isolated from their own family. At baseline approximately $25 \%$ of the colonized infants received their S. aureus from non-family individuals, indicating transmission directly or indirectly from HCWs. Despite the improvement in compliance with barrier precautions from $41 \%$ at baseline to $86 \%$ following the hygiene intervention, the transmission from non-family did not decrease. This indicates that other factors may have a prominent impact on bacterial transmission. One factor might be the quality of hand hygiene technique which therefore needs to be studied further. However, to ensure patient safety it is still recommended that all HCWs comply with hygiene guidelines at all time. 


\section{Populärvetenskaplig sammanfattning}

Staphylococcus aureus (S. aureus) eller den gula stafylokocken, är en del av normalfloran hos många människor och finns vanligtvis i näsa och svalg. Bakterien kan även ge olika sorters infektioner så som hud- och mjukdelsinfektioner samt blodförgiftning. S. aureus är ett stort problem inom hälso- och sjukvården där den orsakar många vårdrelaterade infektioner. Forskning har visat att en god handhygien bland vårdpersonal minskar risken för spridning av bakterier inom hälso- och sjukvården. Trots detta är personalens följsamhet till hygienrutiner ofta lägre än 50 \%. För att kunna följa hur $S$. aureus sprids mellan patienter behöver man typa bakterien. Detta innebär att man delar in bakterier som tillhör samma art (S. aureus en art) i flera olika undergrupper. Idag görs detta genom att studera bakteriens genetiska skillnader, t.ex. med hjälp av pulsfält gelelektrofores (PFGE) eller spa typning.

Syftena med den här avhandlingen var att studera hur $S$. aureus sprids i sjukhusmiljö, genom att undersöka hur S. aureus etablerar sig hos nyfödda och att utvärdera spa typningens användbarhet för att beskriva spridningen. Samt att se hur personalens följsamhet till hygienrutiner påverkar spridningen av S. aureus.

Analys av 280 S. aureus visade att spa typning var överlägsen PFGE tack vare dess användarvänlighet, snabbhet och tillgänglighet. Dessutom finns resultaten i en internationell databas, vilket underlättar jämförelser mellan olika laboratorier.

Förekomsten av S. aureus hos de personer som lämnade prov var 50 \% med högst förekomst hos män. S. aureus förekom oftast i navel hos barn och i svalget hos vuxna. Dessutom påvisas spridning av S. aureus från svalg. Detta indikerar att man bör ta odlings-prover även från svalg i de S. aureus screeningprogram som finns inom sjukvården. S. aureus återfanns i $46 \%$ fler av proverna då man anrikade proverna före det att man odlade ut dem på agarplattor. Detta resulterade i att andelen personer som bar på S. aureus ökade till $59 \%$. Anrikning är därför nödvändig för att få veta hur många personer som verkligen är bärare. 
För att bestämma personalens följsamhet till hygienrutiner används idag observationer, som innebär att några personer (observatörer) ur personalgruppen på en avdelning studerar hur deras kollegor följer hygienrutinerna. Det finns även möjlighet att låta personalen själva få uppskatta sin följsamhet efter ett vårdmoment (självskattning). Båda metoderna visade sig säkra när det gällde att bestämma personalens följsamhet.

Utan något speciellt fokus på handhygien (baslinjemätning) var följsamheten till hygienrutinerna 41 \%. För att förbättra följsamheten genomfördes en hygienkampanj. Ett knappt år efter kampanjen var följsamheten 86 \%. Ytterligare två år senare var följsamheten fortfarande högre än vid baslinjemätningen vid tre av fyra deltagande kliniker. Detta bevisar att man kan förbättra följsamheten till hygienrutiner avsevärt men för att uppnå en långvarig effekt måste man kontinuerligt arbeta med frågan.

Både vid den lägre följsamheten vid baslinjemätningen och vid den högre följsamheten vid första uppföljningen bar nästan $60 \%$ av de koloniserade barnen på en S. aureus som kunde härledas till någon i den egna familjen. Vid båda mätningarna fick ungefär $25 \%$ av de koloniserade barnen $\sin$ S. aureus från en person utanför familjen. Detta betyder att personalens ökade följsamhet till hygienrutiner inte gav någon effekt på spridningen av $S$. aureus till nyfödda. Andra faktorer kan därför ha en stor effekt på spridningen av S. aureus. En faktor kan vara hur väl personalen utför handhygienen inte bara att de utför den. Ytterligare studier behövs för att förstå hur spridningen av $S$. aureus kan förhindras. För att säkerställa patientsäkerheten i vården rekommenderas fortfarande all personal att följa hygienrutinerna i alla vårdmoment. 


\section{List of publications}

This thesis is based on the following publications, referred to by roman numerals in the text.

I. Melin S*, Haeggman S, Olsson-Liljequist B, Sjölund M, Nilsson PA, Isaksson B, Löfgren S, Matussek A. Epidemiological typing of methicillin-resistant Staphylococcus aureus (MRSA): spa typing versus pulsed-field gel electrophoresis. Scand J Infect Dis. 2009;41(6-7):433-9.

II. Mernelius S, Svensson PO, Rensfeldt G, Davidsson E, Isaksson B, Löfgren S, Matussek A. Compliance with hygiene guidelines: the effect of a multimodal hygiene intervention and validation of direct observations. Am J Infect Control. 2013 May;41(5):e45-8.

III. Mernelius S, Löfgren S, Lindgren PE, Blomberg M, Olhager E, Gunnervik C, Lenrick R, Thrane MT, Isaksson B, Matussek A. The effect of improved compliance with hygiene guidelines on transmission of Staphylococcus aureus to newborn infants: the Swedish Hygiene Intervention and Transmission of S. aureus study. Am J Infect Control. 2013 Jul;41(7):585-90.

IV. Mernelius S, Löfgren S, Lindgren PE, Matussek A. The role of broth enrichment in Staphylococcus aureus cultivation and transmission from the throat to newborn infants: results from the Swedish hygiene intervention and transmission of S. aureus study. Eur J Clin Microbiol Infect Dis. 2013 Dec;32(12):1593-8.

* The author's maiden name is Melin.

Papers I and IV have been reproduced with the kind permission of the respective publisher. Paper II is available at: http://www.sciencedirect.com/science/article/pii/S0196655312012497 Paper III is available at: http://www.sciencedirect.com/science/article/pii/S0196655312012564 


\section{Abbreviations}

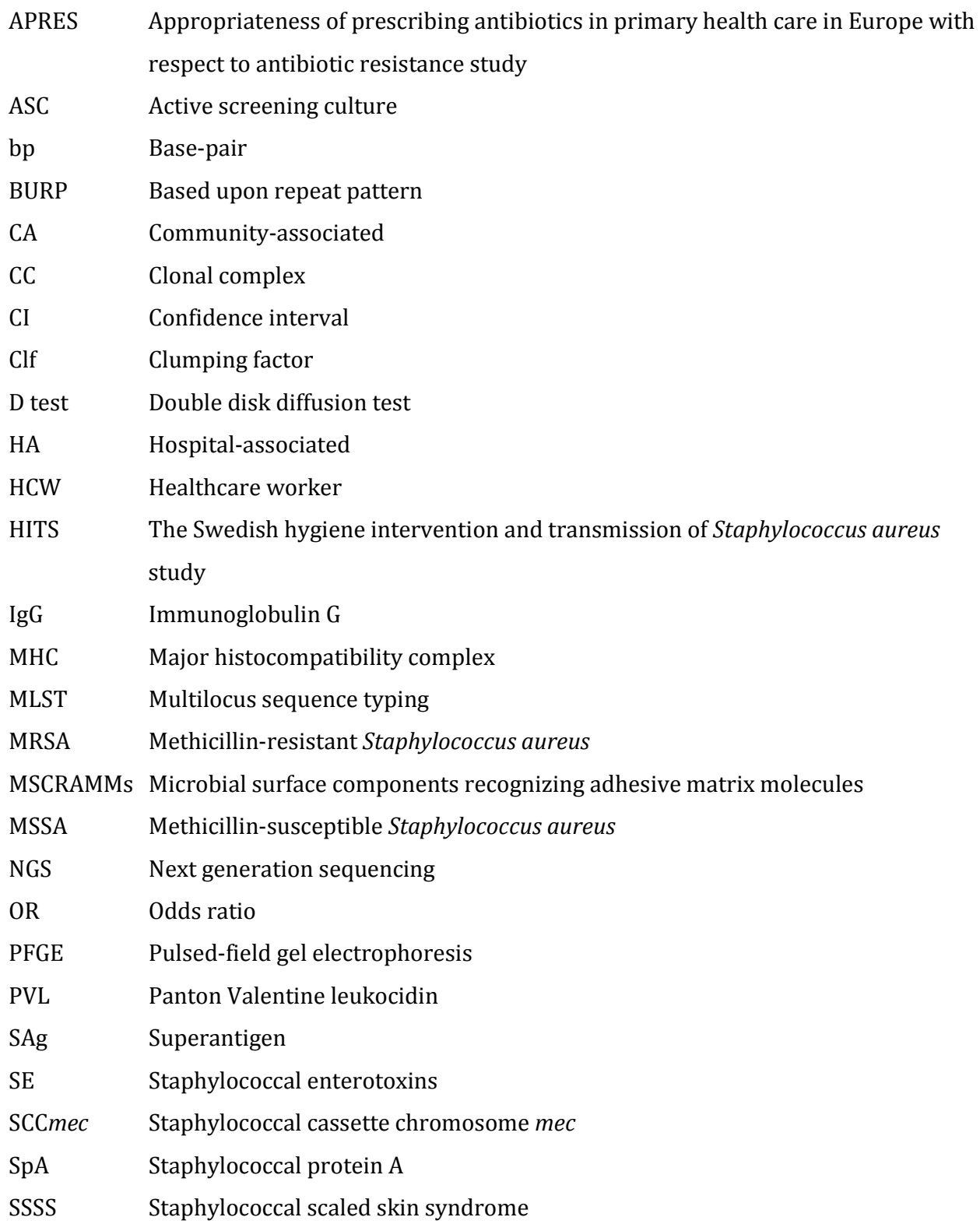


ST Sequence type

TNFR1 Tumor necrosis factor- $\alpha$ receptor

TSS Toxic shock syndrome

TSST-1 Toxic shock syndrome toxin-1

VISA Vancomycin-intermediate MRSA

VRSA Vancomycin-resistant MRSA 


\section{Table of contents}

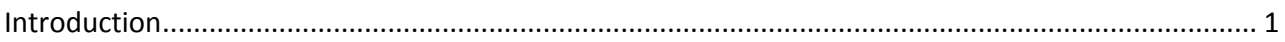

General characteristics of Staphylococcus aureus........................................................................ 1

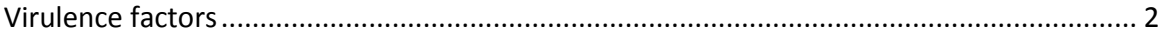

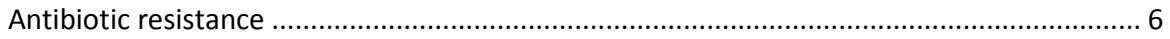

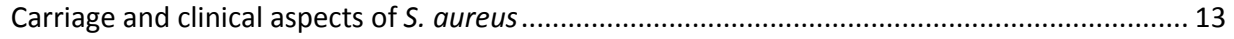

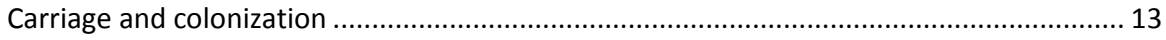

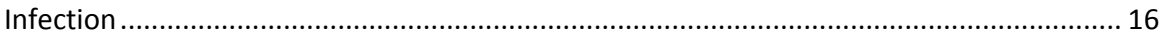

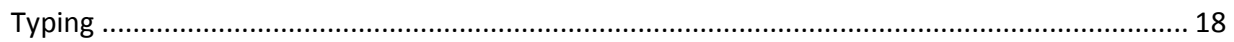

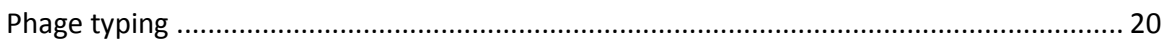

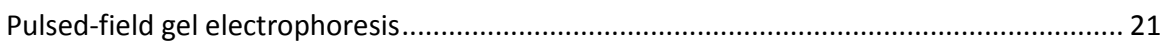

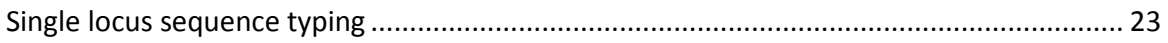

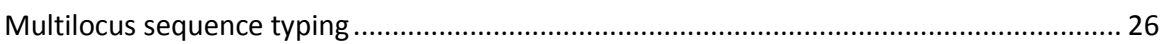

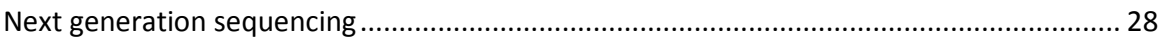

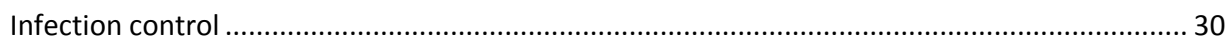

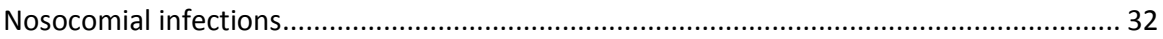

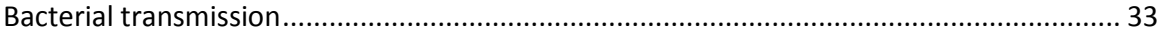

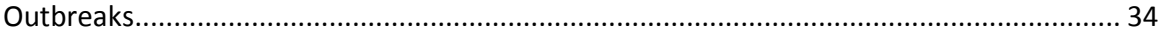

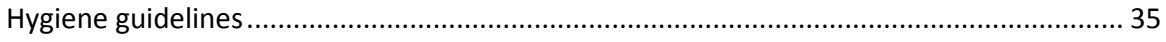

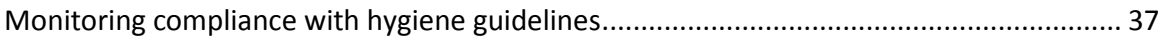

Interventions to improve compliance with hygiene guidelines............................................ 38

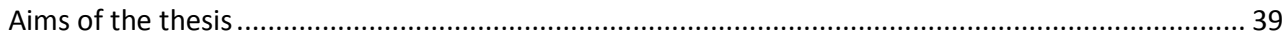

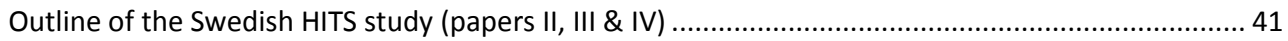

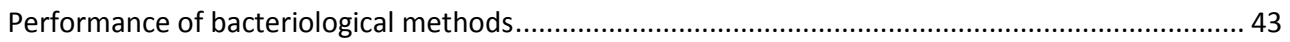

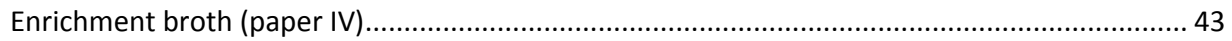

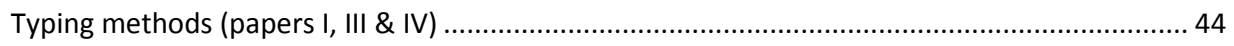

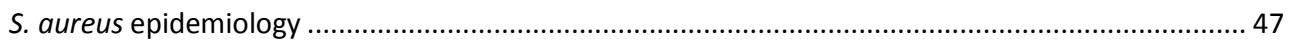

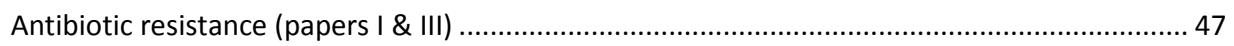


Prevalence of S. aureus (papers III \& IV).

spa type distribution and cluster analysis (papers III \& IV)

Infection control in healthcare settings 55

Validation of direct observations and self-reporting by HCWs (paper II) 55

Compliance with hygiene guidelines (papers II \& III) ... 57

Transmission routes and sources (papers III \& IV) 60

Concluding remarks and future perspectives 63

Acknowledgement.. 65

References 67 


\section{Introduction}

\section{General characteristics of Staphylococcus aureus}

Staphylococcus aureus is a $1 \mu \mathrm{m}$, gram-positive, facultative anaerobic cocci, which characteristically grows in irregular clusters like grapes. The bacterium was first described in 1880 by the English surgeon Sir Alexander Ogston. When examining pus from a surgical abscess from a knee joint under a microscope, he detected spherical bacteria growing in clusters and named them staphylé, after the Greek word for a bunch of grapes. Four years later, Friedrich Rosenbach isolated yellow bacteria and named them S. aureus, referring to the Latin word 'aureus' meaning golden.

Swedish guidelines recommend direct plating onto a solid medium for detection of bacterial growth from skin- and soft-tissue infections, from where $S$. aureus is often isolated (Föreningen för Medicinsk Mikrobiologi vid Svenska Läkaresällskapet \& Folkhälsomyndigheten 2012). Broth enrichment prior to plating is not recommended, but several studies have shown a substantial increase in samples positive for $S$. aureus when incubating the swabs in enrichment broth prior to plating (Wanten et al. 1998; Andrews et al. 2009; Mernelius et al. 2013b). S. aureus is a halophile and therefore a medium with a high concentration of $\mathrm{NaCl}$ has been used to select for the bacteria when cultured. The staphylococcal genus consists of several species, of which the majority are coagulase-negative, e.g., S. epidermidis, S. haemolyticus, and S. saprophyticus. However, $S$. aureus is coagulase-positive, i.e., it will clot plasma, and a coagulase test can therefore be used to differentiate $S$. aureus from other staphylococcal species. S. lugdunensis can produce bound but not free coagulase, whereas $S$. aureus produces both. The tube coagulase test will be negative for S. lugdunensis and S. lugdunensis can thereby be differentiated from S. aureus. S. aureus is also DNAse-positive and will form a clear zone on DNAse agar. These classical diagnostic tests have mainly been replaced by automated species identification, e.g., VITEK and MALDI-ToF mass spectrometry (Föreningen för Medicinsk Mikrobiologi vid Svenska Läkaresällskapet \& Folkhälsomyndigheten 2012). 


\section{Virulence factors}

Bacterial virulence, i.e., bacteria's ability to cause disease, is mainly determined through five different characteristics (Batzing 2002).

1. The microbial physiology, which determines the location of establishment, e.g., an anaerobic bacterium will not establish itself in a superficial skin wound where aerobic conditions prevail.

2. Adherence of the bacteria to the host cell can be mediated through adhesins, i.e., surface molecules that bind to specific host cell receptors.

3. The bacteria also have to be able to escape the antimicrobial control of the host, an example of this is the capsule produced by some bacteria which enables them to evade phagocytosis.

4. Some bacteria are intracellular and must therefore be able to invade the host cell.

5. Perhaps the primary virulence factor is the ability of many pathogenic bacteria to produce toxins. The exotoxins are produced within the bacteria and are secreted during cell growth. Endotoxins are lipopolysaccharides which are part of the cell wall of gram-negative bacteria and are released when these bacteria die and lyse.

S. aureus produces and expresses a vast number of virulence factors, of which some are described in detail below.

\section{Factors involved in adhesion to host cells}

Adhesins are bacterial surface components that mediate bacterial adhesion to host cells. The main types of adhesins are the microbial surface components recognizing adhesive matrix molecules (MSCRAMMs). Important MSCRAMMs of S. aureus are protein A, clumping factor (clf) $\mathrm{A}$ and B, and fibronectin-binding protein A and B. S. aureus also produce secreted adhesines commonly referred to as secreted expanded repertoire adhesive molecules, e.g., coagulase (Chavakis et al. 2007).

The S. aureus-specific staphylococcal protein A $(\mathrm{SpA})$ is a microbial surface protein with antiopsonic and anti-phagocytic effects. SpA was first identified as an immunoglobulin G (IgG) binding protein (Forsgren \& Sjoquist 1966), where the N-terminal mediates the interaction between the protein and the Fc region of the IgG molecule. S. aureus circumvent opsonization by antibodies by hiding the Fc portion of the IgG molecule from the Fc receptors on macrophages and neutrophils and thereby manages to evade phagocytosis. Recent studies have revealed that SpA can also bind von Willebrand factor (Hartleib et al. 2000) and a platelet cell protein (Nguyen et al. 2000). The interaction between $S$. aureus and platelets on the cardiac valve surface is of 
major importance in the induction of infective endocarditis (Sullam et al. 1996). The tumornecrosis factor- $\alpha$ receptor (TNFR1) is also a receptor for SpA. It has been demonstrated that the interaction between SpA and TNFR1 plays an important role in the pathogenesis of staphylococcal pneumonia (Gomez et al. 2004).

ClfA and ClfB are also microbial surface proteins but the genes encoding ClfA and ClfB are distinct from one another. It has been shown that ClfA is involved in the pathogenesis of experimental endocarditis (Moreillon et al. 1995; Entenza et al. 2000). ClfA is also involved in causing arthritis in mice (Josefsson et al. 2001), and impedes phagocytosis of $S$. aureus by macrophages (Palmqvist et al. 2004). Both ClfA and ClfB bind and activate platelets, through fibrinogen-dependent and fibrinogen-independent pathways, which may have an impact on the pathogenesis of invasive disease (O'Brien et al. 2002a). ClfB is involved in nasal colonization with $S$. aureus through the interaction with nasal epithelial cells (O'Brien et al. 2002b).

Coagulase is a secreted adhesive molecule that binds prothrombin and forms a proteolytic active complex. This complex cleaves fibrinogen into fibrin, thereby promoting coagulation on the S. aureus surface, inhibiting phagocytosis (Panizzi et al. 2004; Chavakis et al. 2007). This process can lead to abscess formation (Cheng et al. 2010). An association between coagulase-positive S. aureus and the development of blood-borne staphylococcal pneumonia in mice has been demonstrated (Sawai et al. 1997). However, another study could not identify coagulase as a virulence factor in an experimental endocarditis model (Moreillon et al. 1995).

\section{Toxins}

The $\alpha$-, $\beta$-, $\gamma$ - and $\delta$ - toxins of $S$. aureus are all cytolytic (Chavakis et al. 2007; Zecconi \& Scali 2013). Included in the toxin group are also the exfoliative toxins A and B (Zecconi \& Scali 2013), responsible for staphylococcal scaled skin syndrome (SSSS), which causes skin layers to separate and scale off. SSSS occurs primarily in infants and children and outbreaks have been reported from maternity units (El Helali et al. 2005; O'Connell et al. 2007).

The staphylococcal superantigen (SAg) family consists of toxic shock syndrome toxin-1 (TSST-1) and the staphylococcal enterotoxins (SE) (Zecconi \& Scali 2013). In T cell activation, antigenpresenting cells internalize and process the invading microorganism or antigen and then the major histocompatibility complex (MHC) class II molecules carry the antigen and present it on the surface. The antigen-MHC class II complex is recognized by the T cell receptor, and the activated $\mathrm{T}$ cell releases cytokines (figure 1 ). This process activates less than $0.01 \%$ of the available T cells. The SAgs are able to circumvent the process of internalization and bind directly 
to the outside of the MHC class II protein and the T cell receptor of all major types of T cells (figure 1). As this binding is nonspecific it activates $5 \%$ to $25 \%$ of the T cells, inducing a massive release of cytokines, which in turn can cause extensive and systemic inflammation (Batzing 2002). TSST-1 is associated with the rare illness toxic shock syndrome (TSS), characterized by fever, hypotension, rash, multi-organ ( $\geq 3$ ) involvement and peeling of skin (Bohach et al. 1990). In 1980, $97 \%$ of the TSS cases occurred in women and primarily in menstruating women. It was demonstrated that the usage of certain brands of highly absorbent tampons was correlated with the development of TSS. This correlation was mainly due to three risk factors. First, the high concentration of nutrient-rich blood provides a perfect environment for $S$. aureus growth. Second, the tampons may cause minor cuts that give $S$. aureus and toxins access to the bloodstream. Third, some brands of tampons absorb magnesium and low concentrations of magnesium triggers toxin production (Batzing 2002). The SEA-E and SEG-I are the cause of staphylococcal food poisoning, causing vomiting and diarrhea shortly after ingestion (Proft \& Fraser 2003). S. aureus also produces SAg-like proteins, which help S. aureus to evade the human innate immune response. S. aureus also produces SE-like proteins with unknown function (Zecconi \& Scali 2013).

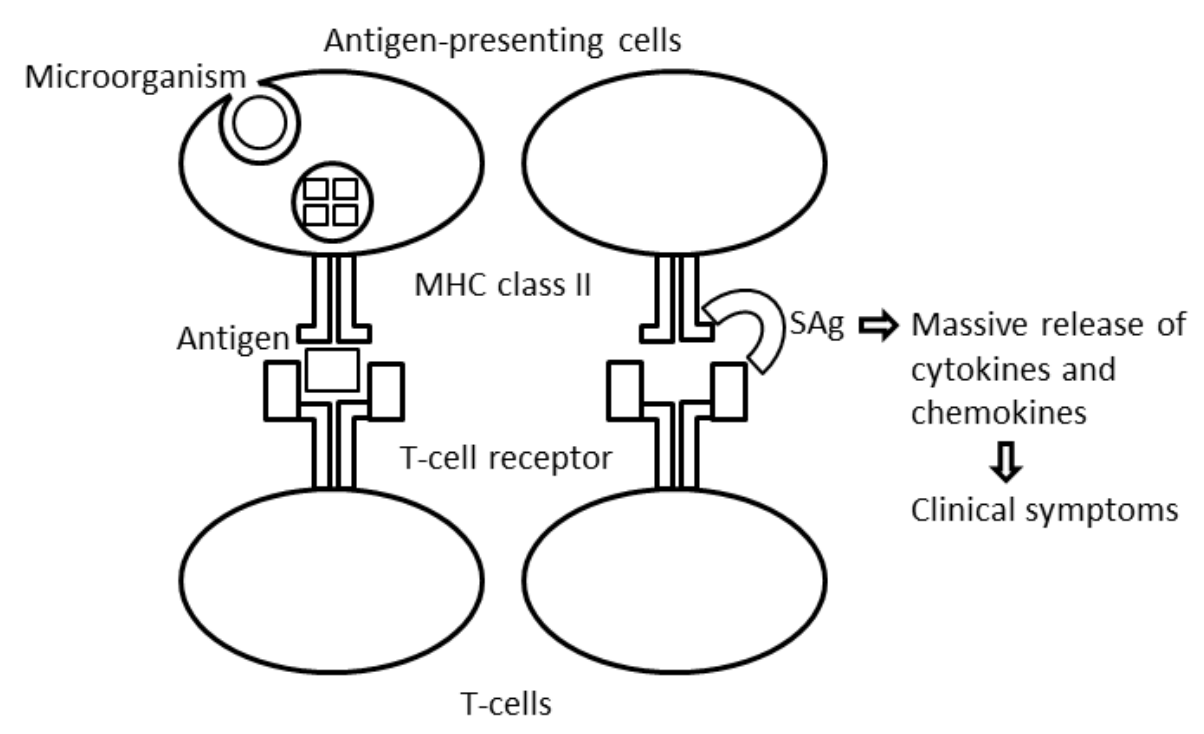

Figure 1. T-cell activation by an antigen and an SAg.

Panton-Valentine leukocidin (PVL) is a pore-forming bicomponent toxin (leukocidin D, E and M are also bicomponent toxins produced by $S$. aureus). It stimulates and lyses neutrophils and macrophages and is involved in necrotizing pneumonia (Chavakis et al. 2007; Zecconi \& Scali 2013). 


\section{Enzymes and other proteins}

S. aureus produce a large number of different enzymes and proteins, which are also regarded as virulence factors. Some of these enzymes and proteins are required for survival, persistence and nasal colonization, others have an antiphagocytic effect and some inhibits the complement (Chavakis et al. 2007). 


\section{Antibiotic resistance}

Bacteria that develop resistance to antibiotics are an increasing problem in healthcare settings and the community. Antibiotic resistance correlates with increased mortality and morbidity, as well as increased costs due to prolonged hospital stay and the requirement for more expensive antibiotics. The development of antibiotic resistance will obviously impede treatment of several bacterial infections. It will also affect other elements of modern hospital care, e.g., cancer treatment, transplantations and advanced surgery, disciplines that are highly reliant on the use of antibiotics to defeat bacterial infections (Barriere 2015).

The development and approval of new antibiotics has declined since the 1980s (U.S. Department of Health and Human Services \& Centers for Disease Control and Prevention 2013). This may be due to the high costs of development and the subsequent risk of producing a drug with no bacteriostatic or bactericide effect due to development of resistance and thereby no way of regaining the invested money.

Antibiotic resistance in $S$. aureus, primarily from skin and wound infections, has been voluntarily registered in Sweden since 2001 through the national surveillance system ResNet (Public Health Agency of Sweden 2014). Resistance to all antibiotics tested has generally been low since the introduction of the surveillance system (figure 2).

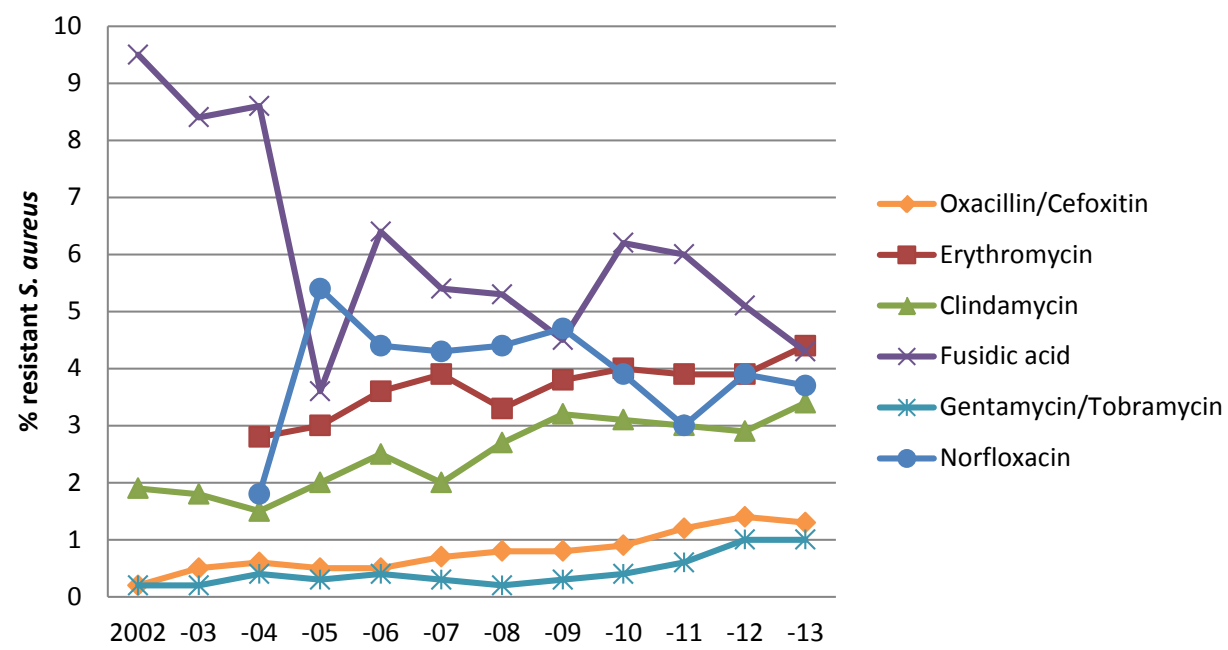

Figure 2. Prevalence of resistance in Swedish S. aureus isolated from primarily skin and wound infections. Oxacillin/Cefoxitin is used for detection of methicillin resistance. Modified from documents provided by the Public Health Agency of Sweden and published with permission (Public Health Agency of Sweden 2014). 


\section{Penicillin resistance}

The discovery of penicillin in 1928 by Alexander Fleming marked the beginning of a new era in medicine. Or as he wrote himself:

“When I woke up just after dawn on September 28, 1928, I certainly didn't plan to revolutionize all medicine by discovering the world's first antibiotic, or bacteria killer. But I guess that was exactly what I did."

When antibiotics were first introduced they were called "wonder drugs" and they could cure previously lethal infectious diseases. In 1942, Anne Miller, who suffered from septicemia, was the first civilian successfully treated with penicillin. The first report of penicillin-resistant S. aureus, through the production of penicillinase, was published in 1944 (Kirby 1944). When Alexander Fleming was subsequently awarded the Nobel Prize in Physiology or Medicine in 1945 , he warned that the overuse of penicillin might result in bacterial resistance. Six years after the introduction of penicillin approximately $25 \%$ of the $S$. aureus isolates recovered from hospitalized patients were already resistant (Chambers 2001). Another ten years later the prevalence of penicillin-resistant $S$. aureus recovered from blood cultures in Denmark had reached 75 \% (Jessen et al. 1969). This level of resistance was simultaneously seen in S. aureus from other countries around the world (Jeljaszewicz \& Hawiger 1966; Ross et al. 1974). Following the dramatic increase of penicillin resistance in $S$. aureus among hospital strains the same trend was observed for community strains (Chambers 2001).

\section{Methicillin resistance}

A penicillinase-resistant penicillin namely methicillin, which showed a bactericidal effect on penicillin-resistant $S$. aureus, was introduced in 1959. Unfortunately, only two years later, the first observation of methicillin-resistant S. aureus (MRSA) was published (Jevons 1961). The first MRSA-epidemic was seen in the late 1960s in several European countries (Keane \& Hone 1974; Kayser 1975; Frimodt-Moller et al. 1997), with a decline again in the early 70s (Kayser 1975; Frimodt-Moller et al. 1997). In the mid-70s outbreaks of MRSA infections were also being reported more frequently from the USA (Boyce \& Causey 1982; Haley et al. 1982). In the late 80s a new pattern was seen for MRSA; infections emerged primarily among young people with no known risk-factors for MRSA and was subsequently defined as community-associated (CA)MRSA. The first cases were reported from Australia (Udo et al. 1993) but subsequently CA-MRSA spread throughout the world. CA-MRSA has often been reported in groups of people in close contact, e.g., sports team participants (Begier et al. 2004), military recruits (Zinderman et al. 2004) and correctional facility inmates (Pan et al. 2003). Initially, certain genetic and phenotypic 
traits were claimed to define and differentiate CA-MRSA from hospital-associated (HA)-MRSA. Most CA-MRSA appear to be more virulent than HA-MRSA and express PVL, which is associated with necrotic pneumonia and necrotic infections of the skin and subcutaneous tissues (Lina et al. 1999). Also, CA-MRSA are usually resistant only to $\beta$-lactam antibiotics (David \& Daum 2010), whereas HA-MRSA are often multidrug-resistant, i.e., resistant to $\geq 3$ classes of antibiotics. As the distinction between HA-MRSA and CA-MRSA based on genetic and phenotypic traits began to blur, and to simplify comparison of different studies the Centers for Disease Control and Prevention Active Bacterial Core Surveillance sites (Minnesota Department of Health 2004) defined CA-MRSA as:

"MRSA that has been isolated from patients who have no:

1. history of positive culture for MRSA from any body-site obtained more than $48 \mathrm{~h}$ after admission to a hospital (if hospitalized);

2. prior MRSA infection or colonization;

3. hospitalization, surgery, residency in a long-term care facility, hemodialysis, or peritoneal dialysis within the past year or

4. current indwelling percutaneous devices or catheters."

Attempts have been made to reach consensus regarding definitions of MRSA acquisition in the Nordic countries, resulting in six categories; acquisition abroad, hospital-acquired and last community-detected with four different types of associated risk-factors (Skov et al. 2008).

The predominant CA-MRSA clone in Europe today is PVL-positive, sequence type (ST) 80 and usually t044 (Stegger et al. 2014). A recent study, using whole-genome sequencing, suggests that this European CA-MRSA developed from a sub-Saharan methicillin-susceptible S. aureus (MSSA) in the 1980s (Stegger et al. 2014). The USA300 clone is widely disseminated throughout the USA and accounted for nearly $80 \%$ of the CA-MRSA in a San Francisco-based study (Liu et al. 2008). The USA300 clone is PVL-positive, ST8 and often t008 (David \& Daum 2010). Between the years of 2005 and 2011 the estimated number of invasive infections due to CA-MRSA in the USA was stable at almost 20000 cases per year, whereas HA-MRSA decreased from approximately 90000 cases in 2005 to 70000 cases in 2011 (U.S. Department of Health and Human Services \& Centers for Disease Control and Prevention 2013).

Resistance to methicillin and all other $\beta$-lactam antibiotics in S. aureus is primarily mediated by the $m e c A$, a gene encoding the penicillin-binding protein 2a. mecA is located on the mobile genetic element Staphylococcal Cassette Chromosome mec (SCCmec) and there are currently 11 
types registered. Historically type I-III has been associated with HA-MRSA. These types are large and carry several different antibiotic resistance genes. Types IV and V are smaller, they only carry the mecA and have historically been associated with CA-MRSA (Hiramatsu et al. 2013). In 2011, a mecA homologue, subsequently named $m e c C$, was described in the UK and Denmark (Garcia-Alvarez et al. 2011). The mecC is associated with SCCmec XI, the most recently described $\mathrm{SCC}$ mec type. Also mecB has been described, however, this has not yet been identified in staphylococcal species (Hiramatsu et al. 2013). It was initially suggested that all MRSA types are descendants of a single ancestral MSSA that acquired mecA (Kreiswirth et al.1993). However, recent studies indicate that $m e c A$ has probably been introduced into several successful lineages of MSSA, as mecA is present in several genetically distinct genotypes of MRSA (Fitzgerald et al. 2001; Enright et al. 2002).

The all inpatient costs are higher and the hospital stay is longer for patients with MRSA bacteremia as compared to MSSA bacteremia (Reed et al. 2005). Although difficult to assess, it seems more cost-effective to implement intensive MRSA control programs, i.e., the search and destroy policy, than to defeat an outbreak (Bjorholt \& Haglind 2004). A meta-analysis also showed that the mortality rate for MRSA bacteremia is significantly higher than for MSSA bacteremia (Cosgrove et al. 2003). In 2011, MRSA was estimated to cause $>11000$ deaths in the USA alone (U.S. Department of Health and Human Services \& Centers for Disease Control and Prevention 2013). It has also been shown that MRSA infections add to the burden of MSSA infections, rather than substituting MSSA infections, as shown in figure 3 (Health Protection Agency 2005).

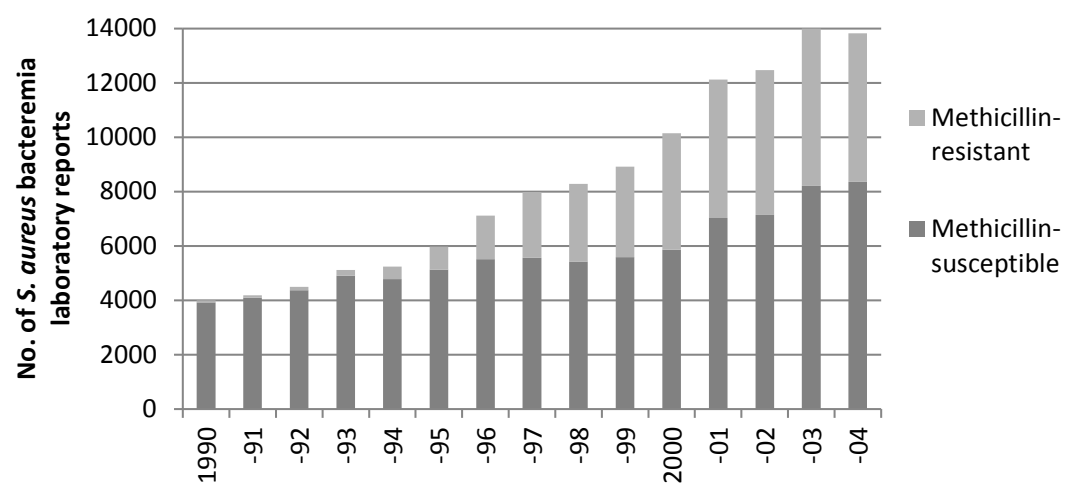

Figure 3. Number of MRSA and MSSA bacteremia laboratory reports from England and Wales 1990 through 2004 (Health Protection Agency 2005). 
S. aureus resistant to methicillin or other $\beta$-lactam antibiotics is included in the Swedish Communicable Disease Act and have been mandatorily notifiable since the year 2000 (Public Health Agency of Sweden \& National Veterinary Institute 2013). Since then the prevalence of MRSA has been consistently below $2 \%$ in Sweden, both among invasive S. aureus isolates (European Centre for Disease Prevention and Control 2014), and among S. aureus isolates from skin and wound infections (figure 2, page 6). Also, no commensal MRSA was reported from Sweden in the "Appropriateness of Prescribing Antibiotics in Primary Health Care in Europe with Respect to Antibiotic Resistance Study" (APRES), a large European study performed in 2010 and 2011, involving 32000 patients from nine countries, generating nearly 7000 S. aureus isolates. The prevalence of commensal MRSA in the other eight countries in the APRES study ranged from $0.8 \%$ in the Netherlands to $2.1 \%$ in Belgium (den Heijer et al. 2013). In the same time-period, the prevalence of invasive MRSA in some European countries reached more than 50 \% (European Centre for Disease Prevention and Control 2014). The low prevalence of MRSA in infections in Sweden, the other Nordic countries and the Netherlands, has been attributed to the restrictive prescribing of antibiotics and the search and destroy policy used in these countries. This policy includes screening of high-risk patients upon admission to hospital and isolation or cohort nursing until the patient is declared negative for MRSA colonization and/or infection. Patients with MRSA are treated in single-bed rooms and screening of patients and healthcare workers (HCWs) who have been in contact with the patient is recommended. Eradication of MRSA carriage and treatment of infections should be offered to patients and HCWs (Åhren \& Larsson 2014). In a low-endemic setting, e.g., Sweden, it is more cost-effective to use chromogenic culture media than PCR for MRSA screening (Wassenberg et al. 2011). However, a recent meta-analysis showed a higher sensitivity for screening with PCR compared to chromogenic culture media (Luteijn et al. 2011). It has also been demonstrated that the turnaround time is substantially lower and that the price is higher for screening with PCR compared to chromogenic culture media (Danial et al. 2011).

Individuals colonized with MRSA rarely need systemic antibiotic treatment. Intensified skin and wound treatment and removal of all possible foreign devices, e.g., catheters, will generally be enough, but decolonization using mupirocin ointment and/or soap containing chlorhexidine may be necessary. When treating infections, the selection of antibiotic should always be based on the resistance pattern obtained by the microbiology laboratory and depends on the focus of infection. Minor skin and soft tissue infections will usually heal without antibiotic therapy, whereas more serious infections can be treated with clindamycin or sulfamethoxazole/trimethoprim. Clindamycin can also be used to treat pneumonia and will reduce the PVL production, associated with necrotizing pneumonia caused by CA-MRSA. The 
first-line recommendation for treatment of invasive infections and infections of the central nervous system is vancomycin. Quinolones and rifampicin should be used with caution and always in combination with another antibiotic, as bacteria can develop resistance very quickly, even during a course of treatment, to these compounds (Hagberg 2014). $\beta$-lactam antibiotics in combination with a $\beta$-lactamase inhibitor, e.g., clavulanic acid, can be used to treat infections caused by $\beta$-lactam antibiotic-resistant bacteria.

\section{Vancomycin resistance}

The primary choice of treatment for invasive infections caused by MRSA is vancomycin. Fortunately, vancomycin intermediate/resistant MRSA (VISA/VRSA) is still uncommon, but sporadic cases have been documented (Sievert et al. 2008; Melo-Cristino et al. 2013). Between 2002 and 2011, 13 cases of VRSA were reported from the USA, all of which were multidrugresistant (U.S. Department of Health and Human Services \& Centers for Disease Control and Prevention 2013). It is of the utmost importance to monitor and prevent the dissemination of VISA/VRSA, in order to keep vancomycin as a treatment option for MRSA.

\section{Fusidic acid resistance}

Fusidic acid is the primary antibiotic used for topical treatment of impetigo, eye infections and infections correlated to a variety of dermatological disorders caused by $S$. aureus. It should be used systemically with caution. Fusidic acid has excellent bone penetration and is therefore used to treat osteomyelitis, but should be used in combination with another antibiotic, due to the high risk of resistance development in bacteria. During the late 90 s an increase in fusidic acidresistant S. aureus was observed in the UK (Brown \& Thomas 2002). Subsequent studies showed a clonal dissemination throughout Europe of a fusidic acid-resistant $S$. aureus correlated to impetigo primarily in young children (Osterlund et al. 2002; Tveten et al. 2002; El-Zimaity et al. 2004). This epidemic is reflected in the Swedish national statistics on resistance (figure 2 , page 6). A dramatic increase in fusidic acid resistance among $S$. aureus was also reported from New Zealand, from $17 \%$ in 1999 to $29 \%$ in 2013. This was also a clonal dissemination, although with a different clone than in Europe. In parallel to this clonal dissemination, a significant increase in dispensing rates for topical fusidic acid was seen in New Zealand (Williamson et al. 2014). The correlation between previous topical use of fusidic acid and resistance in S. aureus has previously been shown in dermatology patients (Heng et al. 2013). Although fusidic acid is not in clinical use in the USA, resistance has been reported (Jones et al. 2011). In the APRES study, fusidic acid resistance was detected in $2.8 \%$ (range: $0.1 \%$ to $7.8 \%$ ) of the European S. aureus isolates (den Heijer et al. 2014). 


\section{Clindamycin resistance}

Inducible clindamycin resistance in erythromycin-resistant $S$. aureus is detected by the double disk diffusion test (D test) where the clindamycin and erythromycin discs are placed $12 \mathrm{~mm}$ to $20 \mathrm{~mm}$ apart (edge to edge) in the bacterial inoculum on the agar plate. If the circular clindamycin inhibition zone is blunted, and thereby resembles a D, on the side facing the erythromycin disc the isolate exhibits inducible clindamycin resistance (The European Committee on Antimicrobial Susceptibility Testing 2014, Version 4.0). An S. aureus displaying inducible clindamycin resistance, as detected by the $\mathrm{D}$ test is shown in figure 4 .

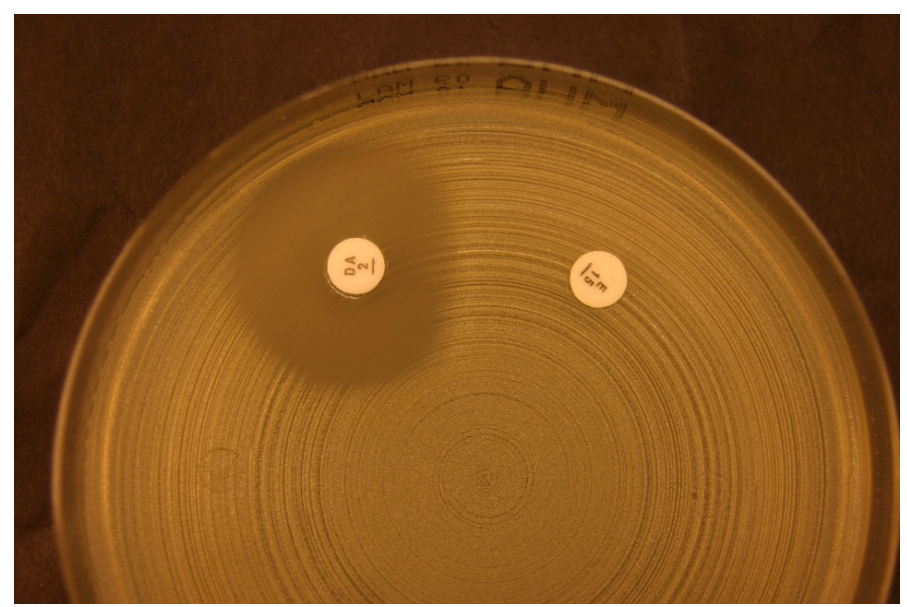

Figure 4. Inducible clindamycin resistance as revealed by the D test. DA=clindamycin, E=erythromycin. 


\section{Carriage and clinical aspects of $S$. aureus}

\section{Carriage and colonization}

The bacterial flora of the skin is divided into resident and transient flora. The resident flora is regarded as the "true" skin flora as it is more or less permanent and is seldom shed to the environment. It is therefore not considered to contribute significantly to cross-infections (exogenous infections). The resident flora is not affected by repeatedly scrubbing or extensive exposure to disinfectants. It contributes to colonization resistance, meaning that it is more difficult for other potentially more pathogenic bacteria to colonize the skin when they have to compete for a colonization site with an already established flora. The transient flora is readily acquired from and shed to the environment, including other people. It is carried superficially on the skin and is the main target during hand hygiene procedures as it is considered to contribute greatly to cross-transmission and infections (Price 1938; Gould 2012).

S. aureus is a commensal of the human flora, colonizing the skin and mucosal surfaces and the anterior nares is considered the premier colonization and carriage site. A thorough review of 18 studies from 1944 until 1994 showed that the mean S. aureus carriage rate in the general population was $37 \%$ (Kluytmans et al. 1997). More recent studies have shown nasal colonization rates of $20 \%$ to $30 \%$ (Andersen et al. 2012; Gamblin et al. 2013; Mernelius et al. 2013b; Olsen et al. 2013; Mehraj et al. 2014). Nasal colonization rates of up to nearly $60 \%$ have been reported among HIV-positive patients (Kotpal et al. 2014), patients on hemodialysis (Duran et al. 2006), intravenous drug addicts and patients with insulin dependent diabetes (Kluytmans et al. 1997). Several studies have shown that carriage and colonization in the throat is more common than colonization of the anterior nares (Nilsson \& Ripa 2006; Hamdan-Partida et al. 2010; Mernelius et al. 2013b). It has also been suggested that transmission of $S$. aureus may occur from the throat although transmission from the anterior nares is more common (Mernelius et al. 2013b). Exclusive throat carriage, i.e., colonization of the throat only, does exist (Mertz et al. 2007; Mertz et al. 2009) and age $\leq 30$ years has been determined a risk factor and exposure to the healthcare system a protective factor for exclusive throat carriage (Mertz et al. 2009). By including screening cultures from the throat the sensitivity of detecting colonization significantly increases and it has therefore been suggested that $S$. aureus screening programs should include sampling of the anterior nares as well as the throat (Mertz et al. 2007). Other anatomical sites, e.g., the axilla, groin, skin and the intestinal tract, are also colonized with S. aureus (Acton et al. 2009; Vento et al. 2013) 
S. aureus nasal carriers are usually divided into three distinct groups (Gould \& McKillop 1954; Kluytmans et al. 1997).

1. Persistent carriers are almost always colonized with S. aureus of a single genetic type.

2. Intermittent carriers are characterized by an on-and-off colonization with $S$. aureus of different types.

3. The last group is composed of the non-carriers, who never carry S. aureus.

The prevalence of the three different carriage patterns varies greatly between different studies (Eriksen et al. 1995; VandenBergh et al. 1999; Muthukrishnan et al. 2013). This variation is probably due to variation in study populations, sample collection, culture methods and how the different carriage patterns are defined. A carrier index (number of samples positive for S. aureus in one individual/number of samples collected from that individual) of $\geq 0.8$ has been suggested to define persistent carriage. A carrier index of 1.0 is rarely used, in order to avoid misclassification if there is one negative culture caused by low levels of bacteria (van Belkum et al. 2009). It does, however, seems that the carrier index should be 1.0 for true persistent carriage if the follow-up period is short or if the number of consecutive samples collected is low (VandenBergh et al. 1999). Although included in early definitions, the requirement of identical genotypes of the isolates is rarely included in more recent studies (van Belkum et al. 2009). In a recent study, individuals of all three carrier patterns were decolonized and subsequently recolonized with a cocktail of different $S$. aureus strains. This study showed higher serum levels of antistaphylococcal antibodies, longer $S$. aureus nasal survival and more CFU per swab sample in persistent carriers compared to both intermittent and non-carriers. There were no differences regarding these parameters between intermittent and non-carriers (van Belkum et al. 2009). It has been demonstrated that persistent carriers suffer a greater risk of $S$. aureus infection than intermittent carriers (Nouwen et al. 2005). These data combined suggest that there are actually only two carrier states; persistent carriers and other. If the carriers termed other are in fact intermittent carriers incidentally characterized as non-carriers, or non-carriers who are temporarily contaminated with S. aureus is still unclear (van Belkum et al. 2009).

Colonization with S. aureus is more prevalent in males than females (Mernelius et al. 2013b; Mehraj et al. 2014). There are conflicting results regarding this gender-associated difference among infants (Lebon et al. 2008; Mernelius et al. 2013b). 
The primary colonization site in newborn infants is the umbilicus (Cursino et al. 2012; Mernelius et al. 2013b) and it has been shown that infant colonization begins directly after birth and reaches adult proportions after $24 \mathrm{~h}$ (Mernelius et al. 2013b). S. aureus nasal carriage decreases in the first year of life (Peacock et al. 2003; Lebon et al. 2008), but increases again around the age of three, peaking at approximately $50 \%$ in the pre-teen years (Bogaert et al. 2004; Datta et al. 2008). In children the prevalence of $S$. aureus appears inversely related to the prevalence of Streptococcus pneumonia (Bogaert et al. 2004). Whereas persistent carriage appears almost nonexisting in infants (Lebon et al. 2008) it has been shown that persistent carriage is more prevalent among older children and adolescents than adults (Armstrong-Esther \& Smith 1976).

It has been demonstrated that more infants were colonized with $S$. aureus transmitted from HCWs rather than from their own parents (Matussek et al. 2007). A more recent study shows that this relationship has changed and most infants are colonized with the same $S$. aureus as their parents (Mernelius et al. 2013a). This relationship is probably dependent on the level of compliance with hygiene guidelines. An increased risk of colonization has been demonstrated for infants with colonized parents as compared to non-colonized parents (Mernelius et al. 2013b). This has also been shown for infants with colonized mothers (Peacock et al. 2003). Other factors that determine infant $S$. aureus carriage have been extensively studied. Breastfeeding (Peacock et al. 2003), number of older siblings (Peacock et al. 2003; Chatzakis et al. 2011) and maternal smoking (Chatzakis et al. 2011) have all been demonstrated to increase the odds for infant carriage. However, these factors were not associated with infant carriage in the study by Lebon et al. (2008). 


\section{Infection}

S. aureus acts as a two-edged sword, as it is by far the most pathogenic for humans of all the staphylococcal species. S. aureus is widely associated with skin- and soft tissue infections and it is also the causative microorganism of several severe conditions, e.g., endocarditis, osteomyelitis, and bacteremia. It was shown as early as the 1950 s that $S$. aureus nasal carriers have an increased risk of developing postoperative wound infections, as compared to noncarriers (Weinstein 1959; Williams et al. 1959). This has more recently been verified in patients undergoing orthopedic (Skramm et al. 2014) and cardiac surgery (Kluytmans et al. 1995). Also S. aureus nasal carriers have a greater risk of developing bacteremia (Wertheim et al. 2004a). It has also been demonstrated that the mortality rate attributed to $S$. aureus bacteremia is lower in carriers compared to non-carriers (Wertheim et al. 2004a). Studies have shown that $>80 \%$ of patients with $S$. aureus bacteremia were previously colonized in the anterior nares with an identical genotype, strongly indicating endogenous infection (von Eiff et al. 2001; Wertheim et al. 2004a). Studies using microarray have failed to identify genes specific to invasive or carriage isolates (Lindsay et al. 2006; Stark et al. 2009). These studies further emphasize the role of colonizing $S$. aureus in the development of invasive disease. They also suggest a genetic predisposition to whether or not the carrier strain will cause invasive disease. Given the correlation between S. aureus nasal carriage and increased risk of endogenous infections, eradication of nasal carriage has been suggested as a strategy to decrease staphylococcal infection rates. Decolonization, using intranasal treatment with mupirocin ointment, has proven highly efficient in reducing S. aureus carriage (Perl et al. 2002). Pre-operative eradication of nasal carriage significantly reduced the rates of surgical-site infections in cardiothoracic patients as compared to a historical control group (Kluytmans et al. 1996b). These results could not be replicated in a large, double-blind, randomized, placebo-controlled study on surgical patients (Perl et al. 2002). A more recent study showed a decreased risk for hospital-acquired S. aureus infection among patients who underwent nasal and skin decolonization prior to surgery (Bode et al. 2010). Also in non-surgical patients contradictory results regarding the efficacy of nasal decolonization on nosocomial S. aureus infections (Wertheim et al. 2004b) and S. aureus bacteremia (Kluytmans et al. 1996a) have been published.

Newborn infants with heavy S. aureus colonization of the umbilicus have an increased risk of subsequent S. aureus infection compared to non-colonized infants (Stark \& Harrisson 1992). Newborn infants colonized with MRSA also have a significantly higher risk of developing an MRSA infection than non-colonized infants (Huang et al. 2006b). A recently published metaanalysis determined the risk of developing an MRSA infection to be 24 times higher for infant 
MRSA carriers than non-carriers (Zervou et al. 2014). Endogenous MRSA infections have also been demonstrated for newborn infants, with indistinguishable isolates collected from the site of infection and colonization (Huang et al. 2006b). The incidence of umbilical infections in developing countries can reach $>20 \%$ and is associated with sepsis (Mir et al. 2011). Topical application of chlorhexidine to the umbilical cord of neonates has proven effective in reducing infection and mortality in developing countries (Soofi et al. 2012). Umbilical infections are, however, rare in developed countries, and there is no evidence that application of antiseptics is needed in these countries (Imdad et al. 2013).

S. aureus is also of major concern in the healthcare environment, as one of the main causes of nosocomial infections. S. aureus frequently causes nosocomial surgical site infections, pneumonia and sepsis (Kampf et al. 2009), increasing the mortality and morbidity of the patients as well as the costs for the hospital. 


\section{Typing}

Pathogenic bacteria thrive in different reservoirs, e.g., humans, animals, water and food. Dissemination of bacteria from any of these reservoirs can produce clusters of colonization or infection, also termed outbreaks. In healthcare settings, typing is primarily used for two purposes; in surveillance of infectious diseases and in outbreak investigations. Surveillance cultures and typing of organisms of extra importance in infection control can detect clusters of these organisms and thereby function as an early warning system for detection and prevention of potential outbreaks. In case of an increased incidence of infections or colonization with a certain bacterial species, typing is used to determine if the isolates are of one type, i.e., an outbreak, or of several different types, indicating an accumulation of sporadic cases. In case of an outbreak, typing is used to determine the extent of the outbreak, detect the source and clarify transmission routes (van Belkum et al. 2007).

To evaluate and validate typing methods six performance criteria and six convenience criteria have previously been set up (van Belkum et al. 2007). The following are the performance criteria.

1. The marker assessed should be stable over time, it must not vary to such a degree that it confuses the epidemiological picture.

2. All isolates should be typeable by the method.

3. The ability to discriminate between different isolates is assessed by the discriminatory power of the method and it is considered ideal if it is $>0.95$. The discriminatory power of a method refers to the probability that two unrelated isolates picked at random from a certain population will be assigned to different types.

4. The discrimination must also be concordant with the epidemiological data.

5. Independent of the laboratory technician, time and place, the results should be reproducible.

6. Finally, to adequately assess the potential of a typing method a well-defined and appropriate test population must be used.

The following convenience criteria should also be considered.

1. The flexibility, i.e., the range of bacterial species that can be studied with minimal modifications of the typing method, is recommended to be high.

2. Rapid typing results are desirable; it is preferential if results are obtained within a working day.

3. Reagents, equipment, knowledge and skill should be easily accessible. 
4. The method should also be easy to use.

5. The method should be cheap to initiate, maintain and perform.

6. The last convenience criterion, the possibility for computerized analysis and use of electronic databases, is of the utmost importance in longitudinal comparisons or studies involving a large number of isolates.

Outbreaks are often located in a single hospital or long-term care facility or to people living in close proximity; therefore, typing related to outbreak investigations can be performed at the local microbiology laboratory. For regional or national surveillance, typing can be undertaken at the reference laboratory. To monitor and define globally disseminated bacterial clones international collaborations are needed. Different typing methods, with different levels of discriminatory power, are required for each level of investigation (van Belkum et al. 2007). Many researchers have made great efforts to find the best typing method, but ultimately there is no such method. There are only methods that are better or worse at answering certain questions.

The importance of being able to communicate typing results between laboratories has been discussed previously. In the spirit of this there is also an ongoing debate on the vocabulary used in the world of bacterial typing. The main discussion involves the terms isolate, strain, type and clone and van Belkum et al. (2007) defined the terms as follows. An isolate is "a population of bacterial cells in pure culture derived from a single colony". A strain is "an isolate or group of isolates that can be distinguished from other isolates of the same genus and species by phenotypic or genotypic characteristics." However, no definite set or number of characteristics has been established to define a strain. By these definitions two isolates can represent the same strain, but two strains cannot be the same isolate. The word 'type' should only be used when the isolate has been characterized by an existing typing scheme, e.g. spa type. Finally the term 'clone' is defined as "bacterial isolates that, although they may have been cultured independently from different sources in different locations and perhaps at different times, still have so many identical phenotypic and genotypic traits that the most likely explanation for this identity is a common origin". The term 'clone' is commonly used to name widespread multidrug-resistant and/or highly virulent bacterial strains (David \& Daum 2010).

One of the main tasks for clinical microbiology laboratories is to perform antibiotic susceptibility testing on isolated pathogenic bacteria. The antibiotic susceptibility pattern can often give a first indication of a possible outbreak, and can thereby be considered the first line phenotypic typing method. It has been proven that routine molecular typing is important in detecting outbreaks, transmission routes and the source of the outbreak (Mellmann et al. 2006; Boers et al. 2011). 


\section{Phage typing}

Historically, phage typing has been used for epidemiological typing of $S$. aureus. This is a phenotypic typing method which characterizes $S$. aureus into more than 20 different phage types. S. aureus is inoculated on the agar of a gridded petri dish, with different phages inoculated in each of the squares in the grid. If one of the phages is specific for the tested $S$. aureus the phage will reproduce within the bacteria, resulting in no bacterial growth and a clear zone in that square, i.e., a plaque is formed. Each phage has a unique name (consisting of a number, sometimes in combination with a letter), and the phage in the grid where a plaque forms determines the specific phage type of that S. aureus (Batzing 2002). As a vast number of different phages had to be kept in stock at each laboratory performing phage typing this typing method was restricted to reference laboratories. It was thereby impossible to obtain rapid typing results to aid in epidemiological investigations. Another problem with phage typing was the large number of untypeable isolates. Due to these inconveniences in combination with the recent development in genetic analysis phage typing is no longer in clinical use. 


\section{Pulsed-field gel electrophoresis}

In conventional gel electrophoresis the electrophoretic conditions will separate DNA fragments based on size. This is accomplished by a sieving effect, where smaller fragments more easily travel through the gel matrix than larger ones, which results in a pattern based on the size of the fragments. However, fragments larger than 20000 base-pairs (bp) travel equally fast through the gel matrix, resulting in no resolution of the fragments. Pulsed-field gel electrophoresis (PFGE) of macrorestricted DNA was developed to enable studies of entire yeast and bacterial genomes. To exclude non-specific restriction of DNA, bacterial cells are first welded into an agarose plug. The embedded cells are subsequently lysed and cell debris, proteinases and nucleases are enzymatically removed and washed away. By the use of a restriction enzyme that cleaves DNA infrequently (for S. aureus usually SmaI (Mulvey et al. 2001; Murchan et al. 2003)) DNA fragments ranging in size from tens to hundreds of kbps are produced. By applying an alternating electric field to the agarose gel containing the DNA, the fragments are forced to change both their conformation and orientation, resulting in a size-dependent separation of the fragments (Peters 2009). The procedure of the PFGE method is outlined in figure 5.
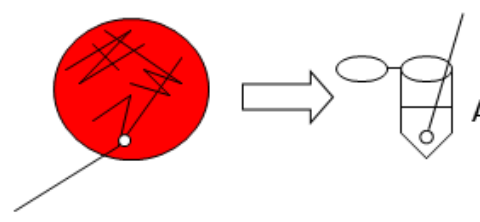

Add agarose
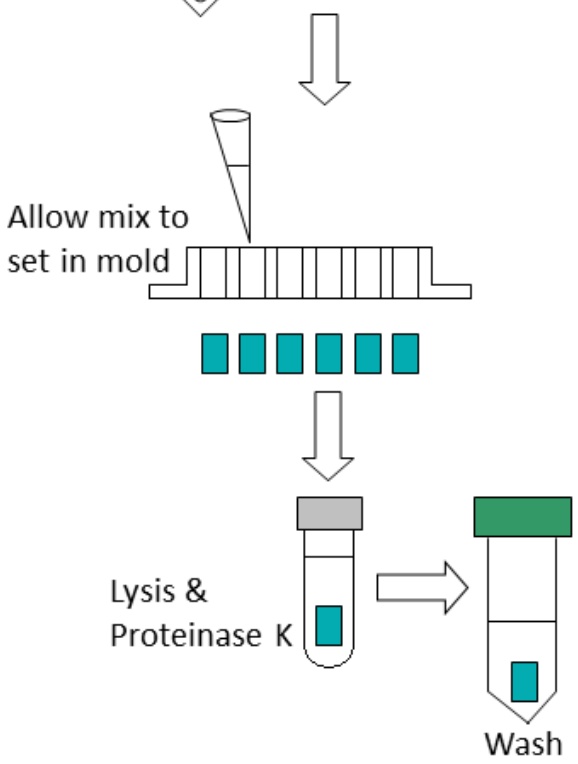

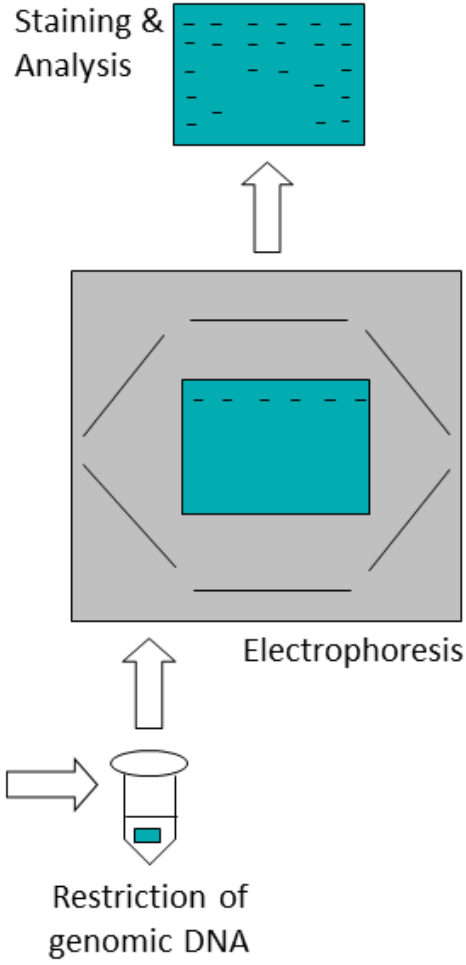

Figure 5. Schematic illustration of the PFGE method. 
The Tenover criteria have been, and still are, widely used for interpretation of restriction fragment patterns (Tenover et al. 1995). Briefly, isolates with the exact same patterns are defined as indistinguishable, those that differ by 2-3 fragments are defined as closely related, by 4-6 fragments as possibly related and by $\geq 7$ fragments as different. Interpretation of restriction fragment patterns by the naked eye is subjective and impractical when working with large datasets; therefore software for analysis of restriction fragment patterns is now frequently used. This has improved the objectivity of the analysis but PFGE is still afflicted by several other problems. Results obtained by different protocols are difficult to compare therefore attempts to harmonize protocols have been made (Mulvey et al. 2001; Murchan et al. 2003). The lack of a consensus protocol, as well as the nature of the data, makes transferring of results between laboratories difficult. Also, PFGE is technically demanding. The cost per sample is low (Vainio et al. 2011), but the number of samples that can be run simultaneously is restricted. The method is highly discriminatory, with an index of diversity often above 0.95 (Cookson et al. 2007). Moreover, it has excellent typeability (Hallin et al. 2007) as well as epidemiological concordance (Strommenger et al. 2008).

PFGE has long been considered gold standard for typing of most bacterial species, including S. aureus (Murchan et al. 2003). Due to the problems with gel-based methods discussed above and development in the field of sequencing in recent years, this has now changed and in studies on epidemiological surveillance and outbreak investigations (Melin et al. 2009) as well as in national reference laboratories (Vainio et al. 2011) sequence-based methods are used to determine the clonal relationship between $S$. aureus isolates. 


\section{Single locus sequence typing}

Gel-based typing methods are afflicted by several problems that are overcome with sequencebased methods. These methods could be based either on sequencing a single locus or multiple loci. Several different typing schemes based on sequencing part of a single $S$. aureus gene has been established, e.g., spa and $c l f B$ typing. In $c l f B$ typing the R-domain of the gene is sequenced. The R-domain consists of a variable number of 18 bp long repeats (Kuhn et al. 2007). However, spa typing is the most well-established and used method today.

\section{spa typing}

S. aureus protein A is a surface protein encoded by the spa gene (figure 6). The gene consists of a cell wall attachment sequence $\left(\mathrm{X}_{c}\right)$, the variable number tandem repeat region $\left(\mathrm{X}_{\mathrm{r}}\right)$, the IgGbinding regions (A-D), a region homologous to A-D (E) and a signal sequence segment (S) (Uhlén et al. 1984). spa typing is based on amplification and sequencing of the $\mathrm{X}_{\mathrm{r}}$ region, which consists of a variable number of $24 \mathrm{bp}$ repeats (rare cases of $21 \mathrm{bp}$ and $27 \mathrm{bp}$ repeats have also been documented) where each repeat has a unique sequence. Different spa types arise from point mutations in the repeats, as well as from deletion and duplication of the repeats. Therefore, the sequence of each spa type is unique and there are spa types of variable length. spa typing was initially based on amplification of the $\mathrm{X}_{\mathrm{r}}$ region and subsequent gel-based analysis of the length of the amplicon (Frenay et al. 1994). This method obviously gave no information regarding the sequence, and two isolates could be classified as indistinguishable based on being equally long, whereas they in fact had repeats differing in sequence. When sequencing became more readily available, the method of spa typing was modified (Frenay et al. 1996) and nowadays it is based on sequencing of the polymorphic $\mathrm{X}_{\mathrm{r}}$ region. The highly conserved regions flanking the $\mathrm{X}_{\mathrm{r}}$ region enables annealing of the primers necessary for amplification and sequencing.

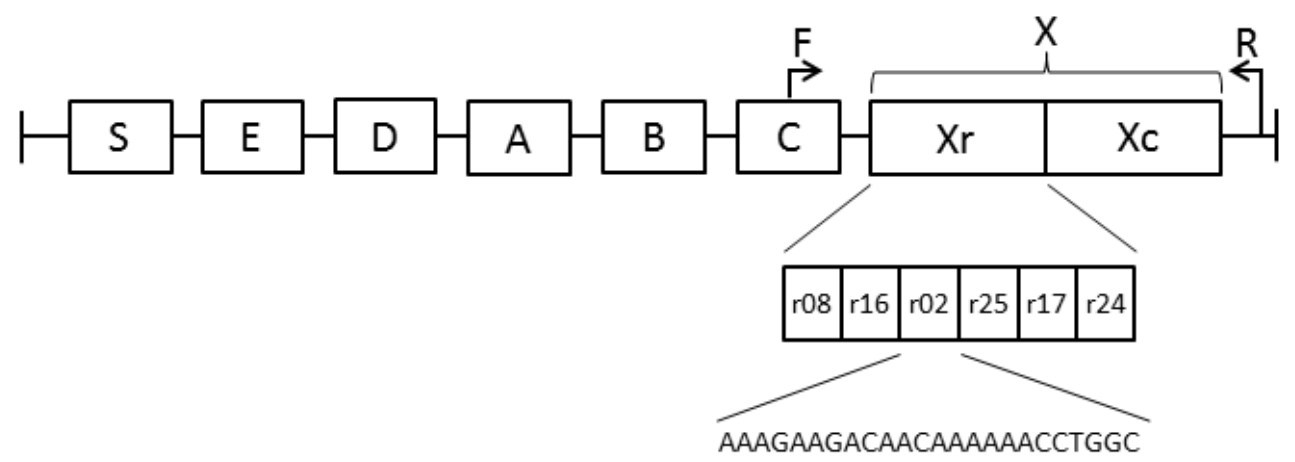

Figure 6. Schematic illustration of the spa gene. The repeat succession outlined represents spa type t138. $F$ and $R$ represent the sites where the forward and reverse primers bind, respectively. 
Analysis of sequence data and attribution of spa types to isolates is easily performed using the Ridom StaphType software. The software is associated with a freely available web-based database (Ridom GmbH 2014) which allows researchers from all over the world to submit and obtain repeat sequences and the repeat succession of spa types. Therefore, both researchers who do and those who do not have access to the software have access to the standardized terminology of spa typing (Harmsen et al. 2003). On March 23, 2015 there were 14777 spa types and 665 repeats registered in the database. At that time, the most prevalent spa type in the database was t032 (10.44\%), in many cases classified as the epidemic MRSA-15.

The Ridom StaphType software assigns names to the repeats and types according to the Ridom nomenclature, where each repeat is assigned a numeric code, e.g., r01 and r02 and the order of the repeats is combined into a spa type, e.g., t001 and t084 (Ridom GmbH 2014). There is also an alternative nomenclature, the Kreiswirth nomenclature, where the repeats are assigned a letterand numeric code, e.g., A1 and D2 and the order of the repeats is combined into a spa type, e.g., 1 and 4 (Koreen et al. 2004). This nomenclature is not as widespread and has not had the same impact around the world as the Ridom nomenclature. The standardized nomenclature used in spa typing is one of its major advantages especially over band-based methods, e.g., PFGE, which makes comparison and exchange of data between laboratories easy. Additionally, spa typing results are acquired relatively quickly. One study showed that it took just under $10 \mathrm{~h}$ to perform spa typing on 24 isolates, whereas typing 12 isolates by PFGE took $40 \mathrm{~h}$ (Vainio et al. 2011).

spa typing shows great typeability (Koreen et al. 2004; Strommenger et al. 2008), epidemiological concordance (Melin et al. 2009) and reproducibility (Shopsin et al. 1999; Strommenger et al. 2008) as well as high discriminatory power (Cookson et al. 2007; Hallin et al. 2007; Babouee et al. 2011). The $\mathrm{X}_{\mathrm{r}}$ region of spa is also stable over time, both in vivo and in vitro (Frenay et al. 1996).

The Based Upon Repeat Pattern (BURP) algorithm was developed to enable long-term epidemiological studies using spa typing. BURP combines spa types with similar repeat patterns into clonal complexes ( $s p a$ CCs). The similarity of the spa types is based on the parsimony assumption, i.e., the hypothesis with the fewest assumptions is most likely to be the correct one. In one study the algorithm gave a similar evolutionary signal as multilocus sequence typing (MLST) and microarray data, indicating its potential as a method for longitudinal studies (Mellmann et al. 2007). 
spa typing has been extensively studied for its appropriateness as a typing tool in epidemiological investigations. Some recommend the method for local outbreak investigations (Strommenger et al. 2008) and for detection of S. aureus transmission (Matussek et al. 2007). Others have shown that spa typing alone is not discriminatory enough to demonstrate the endemic establishment of MRSA (Fossum Moen et al. 2014). There are also indications that spa typing must occasionally be combined with the detection of other genetic markers, e.g., SCCmec or resistance or virulence genes (Hallin et al. 2007; Fossum Moen et al. 2014). There is also evidence that the discriminatory power increases when combining typing of two loci, e.g., spa and clfB (Kuhn et al. 2007). 


\section{Multilocus sequence typing}

In national, global and long-term epidemiological studies typing should be based on a genetic marker which slowly accumulates genetic variation. For many bacterial species the most widely used typing method to do this is MLST, based on sequencing of several highly conserved genes, i.e., housekeeping genes. The $S$. aureus MLST scheme is based on sequencing the internal fragments, approximately 500 bps in length, of each of the following seven housekeeping genes: carbamate kinase $(\operatorname{arcC})$, shikimate dehydrogenase ( $\operatorname{aroE})$, glycerol kinase ( $g l p)$, guanylate kinase ( $g m k)$, phosphate acetyltransferase ( $p t a)$, triosephosphate isomerase ( $t p i)$, and acetyl coenzyme A acetyltransferase (yqiL). Through a web-based server the sequences of each of the seven fragments are assigned a distinct allele number. The combination of these seven allele numbers constitutes the allelic profile, or the ST, of the isolate (Enright et al. 2000; Larsen et al. 2012). For a schematic illustration of the MLST analysis see figure 7. Due to the vast number of different alleles at each locus, it is highly unlikely that two unrelated isolates would have the same ST by chance; therefore, isolates with the same ST can safely be defined as of identical or highly similar genotypes. The discriminatory power of MLST is generally slightly lower than for PFGE and spa typing and therefore the method is highly useable for long-term studies and for the determination of global dissemination of certain genetic linages of $S$. aureus (Cookson et al. 2007). As MLST is a sequence-based method it has the advantage of producing unambiguous results, which are easy to incorporate into electronic databases and transfer between laboratories. As the method requires sequencing of seven genes it is expensive and timeconsuming, especially compared to single locus sequence typing where only one locus per isolate needs to be sequenced.

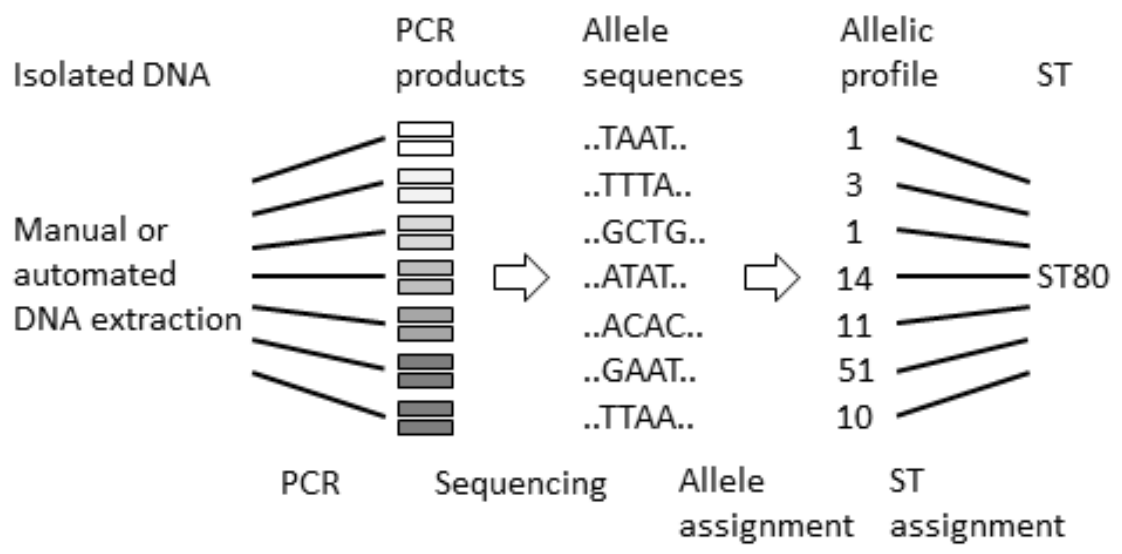

Figure 7. Schematic illustration of the MLST analysis. Modified from: http://beta.mlst.net/Instructions/default.html. 
The application Based Upon Related Sequence Types (eBURST) was developed to describe the relationship of closely related isolates based on MLST data. The method initially forms groups of STs that share identical alleles in at least six of seven loci with at least one other ST in the group. The primary founder of the group is the ST differing from the largest number of other STs in only a single locus. Using these settings all isolates of a group are part of the same CC and the isolates are considered to have recently diverged genetically from each other. STs that have different alleles in more than two loci compared to any other ST cannot be assigned to a group and are called singletons (Feil et al. 2004).

The ST obtained by MLST in combination with the SCCmec type is currently used to name MRSA, e.g., the epidemic clone EMRSA-16 is known as ST36-MRSA-II, an MRSA of ST36 carrying SCCmec type II (Deurenberg et al. 2007). 


\section{Next generation sequencing}

Next generation sequencing (NGS) or second generation sequencing differs from the original sequencing approach using Sanger sequencing in its ability to produce millions of reads (35-700 bps in length) in a single run to a reasonably low cost. To generate the complete sequence of a genome the short sequence reads are assembled by overlapping sequences (de novo assembly) or compared to previously sequenced reference genomes (re-sequencing). With its full coverage of the genome it has been deemed the end-point in typing, with the possibility of absolute resolution between isolates. The method produces large amounts of data and requires heavy computer resources and the requests for well-trained bioinformaticians will increase (Sabat $e t$ al. 2013).

Although the cost associated with NGS is still high it continues to decline (Harris et al. 2013). For NGS to be implemented in routine outbreak investigations and surveillance typing continuous efforts have to be made to shorten the time required for sequencing and analysis (Eyre et al. 2012; Harris et al. 2013). In addition to this, analysis tools and standard procedures to determine the variation between genomes have to be established. There are different approaches used today. The extended MLST produces an allelic profile of the entire core genome, based on hundreds to thousands of alleles, compared to seven for traditional MLST. The pan-genome approach compares the presence or absence of genes of the entire genome between different isolates. The number of single-nucleotide polymorphisms that differs between isolates can also be used. Despite the drawbacks of high costs, prolonged sequencing and analysis time and lack of standard analysis procedures, NGS has recently become widely available to reference and clinical laboratories. Several studies have demonstrated that NGS is highly useful in investigations of MRSA outbreaks (Eyre et al. 2012; Harris et al. 2013). NGS has also been used to demonstrate that an HCW, initially unknown to be colonized with MRSA, was the potential source of an MRSA outbreak (Harris et al. 2013). The importance of interpreting whole-genome data in combination with epidemiological information has been emphasized (Eyre et al. 2012; Diep 2013). Colonizing and infecting $S$. aureus isolates from a single individual, indistinguishable by spa typing and PFGE, have been demonstrated to differ by whole-genome sequencing (Schijffelen et al. 2013). It has also been suggested that the genetic information revealed by NGS will provide insights into the genetic basis of transmissibility and virulence (Diep 2013).

A summary of the advantages, disadvantages and applications of the typing methods for S. aureus described above is given in table 1 . 


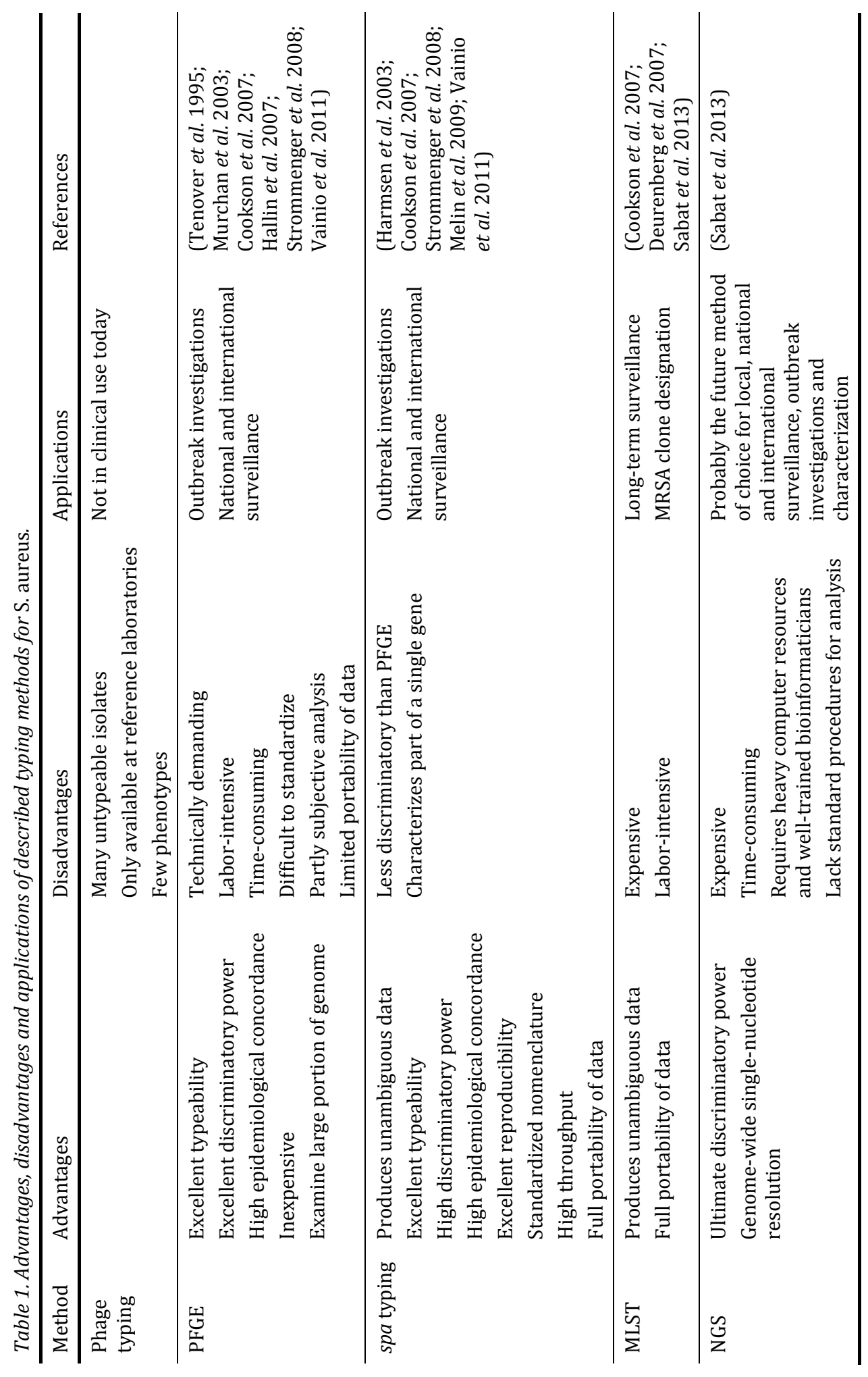




\section{Infection control}

In the 1840s Ignaz Semmelweis laid the foundation for modern infection control when he was working at the General Hospital of Vienna. He observed that the maternal mortality was noticeably higher in one of the two obstetrics clinics. The clinic with the higher mortality rate was staffed by medical doctors, who carried out both deliveries and autopsies during the same shift, without any routines for hand-washing between the two tasks. The other clinic was staffed by midwives, who did not perform autopsies. Semmelweis therefore required the doctors to clean their hands with a chlorinated lime solution when entering the labor room. Following the intervention, the maternal mortality rate in the clinic staffed by doctors decreased to the same level as in the clinic staffed by midwives.

The impact of hand hygiene on transmission of $S$. aureus to newborn infants was studied in 1962. An index infant, colonized with a phage-typeable $S$. aureus, was placed in a bassinet at one end of the study room. On either side (A and B) of the room three infants were placed in individual bassinettes. All contact with the A and B babies was performed after contact with the index baby. Whereas the nurses caring for the A babies always washed their hands after touching the index baby and between touching the A babies, the nurses caring for the $\mathrm{B}$ babies did not perform any hand-washing procedure after touching the index baby or between touching the B babies. This study showed a significantly higher rate of acquisition of the index strain among the B babies, who had been attended to by nurses with unwashed hands, as compared to the A babies, attended to by nurses with washed hands. Also, it required an exposure time to the index strain that was nearly four times as long before the infants in the group handled with washed hands acquired the index strain as compared to those handled with unwashed hands. The study also demonstrated that transmission of S. aureus via the hands of HCWs is of greater importance than transmission via the air (Mortimer et al. 1962).

There are several different approaches to identify bacterial colonization and minimizing transmission and nosocomial infections. Detection of bacterial colonization of patients admitted to hospitals can be done in two ways. The first is by the use of active screening cultures (ASC), with cultures taken upon admission to the hospital and thereafter on a regular basis throughout hospitalization. ASCs can be applied to all patients, i.e., universal screening, or selectively, i.e., to patients with certain risk factors, e.g., skin lesions, catheters or diarrhea. The other way to detect colonization is through clinical microbiological cultures, performed on clinical indications. Comparing ASCs with clinical microbiological cultures revealed that solely relying on the latter resulted in a great underestimation of the number of patients colonized with MRSA (Salgado \& 
Farr 2006). To avoid transmission and nosocomial infections decolonization can be used, either universally targeting all patients in a hospital or ward, or selectively targeting only the patients colonized or infected with the microorganism of interest.

The strategy of choice must be based on the prevalence of the microorganism of interest in that specific geographic area. For instance in areas with a low prevalence of MRSA (5\%) use of ASCs in combination with selective decolonization appears to be the most cost-effective strategy to prevent MRSA transmission and infection whereas for areas with higher prevalence $12 \%$ or $20 \%$ ) universal decolonization seems to be more cost-effective (Gidengil et al. 2015). However, it is also important to take into account the potential of resistance development when implementing strategies involving decolonization.

The search and destroy policy, based on ASCs, isolation and decolonization, has been adopted by the Nordic countries and the Netherlands and has helped to keep the prevalence of MRSA low. The decolonization strategy for MRSA usually involves application of mupirocin ointment intranasally twice a day for five days, and/or daily scrubbing with a chlorhexidine gluconatecontaining soap (Åhren \& Larsson 2014). 


\section{Nosocomial infections}

Nosocomial infections are defined as infections acquired during hospital care or as a result of diagnostic procedures, treatment or nursing in any part of the healthcare system. Infections in HCWs caused by their work are also considered nosocomial (Swedish Association of Local Authorities and Regions 2015). An infection acquired more than $72 \mathrm{~h}$ after admission to a hospital is usually classed as nosocomial. Although nosocomial infections have become almost synonymous with hospital-acquired (or associated) infections, they can also arise in nonhospital environments, such as long-term care facilities.

Nosocomial infections obviously cause a tremendous amount of suffering among patients, but are in Sweden also estimated to cause 750000 extra patient days annually and cost approximately 6.5 million SEK. Point prevalence measurements of nosocomial infections have been performed biannually in Sweden since 2008, showing a stable prevalence of approximately $9 \%$ (Swedish Association of Local Authorities and Regions 2015), which is in line with reports from other European countries (Chalmers \& Straub 2006). It has been shown that improved compliance with hygiene guidelines can reduce the frequency of nosocomial infections by up to $40 \%$ (Pittet et al. 2000).

Nosocomial infections originate either from the commensal flora of the patient itself, through endogen transmission, or through cross-transmission, where the infectious agent originates from someone other than the patient him/herself. There are no clinically significant differences between endogenous infections and cross-infections, but there are differences in the epidemiology and how to prevent the two types of infections. 


\section{Bacterial transmission}

Transmission of microorganisms from person to person is mediated through contact transmission, droplet transmission or airborne transmission. In direct contact transmission microorganisms are transmitted from a colonized or infected person to a susceptible host through body-surface to body-surface contact. In indirect contact transmission microorganisms are transmitted to the host via a contaminated object, e.g., a needle, dressing or the hands of an HCW. Within healthcare settings contact transmission via the hands of HCWs is considered the main transmission route (Weinstein 1991). Far from all transmissions lead to an infection, but a large German study revealed that $10 \%$ of the nosocomial infections among ICU patients could be attributed to cross-transmission (Grundmann et al. 2005). As it is impossible to know the outcome of transmission (ranging from colonization to life-threating infections) the aim must be to hinder all bacterial transmission.

The prevention strategies for cross-transmission are subdivided into two categories. The first category is isolation of the contagious patient from other patients in the same ward. Although this is effective in hindering transmission if done properly, it is expensive and labor-intensive. It is also inconvenient and uncomfortable both for the patient and HCWs. The second way to prevent cross-transmission is to break all possible transmission routes. Cleaning will remove visible dirt mechanically. Soaps and detergents have no antimicrobial activity themselves, but aid in dissolving the dirt. Generally, non-sporulating bacteria and viruses need organic matter to survive, on clean surfaces they will dry out and die. Sterilization per se means to make something sterile, i.e., no microorganisms should be present on the object after the process of sterilization. Reducing the number of microorganisms by a factor of more than $10^{6}$ is, however, considered sufficient for sterilization. The best effect is reached on clean objects, i.e., those free of visible dirt. To remove or kill microorganisms on surfaces disinfectants are used. Depending on the circumstances of disinfection the antimicrobial activity and the toxicity of the compound have to be appropriate balanced. As the main vector for microorganisms in healthcare settings is the hands of HCWs (Weinstein 1991), hand disinfection is the most important factor in preventing bacterial transmission. 


\section{Outbreaks}

An outbreak is defined as a "temporal increase in the incidence of infection (or colonization) by a certain bacterial species, caused by enhanced transmission of a specific strain" (van Belkum et al. 2007). Multiple strains can be included in an outbreak, if the outbreak has been going on for some time or if there is extensive person-to-person transmission (Barrett et al. 2006). ASCs can identify colonization prior to any clinical infections are seen and thereby identify an outbreak early on. Outbreak investigations include several different strategies. The source of the outbreak and the route of transmission are determined by epidemiological typing of the causative microorganism. Antibiotic therapy can be changed to eliminate the source of the outbreak and hygiene efforts are reviewed and improved to prevent any further transmission. 


\section{Hygiene guidelines}

The Swedish National Board of Health and Welfare has published a regulation on hygiene guidelines in healthcare, mandatory for all HCWs performing examinations, patient care and treatment, i.e., bedside tasks (The National Board of Health and Welfare 2007). The regulation comprises the following eleven points:

1. Work clothes must be short-sleeved.

2. Work clothes must be changed daily or more often if needed.

3. Hands and forearms must be free from wristwatches and jewelry.

4. Hands must be disinfected with an alcohol-based disinfection agent, or other agent with equal effect, immediately prior to and after every direct contact with patients.

5. Hands must be disinfected prior to and after use of gloves.

6. Hands must, if visually soiled, be washed with soap and water prior to disinfection.

7. When nursing a patient with gastroenteritis, the hands must always be washed with soap and water prior to disinfection.

8. Hands must be dry when applying disinfection agent.

9. A disposable plastic apron or protective gown must be used if there is a risk the work clothes will come into contact with body fluids or other biological materials.

10. Disposable gloves must be used in contact, or if there is a risk of contact, with body fluids or other biological materials.

11. Gloves must be removed directly after, and changed between different, bedside tasks.

\section{Hand hygiene}

Originally, hand-washing was the recommended method for cleaning hands in healthcare settings. Unfortunately, the compliance with hand-washing has usually been unacceptably low, seldom exceeding $40 \%$ (Widmer 2000). There is evidence that promotion campaigns to improve hand hygiene including the introduction of alcohol-based hand rub have been more successful than trying to improve compliance with already existing hand-washing guidelines (Bischoff et al. 2000; Pittet et al. 2000). Also the antimicrobial effect of alcohol-based hand rub is significantly better than that of hand-washing (Ayliffe et al. 1978), which only reduces the transient flora of the hands. Although early studies showed conflicting results regarding the bactericidal effect of alcohol (Price 1939), this effect is now well established (Price 1939; Salvage et al. 2014). The improved bactericidal effect when scrubbing the hands with alcohol as compared to just dipping them in alcohol was established early (Price 1939). Hand-washing requires 1-2 min to perform correctly, whereas hand disinfection requires less than 30 seconds 
of working time. During disinfection HCWs can perform other healthcare-related tasks, such as reading a radiograph or introducing themselves to the patient, activities more difficult to perform while washing the hands. Additionally, whereas hand-washing dries out the skin, hand disinfection with an alcohol-based hand rub has no such effect. However, the application of a moisturizer is recommended both after hand-washing and hand disinfection. These drawbacks of hand-washing have led to the recommendation and introduction of waterless disinfection with alcohol-based hand rub in healthcare settings (Widmer 2000). Hand-washing is still recommended when the hands are visibly soiled and when handling patients with gastroenteritis or infected with spore-forming bacteria, since non-enveloped viruses and spores are highly tolerant to alcoholic disinfectant solutions.

Compliance with hygiene guidelines in recent studies, mainly reflecting the use of alcohol-based hand rub has generally been found to be below $50 \%$ (Costers et al. 2012; Tromp et al. 2012; Biswal et al. 2014). Compliance with hygiene guidelines is generally thought to be low when the activity index (number of opportunities for hand hygiene per hour of care) is high, which was confirmed by Pittet et al. (2000). The apprehension that compliance is lower during night shifts than during day shifts has, however, not been confirmed (Pittet et al. 1999). Some studies have shown a significantly lower compliance with hygiene guidelines among physicians compared to other professions (Randle et al. 2010; Scheithauer et al. 2011; Costers et al. 2012). A more recent study did not show any general differences in compliance rates between physicians, midwives and registered nurse assistants (Mernelius et al. 2013c). Compliance with disinfection of the hands prior to patient contact generally renders lower compliance than disinfection after patient contact (Mernelius et al. 2013c; Biswal et al. 2014). 


\section{Monitoring compliance with hygiene guidelines}

Gold standard for monitoring compliance with hygiene guidelines is direct observations (Boyce 2008), a method where HCWs (observers), from the own department or unit, monitor their colleagues compliance with hygiene guidelines. The observers are educated by infection control nurses and infection control practitioners on infection control and hygiene guidelines. The components monitored to determine compliance with hygiene guidelines in Sweden are described in table 2.

Table 2. The components monitored to determine compliance with hygiene guidelines in Sweden.

\begin{tabular}{ll}
\hline Barrier precautions* & Dress code $\dagger$ \\
\hline B1. Hand disinfection before patient contact & D1. Short-sleeved work clothes \\
\hline B2. Hand disinfection after patient contact & $\begin{array}{l}\text { D2. Hands and forearms free from } \\
\text { watches and jewelry }\end{array}$ \\
\hline B3. Correct use of gloves & D3. Short or restrained hair
\end{tabular}

B4. Correct use of plastic apron or protective gown

*Variables B1 and B2 "yes" or "no" only, variables B3 and B4 also "not applicable" for situations where gloves and/or apron or gown are not necessary.

tVariables D1 to D3 “yes" or "no" only.

Even though direct observations are gold standard for monitoring compliance with hygiene guidelines, the method is considered expensive, and self-reporting has therefore been suggested as an alternative method. However, both methods are time-consuming and many have therefore searched for a substitute marker to indirectly measure compliance with hygiene guidelines, e.g., the usage of hand hygiene products (Haas \& Larson 2007). Eckmanns et al. (2006) showed a positive correlation between hand hygiene compliance and hand rub consumption. The efficacy of hand hygiene monitoring technology, i.e., systems that count alcohol-based hand rub or soap dispensing events or in other ways estimate compliance and/or provide hand hygiene reminders, has recently been reviewed. To generally adopt hand hygiene monitoring technology could not be recommended based on the seven studies included and the need for further and scientifically better studies was emphasized (Srigley et al. 2015).

Validation of direct observations has been performed on a small scale, showing no difference in results between different observers (Tromp et al. 2012). This was confirmed in another study, which also concluded that self-reporting by HCWs is also a valid way to monitor compliance with hygiene guidelines (Mernelius et al. 2013c). 


\section{Interventions to improve compliance with hygiene guidelines}

The hands of HCWs is the main vector for transmission of microorganisms in healthcare settings (Weinstein 1991) and to reduce the number of nosocomial infections several studies have attempted to improve the compliance with hygiene guidelines, especially hand hygiene. The most successful way to accomplish this has proven to be by applying a multimodal hygiene intervention (Pittet et al. 2000; Kirkland et al. 2012; Tromp et al. 2012; Mernelius et al. 2013c; Biswal et al. 2014). Hygiene interventions that are multidisciplinary, including all disciplines of HCWs, also physicians, also appear to be more successful (Mernelius et al. 2013c). Attempts have been made to clarify which of the initiatives of an intervention result in the greatest improvement of compliance with hygiene guidelines (Kirkland et al. 2012). This has resulted in the conclusion that a combination of initiatives is probably the key to success (Pittet et al. 2000). Improved compliance with hygiene guidelines has resulted in reductions in healthcareassociated infections, healthcare-associated S. aureus infections (Kirkland et al. 2012), MRSA acquisition rate and colonization pressure (Chun et al. 2014) as well as the prevalence of nosocomial infections and the incidence of MRSA infections and bacteremia (Pittet et al. 2000).

Many studies have shown a long-term effect of hygiene interventions on compliance with hygiene guidelines (Kirkland et al. 2012; Tromp et al. 2012; Mernelius et al. 2013c; Biswal et al. 2014) whereas others have demonstrated the opposite (Gould \& Chamberlain 1997). All studies reporting on a long-term effect were multimodal, whereas the study reporting no long-term effect only featured a single intervention. It appears as if continuous reminders or minor sequential interventions need to be implemented for a sustained effect (Pittet et al. 2000; Kirkland et al. 2012).

The involvement of patients in improving the compliance with hand hygiene among HCWs has also been studied, with a comprehensive review recently published on the subject (Davis et al. 2015). Some studies show that patients were more willing to remind HCWs to conduct hand hygiene when encouraged to do so by an HCW (Davis et al. 2011; Davis et al. 2013) or if prompted in multiple ways (Pittet et al. 2011). Patients in general appear to be more willing to confront nurses than physicians regarding their hand hygiene (Davis et al. 2011; Pittet et al. 2011). Very few patients did, however, actually confront HCWs about their hand hygiene (Pittet et al. 2011; Schwappach et al. 2011). 


\section{Aims of the thesis}

The main aims of this thesis are to study bacterial transmission, with S. aureus colonization of newborn infants as a model, and to evaluate the impact of compliance with hygiene guidelines on transmission.

The specific aims of this thesis were to:

- Evaluate the usefulness of spa typing in epidemiological investigations (paper I).

- Establish S. aureus colonization rates, antibiotic susceptibility patterns and spa type epidemiology (papers III \& IV).

○ Determine the effect of the inclusion of an enrichment broth prior to plating, on S. aureus recovery (paper IV).

- Elucidate from which sites transmission of S. aureus occurs (paper IV).

- Validate direct observations and self-reporting by HCWs for monitoring compliance with hygiene guidelines (paper II).

- Improve the compliance with hygiene guidelines by a multimodal and multidisciplinary hygiene intervention (paper II).

○ Determine the effect of different rates of compliance with hygiene guidelines, on S. aureus transmission (paper III). 


\section{Outline of the Swedish HITS study (papers II, III \& IV)}

The Swedish Hygiene Intervention and Transmission of S. aureus (HITS) study is a study in three parts aiming at clarifying the correlation between different compliance rates with hygiene guidelines and transmission of $S$. aureus to newborn infants. The study setting was four departments of obstetrics and gynecology, at four different hospitals. Characteristics of the four departments and patients are given in table 1, paper III.

\section{Part one - Baseline (spring 2008)}

Compliance with hygiene guidelines (barrier precautions and dress code, according to table 2, with the exception of D3, page 37) was monitored through direct observations. Samples to identify S. aureus colonization were collected from the anterior nares and throat of HCWs in the participating departments at the start of their shift, from parents upon arrival at the delivery ward and from visiting adults. Mothers were also sampled from the vagina. Samples from the anterior nares and umbilicus were collected from newborn infants at the age of $2 \mathrm{~h}$ and subsequently every $24 \mathrm{~h}$ until discharge, when the final samples were collected. Visitors were sampled from the anterior nares and throat if older than 18 years. All adults and visiting siblings were also sampled from any skin lesions (table 3). All samples were collected using cotton swabs. From the departments environmental and air samples were also collected, by contact plates and a surface air sampler, respectively.

Table 3. Number of samples collected from each site in each population at baseline.

Infants Fathers Mothers HCWs Visitors

2h. 24 h. 48 h. Discharge

\begin{tabular}{lllllllll}
\hline Umbilicus & 213 & 147 & 60 & 205 & & & & \\
\hline Nares & 213 & 147 & 62 & 203 & 215 & 215 & 390 & 36 \\
\hline Throat & & & & & 215 & 215 & 390 & \\
\hline Vagina & & & & & 205 & & \\
\hline Skin lesion & & & & 22 & 12 & 24 & 5 \\
\hline
\end{tabular}


Transmission routes were established using spa typing. We evaluated four possible transmission routes for $S$. aureus colonizing newborn infants. First, if the infant and one of its family members were colonized with S. aureus of the same spa type, regardless of whether the spa type was also present elsewhere, the infant's own family was considered the origin of transmission. Second, HCWs and/or other families were considered the source of transmission if the infant's spa type was found among HCWs, any of the other infants simultaneously cared for in the department, or any family member of those infants. Third, the environment was considered the source of transmission if the infant's spa type could only be detected in the environment. And finally, if the spa type of the $S$. aureus colonizing an infant could not be detected among its own family, any other family, HCW or in the environment, the source of transmission was considered unknown.

\section{Part two - The Intervention (autumn 2008)}

A multimodal and multidisciplinary hygiene intervention was launched in each department and continuous monitoring of the compliance with hygiene guidelines was performed. The intervention comprised the following parts: a lecture, a workshop, safety briefings, posters, an infection control audit, supporting visits and phone calls from infection control nurses, feedback on the progress and compliance rates, education of more observers and training in, and assessment of, the hand hygiene technique.

\section{Part three - The post-interventional phase (2009-2010)}

When the departments had reached and stabilized at a level of compliance with hygiene guidelines of $\geq 80 \%$ (point of stability), sampling (table 4) and identification of transmission routes were performed in the same way as during baseline. The compliance with hygiene guidelines was also assessed three years after the intervention was initiated (follow-up).

Table 4. Number of samples collected from each site in each population at the post-interventional phase.

Infants Fathers Mothers HCWs Visitors

2 h. 24 h. 48 h. Discharge

\begin{tabular}{lllllllll}
\hline Umbilicus & 233 & 167 & 60 & 215 & & & & \\
\hline Nares & 232 & 166 & 60 & 216 & 230 & 233 & 318 & 45 \\
\hline Throat & & & & & 229 & 229 & 319 & 3 \\
\hline Vagina & & & & & 233 & & \\
\hline Skin lesion & & & & 30 & 12 & 26 & 1 \\
\hline
\end{tabular}




\section{Performance of bacteriological methods}

\section{Enrichment broth (paper IV)}

In paper IV, 2371 samples were examined for S. aureus growth, out of which 488 samples were positive by direct plating and an additional 225 samples by incubating the swabs in enrichment broth prior to plating. This corresponds to a total increase of S. aureus-positive samples by $46 \%$ using enrichment broth prior to plating (table 1, paper IV). The largest increase in S. aureuspositive samples was seen for vaginal samples with a $267 \%$ increase in positive samples when plating after incubation in enrichment broth. This corresponds to an increase from three to eleven positive samples, out of 157 , so due to the small sample size these results need to be interpreted with caution. It has been demonstrated that $S$. aureus rectovaginal colonization in mothers does not pose a risk for early onset neonatal sepsis (Tomlinson et al. 2011). The premier colonization site for adults was the throat $(47 \%, \mathrm{p}<0.001$ compared to other sites sampled) and the number of $S$. aureus-positive samples from throat was doubled after enrichment compared to direct plating. Also for samples from the nares of infants the number of positive samples more than doubled after enrichment. Incubating the swabs from the other sites cultured (skin lesions, nares of adults and umbilicus of newborn infants) in enrichment broth prior to plating all generated more positive samples than direct plating. These results indicate that incubation of swabs in enrichment broth prior to plating is necessary to determine more truthful S. aureus colonization rates. A study on pregnant women and their newborn infants identified an increased $S$. aureus yield by the addition of an enrichment broth prior to plating (Andrews et al. 2009). An increased sensitivity of S. aureus detection when using an enrichment broth was also demonstrated by Wanten et al. (1998). The recommendation to use an enrichment broth prior to plating is not included in the Swedish guidelines for culturing samples from skin and soft tissue infections, from which S. aureus is often isolated (Föreningen för Medicinsk Mikrobiologi vid Svenska Läkaresällskapet \& Folkhälsomyndigheten 2012). 


\section{Typing methods (papers I, III \& IV)}

In paper I, 280 MRSA isolates from colonized or infected individuals were characterized by antibiotic susceptibility testing, spa typing, PFGE and PVL gene presence/absence. Also, MLST was performed on representative isolates from the collection. A thorough epidemiological investigation of each MRSA case was possible thanks to the low prevalence of MRSA in Sweden. Therefore the epidemiological data was considered gold standard when evaluating the performance of spa typing and PFGE.

All isolates were typeable both by spa typing and PFGE, resulting in $100 \%$ typeability. The index of diversity was 0.94 (95\% confidence interval [CI] 0.92-0.95) for spa typing and 0.95 (95\% CI 0.93-0.96) for PFGE, both in the order of the desired diversity index of 0.95 (van Belkum et al. 2007). Of the 35 outbreaks detected, only one consisted of isolates of different spa types (table I, paper I), rendering great epidemiological concordance (99.5\%). One isolate in this outbreak was of a spa type that differed by one point mutation in the eighth repeat from the predominant spa type (table 5), indicating a close genetic relationship between the two types. In six of the outbreaks, isolates of two or more distinguishable, but $>80 \%$ similar and therefore considered closely or possibly related, PFGE patterns were observed. Due to the interpretation criteria used the epidemiological concordance of PFGE was $100 \%$ ( $\mathrm{p}=0.33$ compared to epidemiological concordance for spa typing).

Table 5. Repeat succession of the two spa types observed in one outbreak in paper I and the repeat sequences of the repeats differing between the spa types.

\begin{tabular}{llll}
\hline spa type & Repeat succession & Repeat no. & Repeat sequence \\
\hline t032 & $26-23-23-13-23-31-29-17-31-$ & r17 & AAAGAAGACGGCAACAAGCCTGGT \\
& $29-17-25-17-25-16-28$ & & \\
\hline t1377 & $26-23-23-13-23-31-29-110-31-$ & r110 & AAAGAAGACGACAACAAGCCTGGT \\
& $29-17-25-17-25-16-28$ & & \\
\hline
\end{tabular}

spa typing results can be obtained within $12 \mathrm{~h}$ starting with a pure bacterial culture (Vainio et al. 2011). Although this is slightly slower than optimal for ultimate clinical use of epidemiological typing (van Belkum et al. 2007) it is faster than PFGE, where the run-time on the instrument alone (the process in which fragments are separated on the gel) usually takes about $24 \mathrm{~h}$ (Murchan et al. 2003). DNA has successfully been prepared directly from frozen bacteria (S. Mernelius, unpublished data) and by omitting culturing; the process of spa typing has been speeded up further. For analysis by PFGE, bacteria have to be cultured, as the DNA concentration in the plug has to be standardized to enable inter-laboratory comparison of results (Murchan et 
al. 2003). spa typing can easily process samples in a 96-well format, whereas for PFGE, the maximum number of samples that can be run on one gel, and thereby the maximum number of samples that can be processed simultaneously, is 39. For in-house sequencing the set-up cost for spa typing is quite heavy, but this is also true for the instrumentation needed to perform PFGE. Sequencing performed by commercial sequencing companies can save a laboratory a lot in investment costs. As spa typing is based on amplification by PCR, the reagents for this method are more expensive than for PFGE, which is based on macrorestriction of unamplified material. PFGE, on the other hand, is more labor-intensive, and therefore the staff cost for PFGE exceeds that for spa typing. Data analysis of PFGE restriction patterns requires an experienced technician, and includes moderately subjective interpretation of weak bands and double bands. In contrast, data analysis of spa data is very easy and requires a minimum of interpretation as only isolates with exactly identical sequences are considered clonal and are assigned the same spa type. Therefore spa typing is superior to PFGE when analyzing a large number of isolates.

Another advantage of spa typing over PFGE is the standardized nomenclature and thereby the transportability of data between laboratories. Paper I includes MRSA from four different counties. The microbiology laboratories in each county could have performed spa typing inhouse and easily transferred the results electronically to one coordinating laboratory, whereas PFGE had to be performed at one central laboratory for optimal comparability.

Both spa typing and PFGE have shown high discriminatory power (Cookson et al. 2007) and $100 \%$ typeability (Hallin et al. 2007). In paper I, both methods performed comparably well regarding discriminatory power, typeability and epidemiological concordance. spa typing was considered superior to PFGE thanks to its accessibility, ease of use and rapidity. This is in line with previous studies that have found spa typing well suited for outbreak investigations (Shopsin et al. 1999; Strommenger et al. 2008). A recent study from Norway, a low-prevalence country for MRSA like Sweden, detected clonal dissemination of a single spa type (t304), and recommended supplementary typing methods in addition to spa typing for this situation (Fossum Moen et al. 2014). Other studies have also implied that spa typing should be used in combination with the analysis of additional markers, e.g. SCCmec or virulence or resistance genes, to fully clarify epidemiological connections (Hallin et al. 2007; Strommenger et al. 2008). Isolates of identical spa types were observed in different outbreaks in paper I. The presence or absence of PVL among these isolates could in some cases differentiate these outbreaks from one another. 
In papers III and IV spa typing was used to determine transmission routes of $S$. aureus to newborn infants. The origin of the $S$. aureus colonizing the infants could be identified as another person or the environment in $83 \%$ to $84 \%$ in these studies, although there were approximately 10000 different spa types registered in the Ridom Spa Server database at that time (Ridom $\mathrm{GmbH} 2014)$. The large proportion of certain transmission routes despite the vast number of spa types present reflects the potential of spa typing as a valid epidemiological typing tool. A previous study has also used spa typing to reveal transmission of $S$. aureus among newborn infants (Matussek et al. 2007).

In line with the results in paper I, several studies have shown that the discriminatory power of MLST is lower than that of spa typing and PFGE (Cookson et al. 2007; Hallin et al. 2007). MLST is therefore not suitable for local outbreak investigations as isolates from different outbreaks would be assigned the same ST and thereby confuse the epidemiological conclusions. 


\section{S. aureus epidemiology}

\section{Antibiotic resistance (papers I \& III)}

The prevalence of resistance in S. aureus in the Swedish HITS study (paper III), in skin and wound infections in Sweden and from the Swedish data in the APRES study are shown in table 6. Two isolates resistant to cefoxitin, the antibiotic used to screen for MRSA, were detected in paper III and one was confirmed to be an MRSA by the detection of mecA. The colonizing S. aureus isolated from healthy individuals in paper III were significantly less resistant to cefoxitin and fusidic acid than the $S$. aureus causing infections collected nationally. (Statistics based on the assumption that 15 clinical microbiology laboratories delivered data on 100 isolates each.) This was also true for clindamycin and erythromycin in the years of 2009 and 2010, whereas no difference was seen for these antibiotics in 2008. Resistance to fusidic acid was also significantly lower among S. aureus in paper III, compared to the Swedish data in the APRES study. There were no differences in resistance to cefoxitin, clindamycin or erythromycin in paper III and the APRES study, both including colonizing S. aureus. The level of antibiotic resistance in Sweden is generally low which is reflected in paper III. This is probably due to the restrictive antibiotic prescription policy in Sweden.

Table 6. Prevalence of resistance (\%) among S. aureus from the Swedish HITS study (paper III), the Swedish national database and the APRES study.

\begin{tabular}{llllll}
\hline Year & & Cefoxitin & Clindamycin & Erythromycin & Fusidic acid \\
\hline 2008 & Baseline* $^{*}$ & 0.1 & 2.0 & 2.1 & 0.9 \\
\hline 2008 & National data $^{\dagger}$ & 0.8 & 2.7 & 3.3 & 5.3 \\
\hline $2009-10$ & Follow-up* $^{*}$ & 0.0 & 1.4 & 1.5 & 0.7 \\
\hline 2009 & National data $^{\dagger}$ & 0.8 & 3.2 & 3.8 & 4.5 \\
\hline 2010 & National data $^{\dagger}$ & 0.9 & 3.1 & 4.0 & 6.2 \\
\hline $2010-11$ & APRES study $^{\dagger}$ & 0.0 & 1.5 & 1.6 & 1.9 \\
\hline $\begin{array}{l}* \text { Data from paper III } \\
+ \text { Data from (Public Health Agency of Sweden 2014) }\end{array}$ \\
* Data from (den Heijer et al. 2013; den Heijer et al. 2014)
\end{tabular}


In paper III, 32 erythromycin-resistant isolates were detected, of which 30 (94\%) exhibited inducible clindamycin resistance, the other 2 (6\%) were clindamycin-susceptible. The prevalence of inducible clindamycin resistance varies greatly in different studies (Siberry et al. 2003; Vandana et al. 2009). Clindamycin can be used to treat pneumonia and more serious skin and soft tissue infections caused by MRSA (Hagberg 2014). Treatment failure of an MRSA infection with clindamycin due to inducible clindamycin resistance has been documented (Siberry et al. 2003). Treatment with clindamycin of infections caused by inducible clindamycinresistant $S$. aureus should be avoided, as the exposure of clindamycin to these bacteria might provoke further resistance development. Inducible clindamycin resistance can be detected by the D test (The European Committee on Antimicrobial Susceptibility Testing 2014, Version 4.0) and to discriminate between isolates exhibiting inducible resistance and susceptibility this method has to be applied to all clinical isolates of S. aureus (Vandana et al. 2009).

The distribution of resistant isolates was similar between parents, infants and HCWs (paper III). This indicates that more resistant strains of $S$. aureus are not accumulated in healthcare settings and that HCWs do not harbor a specific institutional flora, more resistant to antibiotics than the flora present in the community.

The MRSA incidence in Jönköping County between 2009 and 2013 was among the highest in Sweden (Public Health Agency of Sweden \& National Veterinary Institute 2013). From this, one may draw the conclusion that infection control was not as efficient in this county, compared to other counties. The national point prevalence measurements on compliance with hygiene guidelines show that Jönköping County has been among the best since the measurements began in 2010. In 2014 the compliance with hygiene guidelines in Jönköping County was the highest in Sweden (86.6 \%) (Swedish Association of Local Authorities and Regions 2014). Instead the high MRSA incidence may imply a well-functioning infection control program, with extensive screening of risk patients as well as contact tracing.

The prevalence of multidrug resistance (resistance to $\geq 3$ classes of antibiotics) among Swedish S. aureus isolates was $0.2 \%$, compared to $2 \%$ to $3 \%$ in the $S$. aureus from the other eight participating European countries in the study by den Heijer et al. (2013). In paper I, where all isolates were methicillin-resistant, 109 (39\%) were classified as multidrug-resistant whereas no multidrug-resistant isolates were identified in paper III. It has been shown that MRSA isolates are more often multidrug-resistant compared to MSSA isolates (Erami et al. 2014). This is not surprising as some of the SCCmec types are known to carry several antibiotic-resistance genes. 


\section{Prevalence of S. aureus (papers III \& IV)}

In paper III a total of 6530 samples were collected from mothers $(n=448)$, fathers $(n=446)$, newborn infants ( $n=449,215$ girls), HCWs (93\% females, $n=711)$ and visiting siblings $(n=79)$ as well as relatives $(n=3)$. Environmental samples $(n=496)$ were collected with contact plates and a total of $24000 \mathrm{~L}$ of air was sampled using a surface air sampler. For detailed sampling schemes see table 3 (page 41) and table 4 (page 42).

The colonization rates ranged from $44 \%$ to $66 \%$ among adults (table 2, paper III), showing that fathers were colonized to a larger extent than mothers, HCWs and infants $(\mathrm{p}<0.01)$. Also in paper IV adult males were significantly more often colonized than women, an expected result as the 2434 samples in paper IV were part of the collection in paper III, only differing in the culture technique used. The procedure of using an enrichment broth prior to plating (paper IV) revealed colonization rates ranging from $51 \%$ to $70 \%$ among adults. A gender-associated difference in colonization, with males being more frequently colonized compared to females, has been demonstrated in previous studies (Bischoff et al. 2004; Herwaldt et al. 2004; Sangvik et al. 2011; Olsen et al. 2012). Initially, the reason for this association was unknown and scarcely studied (Bischoff et al. 2004). More recent research has shown an inverse correlation of S. aureus colonization and carriage to serum concentrations of vitamin D among non-smoking men. It has been suggested that vitamin D up-regulates the antibacterial immune defense and high concentrations of vitamin D would thereby kill off $S$. aureus and reduce colonization (Olsen et al. 2012). There are indications that the immune defense is somehow boosted by female sex hormones (Marriott \& Huet-Hudson 2006). This could explain the lower S. aureus colonization rates among females compared to males described in paper III and previous studies (Bischoff et al. 2004; Herwaldt et al. 2004; Sangvik et al. 2011) as well as why the association between colonization and carriage status and serum concentration of vitamin D was more prominent among males (Olsen et al. 2012). Due to the few hours of sun-light during the winter in Scandinavia, low serum concentrations of vitamin D, and thereby a higher prevalence of S. aureus, can be expected during this period. This was also demonstrated in a Swedish study, where $S$. aureus colonization rates were approximately $20 \%$ higher in March compared to August (Nilsson \& Ripa 2006). The gender-associated difference so prominent among adults was not detected among infants (table 2, paper III). It has been shown previously that male infants are colonized to a larger extent than female infants (Lebon et al. 2008). There was no statistically significant difference in colonization rates between mothers and HCWs, who were mainly females (paper III). These differences indicate that $S$. aureus colonization patterns are not influenced by pregnancy. 
The $S$. aureus colonization of infants increased from approximately $40 \%$ (table 2, paper III) to $61 \%$ when incubating the swabs in enrichment broth prior to plating (table 2, paper IV). Infant colonization began immediately at birth, with $17 \%$ of the infants being colonized already at the age of $2 \mathrm{~h}$, climbing to $47 \%$ at the age of $24 \mathrm{~h}$ (figure 1, paper IV). Paper IV show that newborn infants were more commonly colonized in the umbilicus (53\%) than in the anterior nares ( $42 \%, \mathrm{p}<0.05$ ). In paper III, $25 \%$ of the newborn infant carriers were detected by analyzing the anterior nares only and $95 \%$ by analyzing umbilicus only. Similarly to this, a previous study showed that $73 \%$ of the newborn infant $S$. aureus carriers were detected by culturing the umbilical only, whereas only $36 \%$ were detected by nares culture only (Andrews et al. 2009).

Prevalence of $S$. aureus in different sites in male and female adults and infants was determined in paper IV and is shown in figure 8. For adults the most prevalent colonization site was the throat ( $47 \%, \mathrm{p}<0.001$ compared to other sites sampled). This has been shown in previous studies (Nilsson \& Ripa 2006; Hamdan-Partida et al. 2010) and it has been suggested that the throat should be included in S. aureus screening programs (Wanten et al. 1998). Previously, the anterior nares have been considered the premier colonization site and therefore much of the S. aureus research has been performed on nasal carriers (Kluytmans et al. 1997).
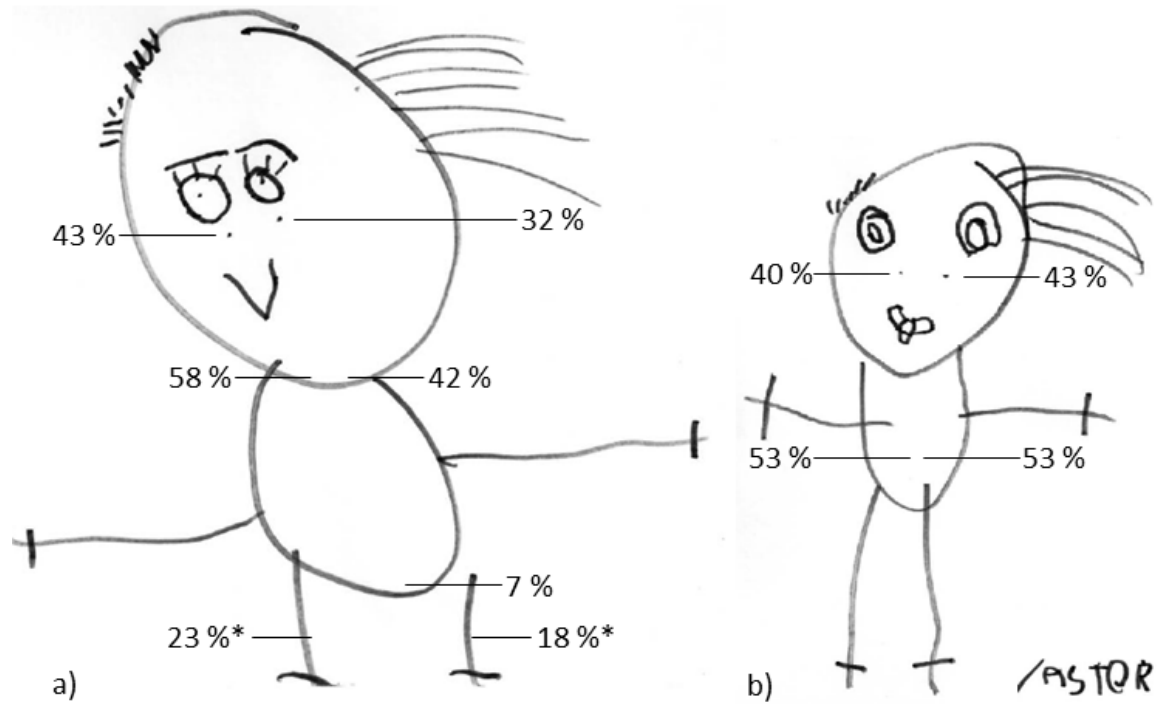

Figure 8. Prevalence of S. aureus in the sites sampled in a) male (left) and female (right) adults and b) male (left) and female (right) infants.

* Skin lesions

Drawing by Astor Mernelius, after idea by Elisabeth Norén. 
A recent European study revealed that Sweden had the highest prevalence of $S$. aureus nasal carriage (30\%) among the nine participating countries (den Heijer et al. 2013). The prevalence of nasal colonization among adults was $27 \%$ (paper IV) when using direct plating, the same method as used in the paper by den Heijer et al. (2013). When incubating the swabs in enrichment broth prior to plating the prevalence of nasal S. aureus colonization was $37 \%$ (paper IV), thereby being the second most common colonization site among adults.

S. aureus was detected in 17 (3.4\%, 10 at baseline and 7 at follow-up) of the 496 environmental samples collected in paper III. S. aureus was found in lavatories $(n=4)$, areas exclusively used by HCWs $(n=5)$, ward rooms $(n=2)$, a milk kitchen $(n=1)$, on medical equipment $(n=4)$ and on a Pilates ball used by the mothers (n=1). No S. aureus was detected in the $24000 \mathrm{~L}$ of air sampled. The focus of environmental and air contamination in hospitals has primarily been on MRSA, rather than MSSA. The prevalence of MRSA on surfaces and in the air in hospitals is low, even in countries where MRSA is endemic (Creamer et al. 2014; Mirzaii et al. 2014). Despite this, it has been demonstrated that patients admitted to rooms previously occupied by patients with MRSA has an increased risk of acquiring MRSA compared to patients admitted to rooms previously occupied by non-MRSA patients (Huang et al. 2006a). It has also been shown that a prolonged MRSA outbreak was stopped by intensified cleaning (Rampling et al. 2001). 


\section{spa type distribution and cluster analysis (papers III \& IV)}

The probability of isolating two indistinguishable strains from two individuals with connections in time and space but with no known transmission events is a function of the prevalence of those strains in the corresponding community. Knowing the prevalence of different strains in the community will therefore aid in the understanding of the increased prevalence of specific strains in the healthcare setting. If a strain assumes endemic proportions in the community, a high prevalence in the healthcare setting might not indicate an outbreak or increased transmission. This situation requires additional typing and characterization of the isolates to resolve potential outbreaks. Increased prevalence in healthcare settings of fairly uncommon community strains does, however, imply intra-healthcare transmission and a possible ongoing outbreak.

A total of 314 different spa types were identified in paper III. Of these, $49 \%$ were unique to single individuals. The most common spa types among newborn infants, parents, HCWs, relatives and siblings at baseline and follow-up are shown in figure 1, paper III. The spa type most commonly isolated was t084 ( $n=104)$, followed by t012 ( $n=65), t 015(n=50), t 021(n=42)$ and t002 $(n=41)$. The four most common spa types in paper III were also the four most common in paper IV (figure 2, paper IV). A previous study from partly the same geographical area showed that $\mathrm{t} 012$, $\mathrm{t} 015$ and $\mathrm{t} 021$ were the most common spa types (Matussek et al. 2007), indicating that major clones do not fluctuate greatly over time. In the same study, t084 was not detected at all (Matussek et al. 2007) which could indicate that the molecular epidemiology of S. aureus is somewhat dynamic. t084 has recently been described as one of the most common spa types in studies both from northern Norway and Nigeria (Sangvik et al. 2011; Kolawole et al. 2013; Olsen et al. 2013).The high prevalence of $t 084$ both among adults and infants indicates that it is highly transmittable and a successful colonizer. S. aureus of spa type t084 was also the predominant colonizing type, but also the cause of four cases of bacteremia, in the neonatology department in one of the hospitals participating in the Swedish HITS study (paper III). The t084 in the neonatology department had unfortunately also acquired tobramycin resistance. The introduction into healthcare settings of such a transmittable type, carrying virulence factors or resistance genes, poses a great threat to healthcare.

No specific spa types were correlated to male or female gender, or to the nares or throat among adults (paper IV). Gender-specific spa types have been identified previously (Sangvik et al. 2011). The study demonstrating this correlation was, however, larger than ours. A significant association between HCWs and a specific spa type (t160) was identified in paper IV, which is in line with a previous study, which, however, identified an association between two other 
spa types, namely t012 and t015, and HCWs (Olsen et al. 2013). t160 was also the most common spa type in nursing homes in the same geographical area as the studies in papers III and IV (Stark et al. 2014). This adds to the indication already suggested, based on the high prevalence of the previously undetected t084 in the region, that some strains are more prone to transmission and are more successful colonizers.

Simultaneous $S$. aureus colonization in more than one site was observed in 140 individuals of which 42 (30\%) were colonized with isolates of different spa types in at least two sites (paper IV). These individuals were termed multiclonal individuals. The phenomenon of multiclonal individuals has also been described in elderly persons living in nursing homes (Stark et al. 2014). Multiclonal colonization could mislead epidemiological conclusions. In paper III, $17 \%$ of the $S$. aureus transmissions to newborn infants were of unknown origin; these transmissions might to some extent be explained by multiclonal colonization. Antibiotic treatment may also be hampered by the presence of an undetected resistant strain in clinical samples. A mathematical model predicted that approximately $7 \%$ of the individuals would be colonized by more than one $S$. aureus strain, based on the typing of three colonies from the anterior nares (Cespedes et al. 2005). A recent study on multiclonal colonization in children in which four to 15 colonies were typed from each sample revealed that $30 \%$ contained two or three different strains of $S$. aureus (Mongkolrattanothai et al. 2011). However, typing of several colonies from each sample is time-consuming and labor-intensive. Therefore a culture independent method to clarify multiclonal colonization in one site has been described (Matussek et al. 2011).

BURP cluster analysis of the 170 different spa types detected in paper IV revealed 19 spa CCs and nine singletons. The four largest spa CCs contained $52 \%$ of the spa types and $62 \%$ of the isolates. For details of these spa CCs see table 7. Of the detected spa types, twelve were shorter than five repeats, and were by default excluded from the analysis. Shorter spa types contain little genetic information and the reliability of the evolutionary analysis based on these spa types is limited (Mellmann et al. 2007). Of the 29 most commonly identified spa types (figure 2, paper IV), 12 were found in the largest spa CC (spa CC 015). This spa CC has previously been identified as the largest spa CC among elderly people living in nursing homes in southern Sweden (Stark et al. 2014). Only two of the 29 most common spa types (t084, the most commonly identified spa type, and t085) were found in the second largest spa CC. 
Table 7. The number and percentage of spa types and isolates in the four largest spa CCs in paper IV.

\begin{tabular}{lll}
\hline & \multicolumn{2}{c}{ Number of } \\
& spa types (\%) & isolates (\%) \\
\hline spa CC 015 & $53(31 \%)$ & $297(38 \%)$ \\
\hline spa CC 084 & $13(8 \%)$ & $113(14 \%)$ \\
\hline spa CC 349 & $13(8 \%)$ & $33(4 \%)$ \\
\hline spa CC 002 & $10(6 \%)$ & $46(6 \%)$ \\
\hline
\end{tabular}

Only nine of the 42 individuals (21\%) that were colonized with two different spa types in different sites, were colonized with spa types from the same spa CC, indicating close genetic relatedness. Even lower prevalence of congruence between spa types in samples collected from individuals over time has been reported (Stark et al. 2014). The colonization with genetically different spa types in different sites indicates that there is a close match between the bacteria and not only the host, but also the specific site of colonization in that host. 


\section{Infection control in healthcare settings}

\section{Validation of direct observations and self-reporting by HCWs (paper II)}

Direct observations are considered gold standard for monitoring compliance with hygiene guidelines (Boyce 2008). As the method is considered time-consuming and expensive other methods, e.g., self-reporting by HCWs or alcoholic hand rub consumption, have been suggested. The validity of direct observations and self-reporting by HCWs seems scarcely studied. Therefore direct observations and self-reporting by HCWs using the Swedish protocol for monitoring compliance (table 2, page 37 ) were validated in three ways in paper II.

1. Double appraisal. This was used to determine the concordance between two observers, who simultaneously and blinded to the reporting of the other observer monitored the compliance of the same HCW performing a bedside task.

2. Multi appraisal. This was used to determine the concordance between several observers as well as between observers and the infection control nurses. The compliance with hygiene guidelines for a prerecorded bedside task was monitored by all observers $(n=226)$ present at an educational meeting for observers.

3. Self-reporting by HCWs. An experienced observer monitored the compliance with hygiene guidelines of an HCW. This HCW was subsequently asked to fill out a compliance form for the same, recently performed, bedside task.

In the double appraisal 69 observed bedside tasks were evaluated. The concordance between observers was $99 \%$ for barrier precautions and $97 \%$ for the dress code, as the compliance was judged identical by 68 and 67 observer-pairs, respectively. Within observer-pairs there were 4 discrepancies registered regarding hand disinfection after patient contact, 6 regarding glove use and 1 each regarding short sleeves and short or restrained hair. The high concordance between observers demonstrated is in line with a previous small-scale validation of direct observations (Tromp et al. 2012). 
In the multi appraisal, $95 \%$ to $100 \%$ of the observers correctly judged the seven different components of the hygiene guidelines, showing great concordance between observers as well as between observers and the experts, i.e., the infection control nurses. There were no statistical significant differences in compliance rates when determined by experienced observers or new observers.

For self-reporting by HCWs 49 bedside tasks were evaluated. When the compliance with barrier precautions and the dress code was registered by self-reporting HCWs it was $76 \%$ and $96 \%$, respectively, and when registered by the observers it was $71 \%$ and $94 \%$, respectively. The differences in compliance rates were not statistically significant. The concordance between the self-reporting HCWs and the observers was $94 \%$ for barrier precautions (3 discrepancies registered) and $98 \%$ for the dress code ( 2 discrepancies registered). These results indicate that self-reporting by HCWs is a valid method to monitor compliance with hygiene guidelines.

However, self-reporting by HCWs demands a very good knowledge on hygiene guidelines by all HCWs. Anecdotal evidence on self-reported compliance with hygiene guidelines by HCWs show that HCWs perceive themselves to be $90 \%$ compliant with hygiene guidelines, whereas they believe their coworkers to be only $50 \%$ compliant (Walker et al. 2014). 


\section{Compliance with hygiene guidelines (papers II \& III)}

Baseline compliance in papers II and III reflects the compliance in the participating departments when no extra focus was spent on hygiene guidelines. It was established based on 217 direct observations on barrier precautions and 227 regarding the dress code, reaching compliance rates of $41 \%$ and $93 \%$, respectively. The compliance rates for barrier precautions of each participating department are shown in figure 1, paper II.

Following the initiation of the 10-point hygiene intervention (for details see page 42), observers in each department performed ten direct observations each week. The compliance rates were continuously evaluated by infection control nurses and graphical feedback was sent to and posted in the departments weekly. It took seven months to one year to reach and stabilize at a compliance rate of $\geq 80 \%$. In paper II, this evaluation point was termed 'point of stability' and the compliance rates, based on 556 direct observations on barrier precautions and 580 regarding the dress code, were $85 \%$ and $99 \%$, respectively. In paper III this evaluation point was termed 'follow-up' and the compliance rate was $86 \%$ with barrier precautions and $99 \%$ with the dress code (316 and 342 direct observations were performed, respectively). The compliance rates were significantly higher at point of stability (paper II) and follow-up (paper III) compared to baseline, both regarding barrier precautions and the dress code. This shows that it is possible to markedly improve the compliance with hygiene guidelines by a multimodal and multidisciplinary hygiene intervention, which confirms previous data (Boyce \& Pittet 2002). A hospital-wide study by Kirkland et al. (2012) also demonstrated a statistically significant improvement in compliance with hygiene guidelines approximately one year after initiation of monitoring and giving feedback on compliance rates. This might indicate that the mere attention to the issue of unsatisfactory compliance could be encouragement enough for many to improve their behavior. Studies have shown that compliance with hygiene guidelines improves when introducing an alcohol-based hand rub, but not when promoting hand-washing (Bischoff et al. 2000; Pittet et al. 2000). This may be due to the shorter time required to perform hand disinfection compared to hand-washing or the lack of unfavorable side effects of alcoholbased hand rub compared to hand-washing.

To establish the long-term effect of the intervention an evaluation of compliance rates (followup, paper II) was undertaken three years after the hygiene intervention was launched. Over the entire study period (from baseline to follow-up) a significant improvement in compliance was seen in three of the departments (A, B and D), whereas it was close to significant in department $\mathrm{C}(\mathrm{p}=0.07)$. By performing an extensive educational hygiene intervention and 
promoting alcohol-based hand rub, Pittet et al. (2000) managed to significantly improve the compliance with hygiene guidelines over a period of three years. Also, they used continuous reminders in the form of posters emphasizing the need for good compliance with hygiene guidelines and replaced them weekly. The use of continuous and varied reminders might be necessary to achieve a sustained long-term effect on the compliance. The compliance with barrier precautions was also evaluated three years after follow-up (six years after the hygiene intervention was launched) and ranged from $82 \%$ to $99 \%$ in departments B, C and D. This was significantly higher than at baseline $(\mathrm{p}<0.001)$. Compliance rates for this evaluation point were not available for department A. Recent studies have shown continued improved compliance even after the interventions themselves have ended (Kirkland et al. 2012; Tromp et al. 2012).

The effect on the compliance of the individual parts in the hygiene intervention was not established (paper II). The intention was, however, to improve the compliance with hygiene guidelines, not to evaluate what specific part of the hygiene intervention that did this. In line with the results in paper II, previous studies have shown that multimodal hygiene interventions are successful in improving compliance with hand hygiene (Pittet et al. 2000; Pittet 2001; Tromp et al. 2012). The HCWs participating in the workshops expressed that it gave them an improved understanding for the importance of compliance with hygiene guidelines, which was also the aim of the workshops. The concept of workshops has attracted attention at national and international conferences on infection control and is today used routinely by the infection control nurses locally as well as in other parts of Sweden.

From the patients' point of view correct hand hygiene prior to patient contact is more important than hand hygiene after patient contact, which is primarily performed to protect the HCW. Despite this, the compliance with disinfection of hands prior to patient contact was significantly lower than with the other components of barrier precautions at baseline $(\mathrm{p}<0.001)$ in paper II. Similar results were obtained by Biswal et al. (2014), thus demonstrating the importance of focusing on improving the compliance with hygiene guidelines prior to patient contact in hand hygiene interventions. Disinfection of hands prior to patient contact was also one of the components where the compliance significantly declined from point of stability to follow-up (the other one being proper use of plastic aprons or protective gowns), indicating that without continuous and varied reminders on the importance of hand hygiene, HCWs fall back into old behavioral patterns. Although the posters from the hygiene intervention remained on display in the departments from the time the intervention started until follow up they were not changed at any point, potentially becoming "invisible" to the HCWs. In a large previous study, posters with messages on hygiene guidelines and hand hygiene promotion were replaced weekly (Pittet et al. 2000). 
The correct use of gloves is a common issue of debate at educational meetings for observers (PeO Svensson, personal communication). It has been demonstrated that many nurses go from dirty to clean work and touch commonly used objects and the environment, with contaminated gloves still on (O'Boyle et al. 2001). Therefore the issue of glove use needs to be thoroughly discussed with HCWs.

Compliance with the dress code is necessary to be able to perform hand hygiene correctly. Long sleeves and jewelry on the hands and forearms will impair the hand hygiene, leaving bacteria on the sleeves with the risk of recontamination of the hands and unsatisfactory disinfection of the skin under rings and watches. In paper II, the compliance with the dress code was already high at baseline (average $93 \%$ ) and continued to be so throughout the study (point of stability and follow up $99 \%$ ), indicating a lesser need to focus on the improvement of the compliance with the dress code in future hygiene interventions. The reason for the difference in compliance with barrier precautions and the dress code is most likely due to the fact that HCWs only have to change their cloths and remove their jewelry once per shift. Barrier precautions, on the other hand, usually have to be performed several times per hour of work. A study by Tromp et al. (2012) also demonstrated a continuously high compliance with the dress code in a nursing ward but a significant increase, from relatively low levels, in the outpatient clinic of the same department.

Papers II and III also show that the high compliance with hygiene guidelines can be reached and maintained without external funding, which is in line with previous work (Pittet et al. 2000), emphasizing a high compliance with hygiene guidelines at all time. 


\section{Transmission routes and sources (papers III \& IV)}

A study from 1962 reported that only $10 \%$ of the newborn infants were colonized with the same S. aureus as the infant's mother and $70 \%$ with an S. aureus colonizing an HCW. During post-birth hospitalization during the 60s infants were still nursed by the nurses, primarily seeing their mothers when being fed (Mortimer et al. 1962). This situation has changed dramatically over the years and now infants are roomed in with their mothers and the nursing is mainly performed by the infant's parents. In the study by Matussek et al. (2007) more infants were still colonized with the same $S$. aureus as the HCWs than with $S$. aureus from their own family. The HCWs in the study by Matussek et al. (2007) registered the number of times they touched the newborn infants daily, revealing more physical contact between HCWs and newborn infants than necessary during a day (Gunhild Rensfeldt, unpublished data). Efforts have subsequently been made in the departments to minimize unnecessary physical contact between HCWs and newborn infants, in favor of physical contact between parents and infant. For instance, the father now carries the newborn infant from the mother to the scale and examination table for the first medical examination. This probably have had an effect on transmission as in the Swedish HITS study most newborn infants were colonized with the same S. aureus as their own family (table 3, paper III). Newborn infants of parents colonized with S. aureus had a significantly increased odds ratio (OR) for colonization than infants of noncolonized parents $\left(\mathrm{OR}_{\mathrm{MH}}=2.8,95 \% \mathrm{CI} 1.8-4.5\right.$, adjusted for gender of adult, $\left.\mathrm{p}<0.001\right)$. The increased risk of infant colonization has previously been related to maternal colonization (Peacock et al. 2003).

Paper III revealed a marked improvement in compliance between baseline (41\% for barrier precautions and $93 \%$ for the dress code) and follow-up (86\% for barrier precautions and $99 \%$ for the dress code). Despite the improvement in compliance the transmission of $S$. aureus from HCWs did not decrease. Both at baseline and follow-up approximately $25 \%$ of the colonized newborn infants were colonized with an S. aureus of the same spa type as an HCW and/or someone from another family (table 3, paper III), indicating transmission directly or indirectly from HCWs. Studies have shown that the greatest benefits from hand hygiene occur during the increase from very low levels to approximately 20 \% (Cooper et al. 1999; Beggs et al. 2008). Also, a mathematical model showed that most staphylococcal outbreaks could be prevented if the compliance rate was approximately $55 \%$ (Beggs et al. 2008). With the relatively high compliance rates already at baseline in paper III an effect on transmission might be difficult to detect. 
Although the compliance with hygiene guidelines is unknown from the time of the study by Matussek et al. (2007), it is thought to be lower than at baseline in paper III. To improve the compliance with hygiene guidelines a large national campaign was launched between the study by Matussek et al. (2007) and the study described in paper III, which probably increased the compliance already prior to the baseline measurement. This supposedly improvement might also have had the largest effect on transmission.

The quality of the hand hygiene was not monitored during direct observations and it is therefore possible that although compliance improves over time the technique is continuously poor. The hygiene intervention did include hand hygiene technique practice and assessment (by an infection control nurse) with visualization of the coverage of hand rub on the hands using a fluorescent additive to the hand rub and an ultraviolet device (paper II). At baseline the HCWs were unaware of when the direct observations were performed. The hygiene intervention revealed that monitoring of the compliance would henceforth be performed weekly by direct observations. It has been shown that a key factor in improving compliance with hygiene guidelines is that the HCWs are aware that they are being monitored (Walker et al. 2014). The Hawthorn effect, i.e., the possibility that HCWs change their behavior when they know they are being observed, has also been demonstrated to have an effect on compliance rates (Srigley et al. 2014). It is therefore possible that this effect have led to an overestimation of compliance rates at point of stability and follow-up, in papers II and III, respectively. However, it is assumed that the Hawthorn effect only has a transient effect on the human mind (Srigley et al. 2014). The compliance rates slowly improved after the hygiene intervention and stabilized at a satisfactory level more than six months later. During this time the Hawthorn effect most likely would have subsided and therefore the compliance rates at follow-up (paper III), when the transmission routes were re-examined, most likely do reflect the true compliance with hygiene guidelines.

Paper III only reports the transmission of S. aureus from healthy individuals to newborn infants. Therefore, the transmission patterns from infected individuals could not be evaluated here. Infected individuals are more likely to have higher loads of bacteria, thereby posing an increased risk for transmission. Also, the effect on nosocomial infections by the improved compliance with hygiene guidelines could not be evaluated. However, the incidence of nosocomial infections had probably been low, as the obstetric departments primarily handles healthy patients, and a detectable decrease might have been difficult to identify. Decreased incidence of nosocomial infections by improved compliance rates has previously been described (Pittet et al. 2000; Kirkland et al. 2012). The main advantage of the HITS study (paper III) is the lack or very few bacteria present on the newborn infant as this makes the tracking of colonization easy. It is also the disadvantage, as infants most likely very easy get colonized with the first bacteria they 
encounter. It is therefore unknown to what extent newborn infants substitute their initial flora once they have been living at their home for a period of time. The commensal flora of an adult act as a barrier to colonization with other bacteria or strains. It appears as if the match between the bacteria and the host is very specific (van Belkum et al. 2009) which might indicate that the definite flora is not established directly at birth. This theory is further emphasized by the fact that persistent carriage is almost non-existing in newborn infants (Lebon et al. 2008).

No $S$. aureus were detected in the $24000 \mathrm{~L}$ of air sampled in paper III and although there were indications of transmission from the environment (table 3, paper III) this seems to have been a minor problem. Therefore the truth that has been accepted and preached in infection control over the last few decades, that the main bacterial transmission route within healthcare settings is through the hands of the HCWs, also appears to be true here.

It has been shown that persistent nasal carriers have an increased risk of infection as compared to non-carriers (Kluytmans et al. 1995; Wertheim et al. 2004a; Skramm et al. 2014) and that $>80 \%$ of the infections are caused by the carrier strain, as a result of endogenous transmission (von Eiff et al. 2001; Wertheim et al. 2004a). Eradication of nasal carriage has proven effective in the reduction of endogenous infections (Talon et al. 1995; Kluytmans et al. 1996a; Kluytmans et al. 1996b). Infections caused by strains other than the one detected in the nares of the patient self, have been suggested to originate from HCWs and/or fellow patients (Perl et al. 2002). However, paper IV demonstrates that $7 \%$ of the $S$. aureus transmissions originated from individuals colonized in the throat only. As $34 \%$ of the transmissions originated from nares-only carriers (table 3, paper III) an increased risk of transmission from the nares as compared to the throat was demonstrated (OR=4.8, $95 \% \mathrm{CI} 1.8-12.7)$. The majority of transmissions (61\%) did, however, occur from individuals colonized in multiple sites. The fact that transmission from throat is demonstrated may indicate a risk for droplet transmission, from HCWs and parents by coughing or sneezing. The high prevalence of throat colonization in combination with the indication that transmission from the throat occurs, further emphasizes the importance of including throat samples in screening programs. Eradication of throat colonization may also be necessary to prevent endogenous $S$. aureus infections and nosocomial transmission, as suggested in a recent review article (van Rijen et al. 2008). 


\section{Concluding remarks and future perspectives}

Colonization of newborn infants with $S$. aureus was used as a model for bacterial transmission in a healthcare setting and to evaluate the impact of compliance with hygiene guidelines on transmission.

\section{Performance of bacteriological methods}

To determine more truthful S. aureus colonization rates, incubation of swabs in enrichment broth prior to plating is necessary, as this procedure increased the number of $S$. aureus positive samples, regardless of which site was cultured. This may have an impact on routine diagnostic procedures at microbiology laboratories.

spa typing is well suited for epidemiological investigations in routine microbiological laboratories thanks to its great discriminatory power and epidemiological concordance as well as its accessibility, ease of use and rapidity.

\section{S. aureus epidemiology}

The prevalence of $S$. aureus colonization was higher in men compared to women and the throat was the premier colonization site among adults, followed by anterior nares. Also, transmission from the throat was demonstrated. This highlights the importance of including throat cultures in S. aureus screening programs for adults.

Infant colonization began immediately at birth and reached adult prevalence within $24 \mathrm{~h}$ to $48 \mathrm{~h}$. To determine S. aureus colonization among newborn infants, cultures from the umbilicus is most important, as $95 \%$ of the colonized infants were detected by exclusive analysis of the umbilicus compared to $25 \%$ by exclusive analysis of anterior nares. 
No institutional $S$. aureus spa type prone to transmission was detected, as the spa type distribution and antibiograms were similar among newborn infants, parents and HCWs. Also pregnancy did not appear to influence $S$. aureus colonization, as colonization rates, spa type distribution and antibiograms were similar among mothers and HCWs (mainly women).

To evaluate true transmission in healthcare settings knowledge of the distribution of strains, e.g., through spa typing, in the community is required.

The commensal flora is considered to act as a barrier to colonization with other bacteria or strains. It would be interesting to investigate what $S$. aureus spa types colonizes the infants a period of time after birth to determine whether the initial colonizing flora act as a barrier to colonization also for infants.

\section{Infection control in healthcare settings}

Direct observations and self-reporting by HCWs are both valid methods to monitor compliance with hygiene guidelines.

The compliance with hygiene guidelines was markedly improved by a multimodal and multidisciplinary hygiene intervention and a long-term effect was achieved, but might require continuous and varied reminders to be completely sustained. For instance, workshops, one part of the hygiene intervention, are now routinely used by infection control nurses locally as well as in other parts of Sweden.

The compliance with barrier precautions is not the only factor to be considered in prevention of bacterial transmission, as the increase of compliance from $40 \%$ to more than $80 \%$ did not reduce the transmission of $S$. aureus from HCWs to newborn infants. Factors that might affect transmission are the timing and technique of hand hygiene as well as correct glove use. The fact that transmission from throat was demonstrated may indicate a risk also for droplet transmission, not studied in this thesis.

As this thesis focuses on transmission from healthy colonized individuals to newborn infants it may not reflect transmission patterns from infected individuals. As the load of bacteria most likely affects the risk of transmission, infection would increase the risk of transmission. Therefore, it is of utmost importance that all HCWs comply with hygiene guidelines at all time to ensure patient safety, especially as the high compliance can be reached and maintained at a regular budget. 


\section{Acknowledgement}

I would like to take the opportunity to thank the people who have cheered for me, supported me and helped me with the work leading up to this thesis, but I would also like to thank you who in one way or another have helped me forget about the making of my thesis from time to time.

First and foremost, a huge thanks to my main supervisor, Andreas Matussek. Thank you for believing in me and for giving me the opportunity to work in Jönköping in the first place. Thank you for always being available, no matter how busy you really are and for being the best travel companion during conferences. I hope we will work together with many more projects.

Thanks to my co-supervisor, Sture Löfgren, for always finding the time to truly scrutinize a manuscript, an abstract or an application, and for enjoying it. Also, thank you for your eternal attempts to try to teach me that "less is more" when it comes to words...

Thanks to my co-supervisor, Per-Eric Lindgren, for scientific and academic input, knowledge and support throughout my work.

To all the co-authors of the four papers in this thesis, thank you for helping with the writing and for constructive criticism. Also, thanks to Ann Lindmark, Ann-Sofie Ekblom, Ing-Marie

Einemo, Kirstin Dienus, Maj Ringman, Pia Karlsson and Sofia Lundin for technical assistance. Thank you, Marita Skarstedt, for technical assistance and for actually wanting to help me by proofreading my thesis and for saying that it made the train journey back and forth to Stockholm more fun. Thanks to Lena Nilsson and Madeleine Karlsson for providing data.

Thanks to all the people who have contributed with samples to the studies in this thesis, to the staff members who have coordinated the studies in the participating departments and to those who have obtained compliance data and collected samples day and night. 
Financial support was provided by Futurum - the Academy for Healthcare, Region Jönköping County and the Medical Research Council of Southeast Sweden (FORSS).

The girls! Bettan, do you remember the day we travelled from Linköping to Jönköping and realized that we had more in common than the passion for science? Since that day we have shared advanced statistical problems and mathematical issues of a fifth grader. Thank you for always having the time to share a laugh or a hug! Vera, your humanistic way of seeing things has brought balance to the natural science focus of the office. Thanks to both of you for hilarious "girls-nights-out", I am extremely happy and grateful that the two of you are in my life! Thank you, Lisa, for all the fun in and out of office and for being a moral support whenever a battle had to be fought. Thanks to the three of you for being the best support a girl can have throughout the sometimes hectic time of preparing this book and for the $8^{\text {th }}$ of May.

Thank you, Anna J. Henningsson, for all your wisdom.

Thanks to my co-workers at Laboratory Medicine, Ryhov County Hospital, who have made work days more fun. A special thanks to "fralleklubben", who have made Fridays even better. Also thanks to my co-workers at the Unit for Infectious Disease Control and Health Care Hygiene for excellent and fun collaboration during the HITS-study and for answering my never-ending questions on healthcare hygiene, infection control as well as local and national guidelines and routines.

Tack till alla er som ibland hjälpt mig att glömma allt vad forskning, statistik och avhandling heter. Tack till mina föräldrar, Ann och Staffan, som har skämt bort mig och min familj med allinclusive service när vi kommit på besök. Tack till min bror, Emil, och hans familj, för all god mat och för alla poolbad. Tack klanen Mernelius för roliga semestrar i Hättis och för all hjälp med barnen. Tack till tjejgänget där hemma, en vänskap som hitintills varat halva våra liv. Det började en varm sommardag på Långåkersvägen 9 och det har bara varit roligt sedan dess.

Sist, men inte minst, tack till min man, Pål, och våra underbara söner, Astor och Silve, för att ni påminner mig om att den här boken inte är den viktigaste saken här i världen, det är ni.

Jag älskar er! 


\section{References}

Acton, D. S., Tempelmans Plat-Sinnige, M. J., van Wamel, W. et al. (2009) Intestinal carriage of Staphylococcus aureus: how does its frequency compare with that of nasal carriage and what is its clinical impact? Eur J Clin Microbiol Infect Dis 28, 115-127.

Andersen, P. S., Pedersen, J. K., Fode, P. et al. (2012) Influence of host genetics and environment on nasal carriage of Staphylococcus aureus in danish middle-aged and elderly twins. J Infect Dis 206, 1178-1184.

Andrews, J. I., Fleener, D. K., Messer, S. A. et al. (2009) Screening for Staphylococcus aureus carriage in pregnancy: usefulness of novel sampling and culture strategies. Am J Obstet Gynecol 201, 396 e391-395.

Armstrong-Esther, C. A. \& Smith, J. E. (1976) Carriage patterns of Staphylococcus aureus in a healthy non-hospital population of adults and children. Ann Hum Biol 3, 221-227.

Ayliffe, G. A., Babb, J. R. \& Quoraishi, A. H. (1978) A test for 'hygienic' hand disinfection. J Clin Pathol 31, 923-928.

Babouee, B., Frei, R., Schultheiss, E. et al. (2011) Comparison of the DiversiLab repetitive element PCR system with spa typing and pulsed-field gel electrophoresis for clonal characterization of methicillin-resistant Staphylococcus aureus. J Clin Microbiol 49, 15491555.

Barrett, T. J., Gerner-Smidt, P. \& Swaminathan, B. (2006) Interpretation of pulsed-field gel electrophoresis patterns in foodborne disease investigations and surveillance. Foodborne Pathog Dis 3, 20-31.

Barriere, S. L. (2015) Clinical, economic and societal impact of antibiotic resistance. Expert Opin Pharmacother 16, 151-153.

Batzing, B. L. (2002) Microbiology, an introduction. N. Horne (ed), Wadsworth/Thomas Learning.

Beggs, C. B., Shepherd, S. J. \& Kerr, K. G. (2008) Increasing the frequency of hand washing by healthcare workers does not lead to commensurate reductions in staphylococcal infection in a hospital ward. BMC Infect Dis 8, 114.

Begier, E. M., Frenette, K., Barrett, N. L. et al. (2004) A high-morbidity outbreak of methicillinresistant Staphylococcus aureus among players on a college football team, facilitated by cosmetic body shaving and turf burns. Clin Infect Dis 39, 1446-1453.

Bischoff, W. E., Reynolds, T. M., Sessler, C. N. et al. (2000) Handwashing compliance by health care workers: The impact of introducing an accessible, alcohol-based hand antiseptic. Arch Intern Med 160, 1017-1021.

Bischoff, W. E., Wallis, M. L., Tucker, K. B. et al. (2004) Staphylococcus aureus nasal carriage in a student community: prevalence, clonal relationships, and risk factors. Infect Control Hosp Epidemiol 25, 485-491.

Biswal, M., Rajpoot, S., Dhaliwal, N. et al. (2014) Evaluation of the short-term and long-term effect of a short series of hand hygiene campaigns on improving adherence in a tertiary care hospital in India. Am J Infect Control 42, 1009-1010.

Bjorholt, I. \& Haglind, E. (2004) Cost-savings achieved by eradication of epidemic methicillinresistant Staphylococcus aureus (EMRSA)-16 from a large teaching hospital. Eur J Clin Microbiol Infect Dis 23, 688-695. 
Bode, L. G., Kluytmans, J. A., Wertheim, H. F. et al. (2010) Preventing surgical-site infections in nasal carriers of Staphylococcus aureus. N Engl J Med 362, 9-17.

Boers, S. A., van Ess, I., Euser, S. M. et al. (2011) An outbreak of a multiresistant methicillinsusceptible Staphylococcus aureus (MR-MSSA) strain in a burn centre: the importance of routine molecular typing. Burns 37, 808-813.

Bogaert, D., van Belkum, A., Sluijter, M. et al. (2004) Colonisation by Streptococcus pneumoniae and Staphylococcus aureus in healthy children. Lancet 363, 1871-1872.

Bohach, G. A., Fast, D. J., Nelson, R. D. et al. (1990) Staphylococcal and streptococcal pyrogenic toxins involved in toxic shock syndrome and related illnesses. Crit Rev Microbiol 17, 251272.

Boyce, J. M. (2008) Hand hygiene compliance monitoring: current perspectives from the USA.J Hosp Infect 70 Suppl 1, 2-7.

Boyce, J. M. \& Causey, W. A. (1982) Increasing occurrence of methicillin-resistant Staphylococcus aureus in the United States. Infect Control 3, 377-383.

Boyce, J. M. \& Pittet, D. (2002) Guideline for Hand Hygiene in Health-Care Settings. Recommendations of the Healthcare Infection Control Practices Advisory Committee and the HIPAC/SHEA/APIC/IDSA Hand Hygiene Task Force. Am J Infect Control 30, S1-46.

Brown, E. M. \& Thomas, P. (2002) Fusidic acid resistance in Staphylococcus aureus isolates. Lancet 359, 803.

Cespedes, C., Saïd-Salim, B., Miller, M. et al. (2005) The clonality of Staphylococcus aureus nasal carriage. J Infect Dis 191, 444-452.

Chalmers, C. \& Straub, M. (2006) Standard principles for preventing and controlling infection. Nurs Stand 20, 57-65.

Chambers, H. F. (2001) The changing epidemiology of Staphylococcus aureus? Emerg Infect Dis 7, 178-182.

Chatzakis, E., Scoulica, E., Papageorgiou, N. et al. (2011) Infant colonization by Staphylococcus aureus: role of maternal carriage. Eur J Clin Microbiol Infect Dis 30, 1111-1117.

Chavakis, T., Preissner, K. T. \& Herrmann, M. (2007) The anti-inflammatory activities of Staphylococcus aureus. Trends Immunol 28, 408-418.

Cheng, A. G., McAdow, M., Kim, H. K. et al. (2010) Contribution of coagulases towards Staphylococcus aureus disease and protective immunity. PLoS Pathog 6, e1001036.

Chun, H. K., Kim, K. M. \& Park, H. R. (2014) Effects of hand hygiene education and individual feedback on hand hygiene behaviour, MRSA acquisition rate and MRSA colonization pressure among intensive care unit nurses. Int J Nurs Pract.

Cookson, B. D., Robinson, D. A., Monk, A. B. et al. (2007) Evaluation of molecular typing methods in characterizing a European collection of epidemic methicillin-resistant Staphylococcus aureus strains: the HARMONY collection. J Clin Microbiol 45, 1830-1837.

Cooper, B. S., Medley, G. F. \& Scott, G. M. (1999) Preliminary analysis of the transmission dynamics of nosocomial infections: stochastic and management effects. J Hosp Infect 43, 131-147.

Cosgrove, S. E., Sakoulas, G., Perencevich, E. N. et al. (2003) Comparison of mortality associated with methicillin-resistant and methicillin-susceptible Staphylococcus aureus bacteremia: a meta-analysis. Clin Infect Dis 36, 53-59.

Costers, M., Viseur, N., Catry, B. et al. (2012) Four multifaceted countrywide campaigns to promote hand hygiene in Belgian hospitals between 2005 and 2011: impact on compliance to hand hygiene. Eurosurveillance 17, pII=20161.

Creamer, E., Shore, A. C., Deasy, E. C. et al. (2014) Air and surface contamination patterns of meticillin-resistant Staphylococcus aureus on eight acute hospital wards. J Hosp Infect 86, 201-208.

Cursino, M. A., Garcia, C. P., Lobo, R. D. et al. (2012) Performance of surveillance cultures at different body sites to identify asymptomatic Staphylococcus aureus carriers. Diagn Microbiol Infect Dis 74, 343-348. 
Danial, J., Noel, M., Templeton, K. E. et al. (2011) Real-time evaluation of an optimized real-time PCR assay versus Brilliance chromogenic MRSA agar for the detection of meticillinresistant Staphylococcus aureus from clinical specimens. J Med Microbiol 60, 323-328.

Datta, F., Erb, T., Heininger, U. et al. (2008) A multicenter, cross-sectional study on the prevalence and risk factors for nasal colonization with Staphylococcus aureus in patients admitted to children's hospitals in Switzerland. Clin Infect Dis 47, 923-926.

David, M. Z. \& Daum, R. S. (2010) Community-associated methicillin-resistant Staphylococcus aureus: epidemiology and clinical consequences of an emerging epidemic. Clin Microbiol Rev 23, 616-687.

Davis, R., Parand, A., Pinto, A. et al. (2015) Systematic review of the effectiveness of strategies to encourage patients to remind healthcare professionals about their hand hygiene.J Hosp Infect 89, 141-162.

Davis, R. E., Joshi, D., Patel, K. et al. (2013) The medical student as a patient: attitudes towards involvement in the quality and safety of health care. J Eval Clin Pract 19, 812-818.

Davis, R. E., Sevdalis, N. \& Vincent, C. A. (2011) Patient involvement in patient safety: How willing are patients to participate? BMJ Qual Saf 20,108-114.

den Heijer, C. D., van Bijnen, E. M., Paget, W. J. et al. (2013) Prevalence and resistance of commensal Staphylococcus aureus, including meticillin-resistant S. aureus, in nine European countries: a cross-sectional study. Lancet Infect Dis 13, 409-415.

den Heijer, C. D., van Bijnen, E. M., Paget, W. J. et al. (2014) Fusidic acid resistance in Staphylococcus aureus nasal carriage strains in nine European countries. Future Microbiol 9, 737-745.

Deurenberg, R. H., Vink, C., Kalenic, S. et al. (2007) The molecular evolution of methicillinresistant Staphylococcus aureus. Clin Microbiol Infect 13, 222-235.

Diep, B. A. (2013) Use of whole-genome sequencing for outbreak investigations. Lancet Infect Dis $13,99-101$.

Duran, N., Ocak, S. \& Eskiocak, A. F. (2006) Staphylococcus aureus nasal carriage among the diabetic and non-diabetic haemodialysis patients. Int J Clin Pract 60, 1204-1209.

Eckmanns, T., Schwab, F., Bessert, J. et al. (2006) Hand rub consumption and hand hygiene compliance are not indicators of pathogen transmission in intensive care units. J Hosp Infect 63, 406-411.

El-Zimaity, D., Kearns, A. M., Dawson, S. J. et al. (2004) Survey, characterization and susceptibility to fusidic acid of Staphylococcus aureus in the Carmarthen area. J Antimicrob Chemother 54, 441-446.

El Helali, N., Carbonne, A., Naas, T. et al. (2005) Nosocomial outbreak of staphylococcal scalded skin syndrome in neonates: epidemiological investigation and control. J Hosp Infect 61, 130-138.

Enright, M. C., Day, N. P., Davies, C. E. et al. (2000) Multilocus sequence typing for characterization of methicillin-resistant and methicillin-susceptible clones of Staphylococcus aureus. J Clin Microbiol 38, 1008-1015.

Enright, M. C., Robinson, D. A., Randle, G. et al. (2002) The evolutionary history of methicillinresistant Staphylococcus aureus (MRSA). Proc Natl Acad Sci U S A 99, 7687-7692.

Entenza, J. M., Foster, T. J., Ni Eidhin, D. et al. (2000) Contribution of clumping factor B to pathogenesis of experimental endocarditis due to Staphylococcus aureus. Infect Immun 68, 5443-5446.

Erami, M., Soltani, B., Taghavi Ardakani, A. et al. (2014) Nasal Carriage and Resistance Pattern of Multidrug Resistant Staphylococcus aureus Among Healthy Children in Kashan, Iran. Iran Red Crescent Med J 16, e21346.

Eriksen, N. H., Espersen, F., Rosdahl, V. T. et al. (1995) Carriage of Staphylococcus aureus among 104 healthy persons during a 19-month period. Epidemiol Infect 115, 51-60.

European Centre for Disease Prevention and Control (2014) Antimicrobial resistance interactive database (EARS-Net) http://www.ecdc.europa.eu/en/healthtopics/antimicrobial_resistance/database/Pages/ database.aspx Accessed September 10, 2014. 
Eyre, D. W., Golubchik, T., Gordon, N. C. et al. (2012) A pilot study of rapid benchtop sequencing of Staphylococcus aureus and Clostridium difficile for outbreak detection and surveillance. BMJ Open 2, e001124.

Feil, E. J., Li, B. C., Aanensen, D. M. et al. (2004) eBURST: inferring patterns of evolutionary descent among clusters of related bacterial genotypes from multilocus sequence typing data. J Bacteriol 186, 1518-1530.

Fitzgerald, J. R., Sturdevant, D. E., Mackie, S. M. et al. (2001) Evolutionary genomics of Staphylococcus aureus: insights into the origin of methicillin-resistant strains and the toxic shock syndrome epidemic. Proc Natl Acad Sci U S A 98, 8821-8826.

Forsgren, A. \& Sjoquist, J. (1966) "Protein A" from S. aureus. I. Pseudo-immune reaction with human gamma-globulin. J Immunol 97, 822-827.

Fossum Moen, A. E., Holberg-Petersen, M., Andresen, L. L. et al. (2014) spa typing alone is not sufficient to demonstrate endemic establishment of meticillin-resistant Staphylococcus aureus in a low-prevalence country. J Hosp Infect 88, 72-77.

Frenay, H. M., Bunschoten, A. E., Schouls, L. M. et al. (1996) Molecular typing of methicillinresistant Staphylococcus aureus on the basis of protein A gene polymorphism. Eur J Clin Microbiol Infect Dis 15, 60-64.

Frenay, H. M., Theelen, J. P., Schouls, L. M. et al. (1994) Discrimination of epidemic and nonepidemic methicillin-resistant Staphylococcus aureus strains on the basis of protein A gene polymorphism. J Clin Microbiol 32, 846-847.

Frimodt-Moller, N., Espersen, F., Skinhoj, P. et al. (1997) Epidemiology of Staphylococcus aureus bacteremia in Denmark from 1957 to 1990. Clin Microbiol Infect 3, 297-305.

Föreningen för Medicinsk Mikrobiologi vid Svenska Läkaresällskapet \& Folkhälsomyndigheten (2012) Referensmetodikwiki. http://referensmetodik.folkhalsomyndigheten.se/w/Huvudsida [Swedish] Accessed February 11, 2015.

Gamblin, J., Jefferies, J. M., Harris, S. et al. (2013) Nasal self-swabbing for estimating the prevalence of Staphylococcus aureus in the community. J Med Microbiol 62, 437-440.

Garcia-Alvarez, L., Holden, M. T., Lindsay, H. et al. (2011) Meticillin-resistant Staphylococcus aureus with a novel mecA homologue in human and bovine populations in the UK and Denmark: a descriptive study. Lancet Infect Dis 11, 595-603.

Gidengil, C. A., Gay, C., Huang, S. S. et al. (2015) Cost-Effectiveness of Strategies to Prevent Methicillin-Resistant Staphylococcus aureus Transmission and Infection in an Intensive Care Unit. Infect Control Hosp Epidemiol 36, 17-27.

Gomez, M. I., Lee, A., Reddy, B. et al. (2004) Staphylococcus aureus protein A induces airway epithelial inflammatory responses by activating TNFR1. Nat Med 10, 842-848.

Gould, D. (2012) Skin flora: implications for nursing. Nurs Stand 26, 48-56.

Gould, D. \& Chamberlain, A. (1997) The use of a ward-based educational teaching package to enhance nurses' compliance with infection control procedures. J Clin Nurs 6, 55-67.

Gould, J. C. \& McKillop, E. J. (1954) The carriage of Staphylococcus pyogenes var. aureus in the human nose. J Hyg (Lond) 52, 304-310.

Grundmann, H., Barwolff, S., Tami, A. et al. (2005) How many infections are caused by patient-topatient transmission in intensive care units? Crit Care Med 33, 946-951.

Haas, J. P. \& Larson, E. L. (2007) Measurement of compliance with hand hygiene. J Hosp Infect 66, 6-14.

Hagberg, L. (2014, 2014-11-25) MRSA, behandling. http://www.internetmedicin.se/page.aspx?id=2901 Accessed January 23, 2015.

Haley, R. W., Hightower, A. W., Khabbaz, R. F. et al. (1982) The emergence of methicillin-resistant Staphylococcus aureus infections in United States hospitals. Possible role of the house staff-patient transfer circuit. Ann Intern Med 97, 297-308.

Hallin, M., Deplano, A., Denis, O. et al. (2007) Validation of pulsed-field gel electrophoresis and spa typing for long-term, nationwide epidemiological surveillance studies of Staphylococcus aureus infections. J Clin Microbiol 45, 127-133. 
Hamdan-Partida, A., Sainz-Espunes, T. \& Bustos-Martinez, J. (2010) Characterization and persistence of Staphylococcus aureus strains isolated from the anterior nares and throats of healthy carriers in a Mexican community. J Clin Microbiol 48, 1701-1705.

Harmsen, D., Claus, H., Witte, W. et al. (2003) Typing of methicillin-resistant Staphylococcus aureus in a university hospital setting by using novel software for spa repeat determination and database management. J Clin Microbiol 41, 5442-5448.

Harris, S. R., Cartwright, E. J., Torok, M. E. et al. (2013) Whole-genome sequencing for analysis of an outbreak of meticillin-resistant Staphylococcus aureus: a descriptive study. Lancet Infect Dis 13, 130-136.

Hartleib, J., Kohler, N., Dickinson, R. B. et al. (2000) Protein A is the von Willebrand factor binding protein on Staphylococcus aureus. Blood 96, 2149-2156.

Health Protection Agency (2005) Staphylococcus aureus bacteraemia laboratory reports and methicillin susceptibility (voluntary reporting scheme): England and Wales, 1990 2004.

http://webarchive.nationalarchives.gov.uk/20140714084352/http://www.hpa.org.uk/i nfections/topics_az/staphylo/lab_data_staphyl.htm Accessed November 3, 2014.

Heng, Y. K., Tan, K. T., Sen, P. et al. (2013) Staphylococcus aureus and topical fusidic acid use: results of a clinical audit on antimicrobial resistance. Int J Dermatol 52, 876-881.

Herwaldt, L. A., Cullen, J. J., French, P. et al. (2004) Preoperative risk factors for nasal carriage of Staphylococcus aureus. Infect Control Hosp Epidemiol 25, 481-484.

Hiramatsu, K., Ito, T., Tsubakishita, S. et al. (2013) Genomic Basis for Methicillin Resistance in Staphylococcus aureus. Infect Chemother 45, 117-136.

Huang, S. S., Datta, R. \& Platt, R. (2006a) Risk of acquiring antibiotic-resistant bacteria from prior room occupants. Arch Intern Med 166, 1945-1951.

Huang, Y. C., Chou, Y. H., Su, L. H. et al. (2006b) Methicillin-resistant Staphylococcus aureus colonization and its association with infection among infants hospitalized in neonatal intensive care units. Pediatrics 118, 469-474.

Imdad, A., Bautista, R. M., Senen, K. A. et al. (2013) Umbilical cord antiseptics for preventing sepsis and death among newborns. Cochrane Database Syst Rev 5, Cd008635.

Jeljaszewicz, J. \& Hawiger, J. (1966) The resistance to antibiotics of strains of Staphylococcus aureus isolated in Poland. Bull World Health Organ 35, 231-241.

Jessen, O., Rosendal, K., Bulow, P. et al. (1969) Changing staphylococci and staphylococcal infections. A ten-year study of bacteria and cases of bacteremia. N Engl J Med 281, 627635.

Jevons, M. P. (1961) "Celbenin"-resistant staphylococci. Br Med J 1, 124-125.

Jones, R. N., Mendes, R. E., Sader, H. S. et al. (2011) In vitro antimicrobial findings for fusidic acid tested against contemporary (2008-2009) gram-positive organisms collected in the United States. Clin Infect Dis 52, Suppl 7, 477-486.

Josefsson, E., Hartford, O., O'Brien, L. et al. (2001) Protection against experimental Staphylococcus aureus arthritis by vaccination with clumping factor A, a novel virulence determinant. J Infect Dis 184, 1572-1580.

Kampf, G., Loffler, H. \& Gastmeier, P. (2009) Hand hygiene for the prevention of nosocomial infections. Dtsch Arztebl Int 106, 649-655.

Kayser, F. H. (1975) Methicillin-resistant staphylococci 1965-75. Lancet 2, 650-653.

Keane, C. T. \& Hone, R. (1974) Letter: Methicillin-resistant Staphylococcus aureus. Lancet 1, 458.

Kirby, W. M. (1944) Extraction of a Highly Potent Penicillin Inactivator from Penicillin Resistant Staphylococci. Science 99, 452-453.

Kirkland, K. B., Homa, K. A., Lasky, R. A. et al. (2012) Impact of a hospital-wide hand hygiene initiative on healthcare-associated infections: results of an interrupted time series. BMJ Qual Saf 21, 1019-1026.

Kluytmans, J., van Belkum, A. \& Verbrugh, H. (1997) Nasal carriage of Staphylococcus aureus: epidemiology, underlying mechanisms, and associated risks. Clin Microbiol Rev 10, 505520. 
Kluytmans, J. A., Manders, M. J., van Bommel, E. et al. (1996a) Elimination of nasal carriage of Staphylococcus aureus in hemodialysis patients. Infect Control Hosp Epidemiol 17, 793797.

Kluytmans, J. A., Mouton, J. W., Ijzerman, E. P. et al. (1995) Nasal carriage of Staphylococcus aureus as a major risk factor for wound infections after cardiac surgery. J Infect Dis 171, 216-219.

Kluytmans, J. A., Mouton, J. W., VandenBergh, M. F. et al. (1996b) Reduction of surgical-site infections in cardiothoracic surgery by elimination of nasal carriage of Staphylococcus aureus. Infect Control Hosp Epidemiol 17, 780-785.

Kolawole, D. O., Adeyanju, A., Schaumburg, F. et al. (2013) Characterization of colonizing Staphylococcus aureus isolated from surgical wards' patients in a Nigerian university hospital. PLoS One 8, e68721.

Koreen, L., Ramaswamy, S. V., Graviss, E. A. et al. (2004) spa typing method for discriminating among Staphylococcus aureus isolates: implications for use of a single marker to detect genetic micro- and macrovariation. J Clin Microbiol 42, 792-799.

Kotpal, R., Krishna, P. S., Bhalla, P. et al. (2014) Incidence and Risk Factors of Nasal Carriage of Staphylococcus aureus in HIV-Infected Individuals in Comparison to HIV-Uninfected Individuals: A Case-Control Study. J Int Assoc Provid AIDS Care, pII: 2325957414554005.

Kreiswirth, B., Kornblum, J., Arbeit, R. D. et al. (1993) Evidence for a clonal origin of methicillin resistance in Staphylococcus aureus. Science 259, 227-230.

Kuhn, G., Francioli, P. \& Blanc, D. S. (2007) Double-locus sequence typing using clfB and spa, a fast and simple method for epidemiological typing of methicillin-resistant Staphylococcus aureus. J Clin Microbiol 45, 54-62.

Larsen, J., Enright, M. C., Godoy, D. et al. (2012) Multilocus sequence typing scheme for Staphylococcus aureus: revision of the gmk locus. J Clin Microbiol 50, 2538-2539.

Lebon, A., Labout, J. A., Verbrugh, H. A. et al. (2008) Dynamics and Determinants of Staphylococcus aureus Carriage in Infancy. The Generation R Study. J Clin Microbiol 46, 3517-3521.

Lina, G., Piemont, Y., Godail-Gamot, F. et al. (1999) Involvement of Panton-Valentine leukocidinproducing Staphylococcus aureus in primary skin infections and pneumonia. Clin Infect Dis 29, 1128-1132.

Lindsay, J. A., Moore, C. E., Day, N. P. et al. (2006) Microarrays reveal that each of the ten dominant lineages of Staphylococcus aureus has a unique combination of surfaceassociated and regulatory genes. J Bacteriol 188, 669-676.

Liu, C., Graber, C. J., Karr, M. et al. (2008) A population-based study of the incidence and molecular epidemiology of methicillin-resistant Staphylococcus aureus disease in San Francisco, 2004-2005. Clin Infect Dis 46, 1637-1646.

Luteijn, J. M., Hubben, G. A., Pechlivanoglou, P. et al. (2011) Diagnostic accuracy of culture-based and PCR-based detection tests for methicillin-resistant Staphylococcus aureus: a metaanalysis. Clin Microbiol Infect 17, 146-154.

Marriott, I. \& Huet-Hudson, Y. M. (2006) Sexual dimorphism in innate immune responses to infectious organisms. Immunol Res 34, 177-192.

Matussek, A., Stark, L., Dienus, O. et al. (2011) Analyzing multiclonality of Staphylococcus aureus in clinical diagnostics using spa-based denaturing gradient gel electrophoresis. J Clin Microbiol 49, 3647-3648.

Matussek, A., Taipalensuu, J., Einemo, I. M. et al. (2007) Transmission of Staphylococcus aureus from maternity unit staff members to newborns disclosed through spa typing. Am J Infect Control 35, 122-125.

Mehraj, J., Akmatov, M. K., Strompl, J. et al. (2014) Methicillin-Sensitive and Methicillin-Resistant Staphylococcus aureus Nasal Carriage in a Random Sample of Non-Hospitalized Adult Population in Northern Germany. PLoS One 9, e107937.

Melin, S., Haeggman, S., Olsson-Liljequist, B. et al. (2009) Epidemiological typing of methicillinresistant Staphylococcus aureus (MRSA): spa typing versus pulsed-field gel electrophoresis. Scand J Infect Dis 41, 433-439. 
Mellmann, A., Friedrich, A. W., Rosenkotter, N. et al. (2006) Automated DNA sequence-based early warning system for the detection of methicillin-resistant Staphylococcus aureus outbreaks. PLoS Med 3, e33.

Mellmann, A., Weniger, T., Berssenbrugge, C. et al. (2007) Based Upon Repeat Pattern (BURP): an algorithm to characterize the long-term evolution of Staphylococcus aureus populations based on spa polymorphisms. BMC Microbiol 7, 98.

Melo-Cristino, J., Resina, C., Manuel, V. et al. (2013) First case of infection with vancomycinresistant Staphylococcus aureus in Europe. Lancet 382, 205.

Mernelius, S., Lofgren, S., Lindgren, P. E. et al. (2013a) The effect of improved compliance with hygiene guidelines on transmission of Staphylococcus aureus to newborn infants: the Swedish Hygiene Intervention and Transmission of S. aureus study. Am J Infect Control 41, 585-590.

Mernelius, S., Lofgren, S., Lindgren, P. E. et al. (2013b) The role of broth enrichment in Staphylococcus aureus cultivation and transmission from the throat to newborn infants: results from the Swedish hygiene intervention and transmission of S. aureus study. Eur J Clin Microbiol Infect Dis 32, 1593-1598.

Mernelius, S., Svensson, P. O., Rensfeldt, G. et al. (2013c) Compliance with hygiene guidelines: the effect of a multimodal hygiene intervention and validation of direct observations. $\mathrm{Am} \mathrm{J}$ Infect Control 41, e45-48.

Mertz, D., Frei, R., Jaussi, B. et al. (2007) Throat swabs are necessary to reliably detect carriers of Staphylococcus aureus. Clin Infect Dis 45, 475-477.

Mertz, D., Frei, R., Periat, N. et al. (2009) Exclusive Staphylococcus aureus throat carriage: at-risk populations. Arch Intern Med 169, 172-178.

Minnesota Department of Health (2004) Community-associated methicillin-resistant Staphylococcus aureus in Minnesota. Disease Control Newsletter 32, 61-72.

Mir, F., Tikmani, S. S., Shakoor, S. et al. (2011) Incidence and etiology of omphalitis in Pakistan: a community-based cohort study. J Infect Dev Ctries 5, 828-833.

Mirzaii, M., Emaneini, M., Jabalameli, F. et al. (2014) Molecular investigation of Staphylococcus aureus isolated from the patients, personnel, air and environment of an ICU in a hospital in Tehran. J Infect Public Health.

Mongkolrattanothai, K., Gray, B. M., Mankin, P. et al. (2011) Simultaneous carriage of multiple genotypes of Staphylococcus aureus in children. J Med Microbiol 60, 317-322.

Moreillon, P., Entenza, J. M., Francioli, P. et al. (1995) Role of Staphylococcus aureus coagulase and clumping factor in pathogenesis of experimental endocarditis. Infect Immun 63, 4738-4743.

Mortimer, E. A., Jr., Lipsitz, P. J., Wolinsky, E. et al. (1962) Transmission of staphylococci between newborns. Importance of the hands to personnel. Am J Dis Child 104, 289-295.

Mulvey, M. R., Chui, L., Ismail, J. et al. (2001) Development of a Canadian standardized protocol for subtyping methicillin-resistant Staphylococcus aureus using pulsed-field gel electrophoresis. J Clin Microbiol 39, 3481-3485.

Murchan, S., Kaufmann, M. E., Deplano, A. et al. (2003) Harmonization of pulsed-field gel electrophoresis protocols for epidemiological typing of strains of methicillin-resistant Staphylococcus aureus: a single approach developed by consensus in 10 European laboratories and its application for tracing the spread of related strains. J Clin Microbiol 41, 1574-1585.

Muthukrishnan, G., Lamers, R. P., Ellis, A. et al. (2013) Longitudinal genetic analyses of Staphylococcus aureus nasal carriage dynamics in a diverse population. BMC Infect Dis 13, 221.

Nguyen, T., Ghebrehiwet, B. \& Peerschke, E. I. (2000) Staphylococcus aureus protein A recognizes platelet $\mathrm{gC} 1 \mathrm{qR} / \mathrm{p} 33$ : a novel mechanism for staphylococcal interactions with platelets. Infect Immun 68, 2061-2068.

Nilsson, P. \& Ripa, T. (2006) Staphylococcus aureus throat colonization is more frequent than colonization in the anterior nares. J Clin Microbiol 44, 3334-3339. 
Nouwen, J. L., Fieren, M. W., Snijders, S. et al. (2005) Persistent (not intermittent) nasal carriage of Staphylococcus aureus is the determinant of CPD-related infections. Kidney Int 67, 1084-1092.

O'Boyle, C. A., Henly, S. J. \& Larson, E. (2001) Understanding adherence to hand hygiene recommendations: the theory of planned behavior. Am J Infect Control 29, 352-360.

O'Brien, L., Kerrigan, S. W., Kaw, G. et al. (2002a) Multiple mechanisms for the activation of human platelet aggregation by Staphylococcus aureus: roles for the clumping factors ClfA and ClfB, the serine-aspartate repeat protein SdrE and protein A. Mol Microbiol 44, 10331044.

O'Brien, L. M., Walsh, E. J., Massey, R. C. et al. (2002b) Staphylococcus aureus clumping factor B (ClfB) promotes adherence to human type I cytokeratin 10: implications for nasal colonization. Cell Microbiol 4, 759-770.

O'Connell, N. H., Mannix, M., Philip, R. K. et al. (2007) Infant Staphylococcal scalded skin syndrome, Ireland, 2007--preliminary outbreak report. Euro Surveill 12, e070614 070615.

Olsen, K., Falch, B. M., Danielsen, K. et al. (2012) Staphylococcus aureus nasal carriage is associated with serum 25-hydroxyvitamin D levels, gender and smoking status. The Tromso Staph and Skin Study. Eur J Clin Microbiol Infect Dis 31, 465-473.

Olsen, K., Sangvik, M., Simonsen, G. S. et al. (2013) Prevalence and population structure of Staphylococcus aureus nasal carriage in healthcare workers in a general population. The Tromso Staph and Skin Study. Epidemiol Infect 141, 143-152.

Osterlund, A., Eden, T., Olsson-Liljequist, B. et al. (2002) Clonal spread among Swedish children of a Staphylococcus aureus strain resistant to fusidic acid. Scand J Infect Dis 34, 729-734.

Palmqvist, N., Patti, J. M., Tarkowski, A. et al. (2004) Expression of staphylococcal clumping factor A impedes macrophage phagocytosis. Microbes Infect 6, 188-195.

Pan, E. S., Diep, B. A., Carleton, H. A. et al. (2003) Increasing prevalence of methicillin-resistant Staphylococcus aureus infection in California jails. Clin Infect Dis 37, 1384-1388.

Panizzi, P., Friedrich, R., Fuentes-Prior, P. et al. (2004) The staphylocoagulase family of zymogen activator and adhesion proteins. Cell Mol Life Sci 61, 2793-2798.

Peacock, S. J., Justice, A., Griffiths, D. et al. (2003) Determinants of acquisition and carriage of Staphylococcus aureus in infancy. J Clin Microbiol 41, 5718-5725.

Perl, T. M., Cullen, J. J., Wenzel, R. P. et al. (2002) Intranasal mupirocin to prevent postoperative Staphylococcus aureus infections. N Engl J Med 346, 1871-1877.

Peters, T. M. (2009) Chapter: 15 Pulsed-field gel electrophoresis for molecular epidemiology of food pathogens, p.59-70. In: D. A. Caugant (eds) Molecular epidemiology of microorganisms, Methods in molecular biology. Publisher: Humana Press.

Pittet, D. (2001) Improving adherence to hand hygiene practice: a multidisciplinary approach. Emerg Infect Dis 7, 234-240.

Pittet, D., Hugonnet, S., Harbarth, S. et al. (2000) Effectiveness of a hospital-wide programme to improve compliance with hand hygiene. Infection Control Programme. Lancet 356, 13071312.

Pittet, D., Mourouga, P. \& Perneger, T. V. (1999) Compliance with handwashing in a teaching hospital. Infection Control Program. Ann Intern Med 130, 126-130.

Pittet, D., Panesar, S. S., Wilson, K. et al. (2011) Involving the patient to ask about hospital hand hygiene: a National Patient Safety Agency feasibility study. J Hosp Infect 77, 299-303.

Price, P. (1938) The bacteriology of normal skin; a new quantitative test applied to a study of the bacterial flora and the diinfectant action of mechanical cleansing. The journal of infectious diseases 63, 301-318.

Price, P. B. (1939) Ethyl alcohol as a germicide. Archives of Surgery 38, 528-542.

Proft, T. \& Fraser, J. D. (2003) Bacterial superantigens. Clin Exp Immunol 133, 299-306.

Public Health Agency of Sweden (2014) Sjukdomsstatistik Staphylococcus aureus. http://www.folkhalsomyndigheten.se/amnesomraden/statistik-ochundersokningar/sjukdomsstatistik/staphylococcus-aureus/ [Swedish] Accessed November 6, 2014. 
Public Health Agency of Sweden \& National Veterinary Institute (2013) SWEDRES-SVARM Use of antimicrobials and occurence of antimicrobial resistance in Sweden. Public Health Agency of Sweden and National Veterinary Institute, Solna/Uppsala ISSN 1650-6332.

Rampling, A., Wiseman, S., Davis, L. et al. (2001) Evidence that hospital hygiene is important in the control of methicillin-resistant Staphylococcus aureus. J Hosp Infect 49, 109-116.

Randle, J., Arthur, A. \& Vaughan, N. (2010) Twenty-four-hour observational study of hospital hand hygiene compliance. J Hosp Infect 76, 252-255.

Reed, S. D., Friedman, J. Y., Engemann, J. J. et al. (2005) Costs and outcomes among hemodialysisdependent patients with methicillin-resistant or methicillin-susceptible Staphylococcus aureus bacteremia. Infect Control Hosp Epidemiol 26, 175-183.

Ridom GmbH (2014) Ridom Spa Server. http://spa.ridom.de/ Accessed March 23, 2015.

Ross, S., Rodriguez, W., Controni, G. et al. (1974) Staphylococcal susceptibility to penicillin G. The changing pattern among community strains. JAMA 229, 1075-1077.

Sabat, A. J., Budimir, A., Nashev, D. et al. (2013) Overview of molecular typing methods for outbreak detection and epidemiological surveillance. Euro Surveill 18, 20380.

Salgado, C. D. \& Farr, B. M. (2006) What proportion of hospital patients colonized with methicillin-resistant Staphylococcus aureus are identified by clinical microbiological cultures? Infect Control Hosp Epidemiol 27, 116-121.

Salvage, R., Hull, C. M., Kelly, D. E. et al. (2014) Use of 70\% alcohol for the routine removal of microbial hard surface bioburden in life science cleanrooms. Future Microbiol 9, 11231130.

Sangvik, M., Olsen, R. S., Olsen, K. et al. (2011) Age- and Gender-Associated Staphylococcus aureus spa Types Found among Nasal Carriers in a General Population: the Tromso Staph and Skin Study. J Clin Microbiol 49, 4213-4218.

Sawai, T., Tomono, K., Yanagihara, K. et al. (1997) Role of coagulase in a murine model of hematogenous pulmonary infection induced by intravenous injection of Staphylococcus aureus enmeshed in agar beads. Infect Immun 65, 466-471.

Scheithauer, S., Oude-Aost, J., Heimann, K. et al. (2011) Hand hygiene in pediatric and neonatal intensive care unit patients: daily opportunities and indication- and profession-specific analyses of compliance. Am J Infect Control 39, 732-737.

Schijffelen, M., Konstantinov, S. R., Lina, G. et al. (2013) Whole genome analysis of epidemiologically closely related Staphylococcus aureus isolates. PLoS One 8, e78340.

Schwappach, D. L., Frank, O., Koppenberg, J. et al. (2011) Patients' and healthcare workers' perceptions of a patient safety advisory. Int J Qual Health Care 23, 713-720.

Shopsin, B., Gomez, M., Montgomery, S. O. et al. (1999) Evaluation of protein A gene polymorphic region DNA sequencing for typing of Staphylococcus aureus strains. J Clin Microbiol 37, 3556-3563.

Siberry, G. K., Tekle, T., Carroll, K. et al. (2003) Failure of clindamycin treatment of methicillinresistant Staphylococcus aureus expressing inducible clindamycin resistance in vitro. Clin Infect Dis 37, 1257-1260.

Sievert, D. M., Rudrik, J. T., Patel, J. B. et al. (2008) Vancomycin-resistant Staphylococcus aureus in the United States, 2002-2006. Clin Infect Dis 46, 668-674.

Skov, R., Gudlaugsson, O., Hardardottir, H. et al. (2008) Proposal for common Nordic epidemiological terms and definitions for methicillin-resistant Staphylococcus aureus (MRSA). Scand J Infect Dis 40, 495-502.

Skramm, I., Fossum Moen, A. E., Aroen, A. et al. (2014) Surgical Site Infections in Orthopaedic Surgery Demonstrate Clones Similar to Those in Orthopaedic Staphylococcus aureus Nasal Carriers. J Bone Joint Surg Am 96, 882-888.

Soofi, S., Cousens, S., Imdad, A. et al. (2012) Topical application of chlorhexidine to neonatal umbilical cords for prevention of omphalitis and neonatal mortality in a rural district of Pakistan: a community-based, cluster-randomised trial. Lancet 379, 1029-1036.

Srigley, J. A., Furness, C. D., Baker, G. R. et al. (2014) Quantification of the Hawthorne effect in hand hygiene compliance monitoring using an electronic monitoring system: a retrospective cohort study. BMJ Qual Saf 23, 974-980. 
Srigley, J. A., Gardam, M., Fernie, G. et al. (2015) Hand hygiene monitoring technology: a systematic review of efficacy.J Hosp Infect 89, 51-60.

Stark, L., Matussek, A., Strindhall, J. et al. (2009) Staphylococcus aureus isolates from blood and anterior nares induce similar innate immune responses in endothelial cells. APMIS 117, 814-824.

Stark, L., Olofsson, M., Lofgren, S. et al. (2014) Prevalence and molecular epidemiology of Staphylococcus aureus in Swedish nursing homes - as revealed in the SHADES study. Epidemiol Infect 142, 1310-1316.

Stark, V. \& Harrisson, S. P. (1992) Staphylococcus aureus colonization of the newborn in a Darlington hospital. J Hosp Infect 21, 205-211.

Stegger, M., Wirth, T., Andersen, P. S. et al. (2014) Origin and evolution of European communityacquired methicillin-resistant Staphylococcus aureus. MBio 5, e01044-01014.

Strommenger, B., Braulke, C., Heuck, D. et al. (2008) spa typing of Staphylococcus aureus as a frontline tool in epidemiological typing. J Clin Microbiol 46, 574-581.

Sullam, P. M., Bayer, A. S., Foss, W. M. et al. (1996) Diminished platelet binding in vitro by Staphylococcus aureus is associated with reduced virulence in a rabbit model of infective endocarditis. Infect Immun 64, 4915-4921.

Swedish Association of Local Authorities and Regions (2014) PPM BHK. http://www.skl.se/halsasjukvard/patientsakerhet/vardrelateradeinfektioner/resultatb asalahygienrutinerochkladregler.2277.html [Swedish] Accessed September 10, 2014.

Swedish Association of Local Authorities and Regions (2015) Vårdrelaterade infektioner. http://skl.se/halsasjukvard/patientsakerhet/vardrelateradeinfektioner.746.html [Swedish] Accessed January 27, 2015.

Talon, D., Rouget, C., Cailleaux, V. et al. (1995) Nasal carriage of Staphylococcus aureus and crosscontamination in a surgical intensive care unit: efficacy of mupirocin ointment. J Hosp Infect 30, 39-49.

Tenover, F. C., Arbeit, R. D., Goering, R. V. et al. (1995) Interpreting chromosomal DNA restriction patterns produced by pulsed-field gel electrophoresis: criteria for bacterial strain typing. Journal of clinical microbiology 33, 2233-2239.

The European Committee on Antimicrobial Susceptibility Testing (2014, Version 4.0) Breakpoint tables for interpretation of MICs and zone diameters. http://www.eucast.org Accessed December 2, 2014.

The National Board of Health and Welfare (2007) SOSFS 2007:19. Basal hygien inom hälso- och sjukvården m.m. (Swedish) Published December 10, 2007.

Tomlinson, M. W., Schmidt, N. M., Rourke, J. W., Jr. et al. (2011) Rectovaginal Staphylococcus aureus colonization: is it a neonatal threat? Am J Perinatol 28, 673-676.

Tromp, M., Huis, A., de Guchteneire, I. et al. (2012) The short-term and long-term effectiveness of a multidisciplinary hand hygiene improvement program. Am J Infect Control 40, 732-736.

Tveten, Y., Jenkins, A. \& Kristiansen, B. E. (2002) A fusidic acid-resistant clone of Staphylococcus aureus associated with impetigo bullosa is spreading in Norway. J Antimicrob Chemother $50,873-876$.

U.S. Department of Health and Human Services \& Centers for Disease Control and Prevention (2013) Antibiotic resistance threats in the United States, 2013. http://www.cdc.gov/drugresistance/threat-report-2013/ Accessed November 6, 2014.

Udo, E. E., Pearman, J. W. \& Grubb, W. B. (1993) Genetic analysis of community isolates of methicillin-resistant Staphylococcus aureus in Western Australia. J Hosp Infect 25, 97 108.

Uhlén, M., Guss, B., Nilsson, B. et al. (1984) Complete sequence of the staphylococcal gene encoding protein A. A gene evolved through multiple duplications. J Biol Chem 259, 1695 1702.

Vainio, A., Koskela, S., Virolainen, A. et al. (2011) Adapting spa typing for national laboratorybased surveillance of methicillin-resistant Staphylococcus aureus. Eur J Clin Microbiol Infect Dis 30, 789-797. 
Walker, J. L., Sistrunk, W. W., Higginbotham, M. A. et al. (2014) Hospital hand hygiene compliance improves with increased monitoring and immediate feedback. Am J Infect Control 42, 1074-1078.

van Belkum, A., Tassios, P. T., Dijkshoorn, L. et al. (2007) Guidelines for the validation and application of typing methods for use in bacterial epidemiology. Clin Microbiol Infect 13 Suppl 3, 1-46.

van Belkum, A., Verkaik, N. J., de Vogel, C. P. et al. (2009) Reclassification of Staphylococcus aureus nasal carriage types. J Infect Dis 199, 1820-1826.

van Rijen, M. M., Bonten, M., Wenzel, R. P. et al. (2008) Intranasal mupirocin for reduction of Staphylococcus aureus infections in surgical patients with nasal carriage: a systematic review. J Antimicrob Chemother 61, 254-261.

Vandana, K., Singh, J., Chiranjay, M. et al. (2009) Inducible Clindamycin Resistance in Staphylococcus aureus: Reason for Treatment Failure. J Glob Infect Dis 1, 76-77.

VandenBergh, M. F., Yzerman, E. P., van Belkum, A. et al. (1999) Follow-up of Staphylococcus aureus nasal carriage after 8 years: redefining the persistent carrier state.J Clin Microbiol 37, 3133-3140.

Wanten, G. J., Schneeberger, P. M., Bevers, A. et al. (1998) Optimizing screening procedures for Staphylococcus aureus nasal carriage in patients on haemodialysis. Nephrol Dial Transplant 13, 1256-1258.

Wassenberg, M. W., Kluytmans, J. A., Bosboom, R. W. et al. (2011) Rapid diagnostic testing of methicillin-resistant Staphylococcus aureus carriage at different anatomical sites: costs and benefits of less extensive screening regimens. Clin Microbiol Infect 17, 1704-1710.

Weinstein, H. J. (1959) The relation between the nasal-staphylococcal-carrier state and the incidence of postoperative complications. N Engl J Med 260, 1303-1308.

Weinstein, R. A. (1991) Epidemiology and control of nosocomial infections in adult intensive care units. Am J Med 91, 179S-184S.

Vento, T. J., Calvano, T. P., Cole, D. W. et al. (2013) Staphylococcus aureus colonization of healthy military service members in the United States and Afghanistan. BMC Infect Dis 13, 325.

Wertheim, H. F., Vos, M. C., Ott, A. et al. (2004a) Risk and outcome of nosocomial Staphylococcus aureus bacteraemia in nasal carriers versus non-carriers. Lancet 364, 703-705.

Wertheim, H. F., Vos, M. C., Ott, A. et al. (2004b) Mupirocin prophylaxis against nosocomial Staphylococcus aureus infections in nonsurgical patients: a randomized study. Ann Intern Med 140, 419-425.

Widmer, A. F. (2000) Replace hand washing with use of a waterless alcohol hand rub? Clin Infect Dis 31, 136-143.

Williams, R. E., Jevons, M. P., Shooter, R. A. et al. (1959) Nasal staphylococci and sepsis in hospital patients. Br Med J 2, 658-662.

Williamson, D. A., Monecke, S., Heffernan, H. et al. (2014) A cautionary tale: High usage of topical fusidic acid and rapid clonal expansion of fusidic acid-resistant Staphylococcus aureus. Clin Infect Dis 59, 1451-1454.

von Eiff, C., Becker, K., Machka, K. et al. (2001) Nasal carriage as a source of Staphylococcus aureus bacteremia. Study Group. N Engl J Med 344, 11-16.

Zecconi, A. \& Scali, F. (2013) Staphylococcus aureus virulence factors in evasion from innate immune defenses in human and animal diseases. Immunol Lett 150, 12-22.

Zervou, F. N., Zacharioudakis, I. M., Ziakas, P. D. et al. (2014) MRSA colonization and risk of infection in the neonatal and pediatric ICU: a meta-analysis. Pediatrics 133, e1015-1023.

Zinderman, C. E., Conner, B., Malakooti, M. A. et al. (2004) Community-acquired methicillinresistant Staphylococcus aureus among military recruits. Emerg Infect Dis 10, 941-944.

Åhren, C. \& Larsson, L. (2014) MRSA och VRE. http://www.internetmedicin.se/page.aspx?id=2035 [Swedish] Accessed November 3, 2014. 



\section{Papers}

The articles associated with this thesis have been removed for copyright reasons. For more details about these see:

http://urn.kb.se/resolve?urn=urn:nbn:se:liu:diva-116703 